Issued by Sandia National Laboratories, operated for the United States Department of Energy by Sandia Corporation.

NOTICE: This report was prepared as an account of work sponsored by an agency of the United States Government. Neither the United States Government, nor any agency thereof, nor any of their employees, nor any of their contractors, subcontractors, or their employees, make any warranty, express or implied, or assume any legal liability or responsibility for the accuracy, completeness, or usefulness of any information, apparatus, product, or process disclosed, or represent that its use would not infringe privately owned rights. Reference herein to any specific commercial product, process, or service by trade name, trademark, manufacturer, or otherwise, does not necessarily constitute or imply its endorsement, recommendation, or favoring by the United States Government, any agency thereof, or any of their contractors or subcontractors. The views and opinions expressed herein do not necessarily state or reflect those of the United States Government, any agency thereof, or any of their contractors.

Printed in the United States of America. This report has been reproduced directly from the best available copy.

Available to DOE and DOE contractors from

Office of Scientific and Technical Information

P.O. Box 62

Oak Ridge, TN 37831

Prices available from (703) 605-6000

Web site: http://www.ntis.gov/ordering.htm.

Available to the public from

National Technical Information Service

U.S. Department of Commerce

5285 Port Royal Rd

Springfield, VA 22161

NTIS price codes

Printed copy: A05

Microfiche copy: A01

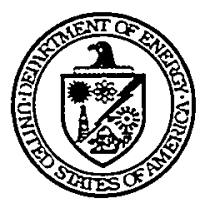




\section{DISCLAIMER}

\section{Portions of this document may be illegible in electronic image products. Images are produced from the best available original document.}


SAND2000-8238

Unlimited Release

Printed May 2000

\title{
Contained Rocket Motor Burn Demonstrations in X-Tunnel: Final Report for the DoD/DOE Joint Demilitarization Technology Program
}

\author{
B. W. Bellow, A. E. Moeller, S. M. Williams \\ Bechtel Nevada \\ R. L. Heinle, C.A. Velsko, B. E. Watkins \\ Lawrence Livermore National Laboratory \\ C. J. Hewitt, H. Fry, J. R. Stephens \\ Los Alamos National Laboratory \\ J. R. Carson, W. C. Gray, W. C. Thomas \\ Radian International \\ R. F. Boehm, Y. -T. Chen, A Smiecinski, K. J. Stetzenbach \\ University of Nevada, Las Vegas \\ and \\ S. W. Allendorf, L. R. Carrillo, S. K. Griffiths, H. A. Johnsen, \\ R. H. Nilson, D. K. Ottesen, R. L. Peabody, C. R. Shaddix, \\ Sandia National Laboratories \\ Edited by \\ Joel Lipkin \\ Environmental Technologies Applications Department \\ Sandia National Laboratories \\ Livermore, CA 94550
}

\begin{abstract}
Three low-pressure rocket motor propellant burn tests were performed in a large, sealed test chamber located at the X-tunnel complex on the Department of Energy's Nevada Test Site in the period May-June 1997. NIKE rocket motors containing double base propellant were used in two tests (two and four motors, respectively), and the third test used two Improved HAWK rocket motors containing composite propellant. The preliminary containment safety calculations, the crack and burn procedures used in each test, and the results of various measurements made during and after each test are all summarized and collected in this document.
\end{abstract}




\section{ACKNOWLEDGEMENT}

The successful execution of the tests described in this report, as well as the painstaking collection of enormous quantities of data from those tests, would not have been possible without the dedication and expertise of the numerous individuals and organizations identified as contributors to this report. The tireless support and patience of these individuals is gratefully acknowledged.

The test series could not have been completed without the continued financial support and encouragement of James Q. Wheeler, Director, US Army Defense Ammunition Center, McAlester, OK. The technical review, oversight and encouragement of Dr. Solim Kwak, US Army Defense Ammunition Center, is also gratefully acknowledged. 


\section{Table of Contents}

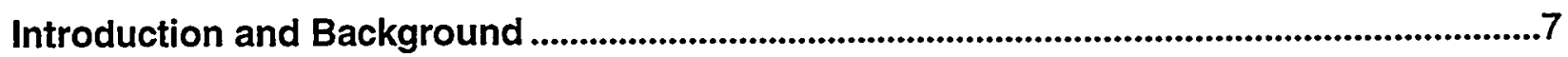

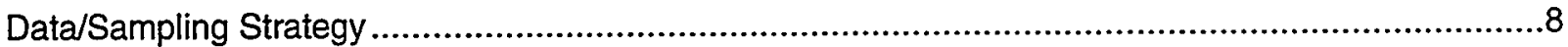

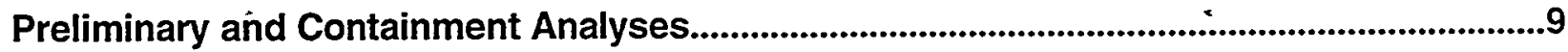

Test Configuration and Arming and Firing Procedures.............................................................14

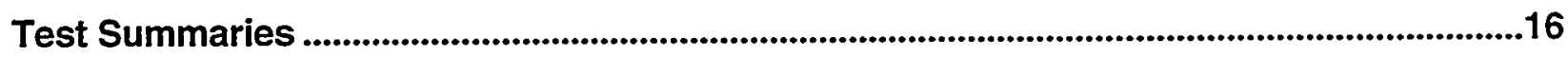

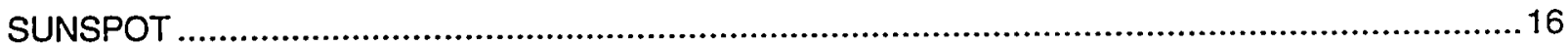

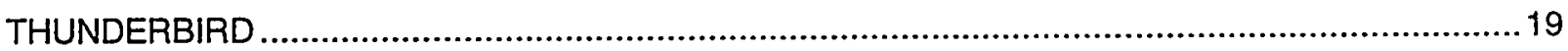

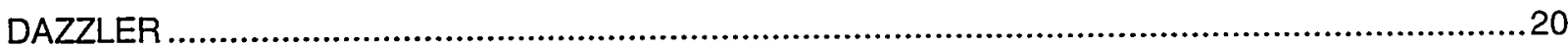

Summary of Instrumentation and Sampling/Analysis Procedures .........................................20

Time-Averaged Measurements_Radian International, LLC (Appendix A) .....................................21

Time-Resolved Bullk Gas Analyses-_LLNL/Bechtel Nevada (Appendix B) ..................................22

Real-Time and Time-Averaged Aerosol Analyses_LANL (Appendix C) .......................................22

Real-Time Gas Species Analyses Using FTIR_LANL (Appendix D) .........................................23

Post-Test Metal Residue Analyses-UNLV (Appendix E) ...........................................................24

In Situ, Laser-Based Measurements of Gas Species Concentrations-SNL (Appendix F) .................24

Time-Resolved Measurements of Test Chamber Pressure and Temperature — LLNL and Bechtel

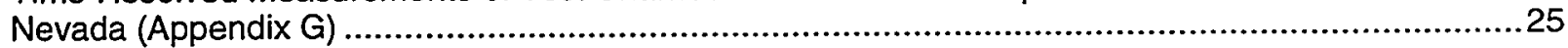

Summary and Conclusions ........................................................................................................26

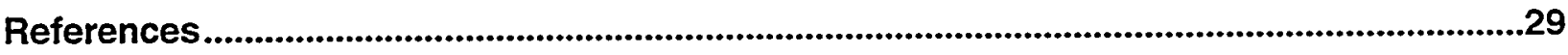

Appendix A .......................................................................................................................

Appendix B .........................................................................................................................45

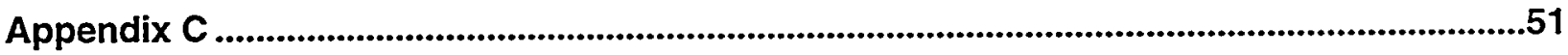

Appendix D ..........................................................................................................................63

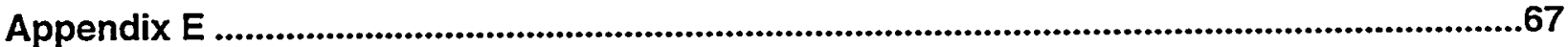

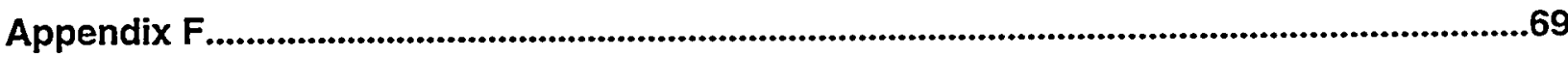

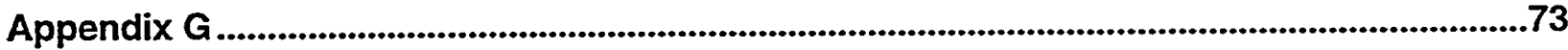




\section{List of Figures}

Figure 1. Computed peak temperatures in test chamber, from Ref (4) ...........................11

Figure 2. Computed peak pressures in test chamber, from Ref (4) ...............................11

Figure 3. Computed temperature histories for combustion of NIKE rocket motor propellant in test chamber, from Ref (4).

Figure 4. Computed pressure histories for combustion of NIKE rocket motor propellant in test chamber, from Ref (4).

Figure 5. Plan view of rocket motor arrangement for SUNSPOT and DAZZLER

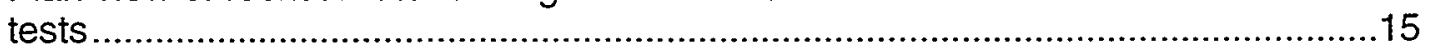

Figure 6. Plan view of rocket motor arrangement for THUNDERBIRD test........................15

Figure $7 a$. View of 4 NIKE M88 rocket motors in test chamber prior to THUNDERBIRD

Figure $7 \mathrm{~b}$. Remnants of NIKE rocket motor cases after THUNDERBIRD

Figure $8 \mathrm{a}$. View of 2 improved Hawk rocket motors in test chamber prior to DAZZLER.

Figure 8b. View of improved Hawk rocket motors after DAZZLER.

Figure 9. Overlay of computed temperature history for THUNDERBIRD [from Ref (4)] with data from TC36 (thermocouple located $6.4 \mathrm{~m}$ above the test chamber invert)

Figure 10. Overlay of computed pressure history for THUNDERBIRD [from Ref (4)] with test data

\section{List of Tables}

Table 1. Contained rocket motor burn tests in $\mathrm{x}$-tunnel ....................................................8

Table 2. Sampling and measurements for Phase II test series ......................................9

Table 3. Explosives used to initiate low-pressure propellant burns ...................................14 


\section{Contained Rocket Motor Burn Demonstrations in X-Tunnel: Final Report for the DoD/DOE Joint Demilitarization Technology Program}

\section{Introduction and Background}

The Joint Demilitarization Technology (JDT) Program is a collaborative effort between the Departments of Defense and Energy (DoD and DOE) that is demonstrating and validating technologies for resource recovery, recycling, and alternative destruction/treatment technologies. The JDT Program is managed by the Demil Technology Office of the US Army Defense Ammunition Center, McAlester, OK, and the US DOE Nevada Operations Office, Las Vegas, NV. In FY97, the JDT Program completed two test series using the X-tunnel complex in Area 25 at DOE's Nevada Test Site (NTS):

- Phase I testing which included four detonation tests (employing M107 $155 \mathrm{~mm}$ HE projectiles), and

- Phase II testing in which three low-pressure rocket motor propellant burns were executed (employing NIKE and Improved HAWK rocket motors).

Executive summaries describing test procedures and the results obtained from both of these JDT Program phases are given in references (1) and (2), respectively. The present report provides additional background information related to the Phase II test series. In addition, this report serves as a guide to the separate data reports that were prepared by the principal investigators who participated in these tests.

The test facility located in the X-tunnel complex at NTS is a mined cavity (the test chamber) that is sealed off from the access drift by a steel and concrete containment barrier. This barrier was designed to withstand blast effects (e.g., shock, shrapnel impacts, and high pressure/temperature environments) as well as to prevent the release of gases produced by munition detonations and rocket motor propellant burns. The volume of the test chamber is roughly $4644 \mathrm{~m}^{3}\left(164,000 \mathrm{ft}^{3}\right)$, and its dimensions are roughly $30.5 \mathrm{~m}$ long, $15.2 \mathrm{~m}$ wide, and $10.7 \mathrm{~m}$ high. Containment calculations performed by Burkhard ( 3 ) indicate that the test chamber and containment barrier can safely contain a detonation of 3000 pounds of double base propellant (roughly equivalent to 2250 pounds of TNT).

The rocket motor burn tests used two different DoD tactical rocket motors: the NIKE M88 and the Improved HAWK. These motors contain propellants that are representative of the two most common formulations found in the demilitarization inventory, i.e., double base and composite. Each NIKE M88 rocket motor contains 341 $\mathrm{kg}$ (750 pounds) of double base type propellant, and each Improved HAWK dual thrust motor contains $294 \mathrm{~kg}$ (647 pounds) of composite type propellant.

Three tests were performed: "SUNSPOT" and "THUNDERBIRD" using 2 and 4 NIKE motors, respectively; and "DAZZLER" using 2 Improved Hawk motors. In each test, linear shaped charges and explosive cutting tape were used to split the steel rocket motor cases longitudinally and partially around the circumference. The explosives also served to initiate the low-pressure (i.e., non-propulsive) propellant burns. This procedure closely followed the DoD Open Burning $(\mathrm{OB})$ process generally referred to as "crack and burn". Test parameters are summarized in Table 1. 
Table 1. Contained rocket motor burn tests in $\mathrm{x}$-tunnel

\begin{tabular}{|l|c|c|c|c|c|}
\hline $\begin{array}{c}\text { Test } \\
\text { Name }\end{array}$ & $\begin{array}{c}\text { Test } \\
\text { Type }^{1}\end{array}$ & $\begin{array}{c}\text { Date } \\
\text { Executed }\end{array}$ & $\begin{array}{c}\text { Number of } \\
\text { Motors }\end{array}$ & $\begin{array}{c}\text { N.E.W. } \\
\text { (pounds) }\end{array}$ & $\begin{array}{c}\text { Inert Weight } \\
\text { (pounds) }\end{array}$ \\
\hline \hline SUNSPOT & $\mathrm{B} 1$ & 14 May 97 & 2 & $1500^{3}$ & 888 \\
\hline THUNDERBIRD & $\mathrm{B} 1$ & 28 May 97 & 4 & $3000^{3}$ & 1776 \\
\hline DAZZLER & $\mathrm{B} 2$ & 11 June 97 & 2 & $1294^{4}$ & 490 \\
\hline
\end{tabular}

1 - B1 = Bum of NIKE rocket motors; B2 = Burn of Improved HAWK rocket motors

2 - Net Explosive Weight (excluding initiating explosive charges)

3 - NC/NG (double base) Propellant

4 - Composite Propellant

\section{Data/Sampling Strategy}

Extracted gas and aerosol samples, combined with in situ and post-test measurements, were used to obtain both time-averaged and time-resolved data in each test. Much of the time-averaged data was used to determine concentrations of the analytes of environmental interest in the combustion cloud. The data collection techniques and analyses employed in these tests focused on the following areas:

- laboratory analyses [using U.S. Environmental Protection Agency (EPA) standardized methods] of gas and particulate samples extracted from the combustion cloud-these analyses used to identify the presence of EPA regulated chemicals,

- rapid, time-resolved measurements of selected gas species and aerosol/particulates using both extraction and in situ methods,

- determination of the presence of toxic gases and explosive mixtures in the tunnel complex (as required by health and safety rules at NTS),

- in situ measurements of combustion cloud gas temperature (time histories and spatial variations), and

- time-resolved measurements of gas pressure in the test chamber.

To a large extent, the gases and aerosols produced in each test were contained in the test chamber and sampled over several hours after test initiation. During the sampling period, these gases cooled and nominally returned to atmospheric pressure and temperature.

Species Generated: A number of gases, chemicals and Resource Recovery Act (RCRA) listed hazardous metals were generated during each rocket motor burn test. These included, for example: $\mathrm{CO}_{2}, \mathrm{CO}, \mathrm{NOx}, \mathrm{HCN}, \mathrm{HCl}, \mathrm{Pb}, \mathrm{Cr}$, products of incomplete combustion [including volatile organic chemicals (VOCs), semi-volatile organic chemicals (SVOCs), dioxins, and furans], residual energetic material, and small aerosols and particulates.

Effluent Measured: Time averaged concentrations of many of the above species were determined by appropriate EPA standard methods. In addition, a few species (bulk gases, NOx, CO, and particulates) were measured using time-resolved methods. Note that dioxins, furans, and $\mathrm{HCl}$ were only measured in the DAZZLER test; where their presence was anticipated as a consequence of the combustion of the composite type propellants in the Improved HAWK rocket motor.

Sample Methods: EPA sampling methods were used to collect time-averaged, "grab" samples on the portal side of the containment barrier. This sampling was initiated after 
it was determined that the pressure and temperature in the test chamber were below safe limits. The total duration of this sampling was typically 60-120 minutes. Solid residue samples were also collected from the chamber after each test. EPA approved methods were used to analyze these samples and determine their leachability [Toxicity Characteristic Leaching Procedure (TCLP)] properties. Small aerosols and particulate entrained in combustion cloud were also sampled using time-resolved techniques. Bulk gas concentrations were determined in real time using several instruments, including some located at the end of a $300 \mathrm{~m}$ long sampling tube running from the test chamber to the tunnel portal. These gas samples were extracted continuously during and after the propellant burns. The analytical instruments used to analyze these gas samples included a mass spectrometer, gas chromatograph, infrared meters, and electrochemical sensors. In addition, in situ, laser-based measurements were made at two sites inside the test chamber. These measurements employed a tunable diode laser with a capability of providing gas phase concentrations of $\mathrm{CO}_{2}, \mathrm{CO}, \mathrm{HCN}, \mathrm{HCl}$ and water in the chamber at a sampling frequency of nominally $1 \mathrm{~Hz}$.

The full suite of measurement types used in the Phase II test series is summarized in Table 2.

Table 2. Sampling and measurements for Phase II test series

\begin{tabular}{|l|c|l|}
\hline \multicolumn{1}{|c|}{ Brief Description } & \multicolumn{1}{|c|}{$\begin{array}{c}\text { Data Summary } \\
\text { in Appendix }\end{array}$} & \multicolumn{1}{|c|}{$\begin{array}{c}\text { Responsible } \\
\text { Organization }\end{array}$} \\
\hline \hline $\begin{array}{l}\text { EPA Standard Methods: VOCs, SVOCs, } \\
\text { particulates, metals, HCN, HCl, Dioxins, } \\
\text { residual energetic material }\end{array}$ & $\mathrm{A}$ & Radian International, LLC \\
\hline Real Time Gas Analyses & $\mathrm{B}$ & LLNL/ Bechtel Nevada \\
\hline $\begin{array}{l}\text { Real Time and Time-Resolved Aerosol and } \\
\text { Particulate Sampling/Analysis }\end{array}$ & $\mathrm{C}$ & LANL \\
\hline FTIR Gas Species Analysis (see note 1) & $\mathrm{D}$ & LANL \\
\hline Metal Residue Analyses & $\mathrm{E}$ & Radian/UNLV \\
\hline In situ Laser Measurement (see note 2) & F & SNL \\
\hline Chamber pressure/gas temperature & G & LLNL/Bechtel Nevada \\
\hline
\end{tabular}

- LANL - Los Alamos National Laboratory

LLNL - Lawrence Livermore National Laboratory

SNL - Sandia National Laboratories

UNLV - University of Nevada, Las Vegas

1 - THUNDERBIRD and DAZZLER only

2 - SUNSPOT and DAZZLER only

\section{Preliminary and Containment Analyses}

The theoretical heat of explosion for the double base propellant in the NIKE M88 rocket motor is $764 \mathrm{cal} / \mathrm{gm}$. Similarly, for the composite propellants in the Improved HAWK rocket motor ${ }^{1}$, the calculated heats of explosion are 597 and $571 \mathrm{cal} / \mathrm{gm}$ for the booster and sustainer grains, respectively. This energy is rapidly released when these propellants burn. The hot combustion products mix with the cool ambient air in the

\footnotetext{
${ }^{1}$ Each Improved Hawk rocket motor is composed of two composite propellant grains: one designated as the booster grain and the other as the sustainer grain.
} 
sealed test chamber, and the temperatures and pressure of all the gases in the chamber increase substantially. In order to insure that these gases would be safely contained, it was necessary to estimate the time histories, and especially the peak values, of pressure and temperature expected in each of the three rocket motor burn tests. Furthermore, even after combustion, the hot gases contained at above atmospheric pressure in the test chamber could be a concern because they represent a source of heat that might weaken the steel components in the containment barrier. Prolonged exposure to these elevated temperatures could also adversely affect any instrumentation located in the test chamber.

Several different numerical simulations of the rocket motor propellants burning in the test chamber were used to obtain these estimates. Nilson and Griffiths (4) developed an analytical model to predict the evolution of the temperature and pressure in a pair of well-mixed control volumes. These volumes were normalized by the volume of the test chamber. In their analysis, it was assumed that each of these volumes has the same pressure but distinct temperatures at any instant, and that the combustion products are released at a uniform rate into the primary control volume, $V^{\star}$. The temperature, pressure and volume of $\mathrm{V}^{*}$ thus increase during the assumed burn time of $t_{b}=20$ seconds. Energy is continuously transferred between control volumes and to the rock walls of the test chamber by buoyancy driven convection, forced convection driven by gas release, and by radiation. All of these energy transfer processes are relatively slow, however, compared to the assumed burn time. For this reason, the peak temperatures and pressures shown in Figures 1 and 2, respectively, for both the NIKE and Improved HAWK rocket motors are determined mainly by the:

- amount of mass and energy released by combustion,

- initial air mass in the test chamber,

- volume of the test chamber, and

- thermodynamic properties of the gases, each taken as ideal with appropriate mean molecular weights and specific heat ratios.

It was assumed that the total energy release was the same as for conventional firing of each motor. That is, no allowance was made for using available oxygen in the test chamber to oxidize the $\mathrm{CO}$ produced by combustion to $\mathrm{CO}_{2}$. For the sake of conservatism, these calculations also assume that the entire test chamber is well mixed (i.e., $V^{\star}=1.0$ ). This assumption tends to reduce both the average gas temperature and the cooling rate of the gases in the test chamber. That is, high local temperatures and cooling rates would be expected to occur if the combustion products were not well mixed and instead formed stable stratified layers containing only moderate amounts of entrained air.

This analysis suggests that combustion of the NIKE rocket motors in the SUNSPOT and THUNDERBIRD tests will produce the highest peak pressures and temperatures in the test chamber. These peak values should be achieved at the end of combustion; followed by rapid decreases as the gas in the chamber cools. These predicted temperature and pressure histories for burning 2 and 4 NIKE rocket motors are shown in Figures 3 and 4, respectively, taken from (4). It is evident that the predicted temperature and pressure decay rates shown in Figures 3 and 4 depend strongly on the apparent emissivity, $\varepsilon^{\star}$, of the hot gases in the test chamber. This parameter relates to the efficiency of heat transfer due to radiation (i.e., high emissivity corresponds to enhanced heat loss to the chamber walls). For these calculations, $\varepsilon^{*}$ was assumed to 


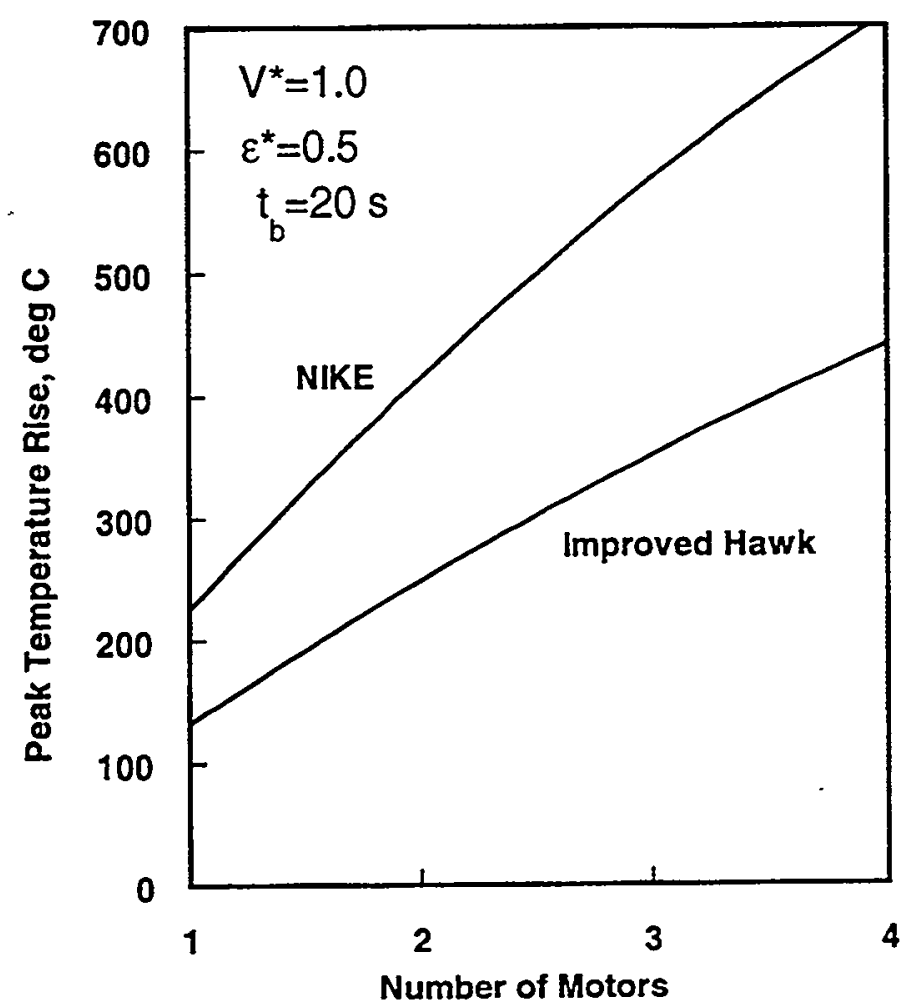

Figure 1. Computed peak temperatures in test chamber, from Ref (4).

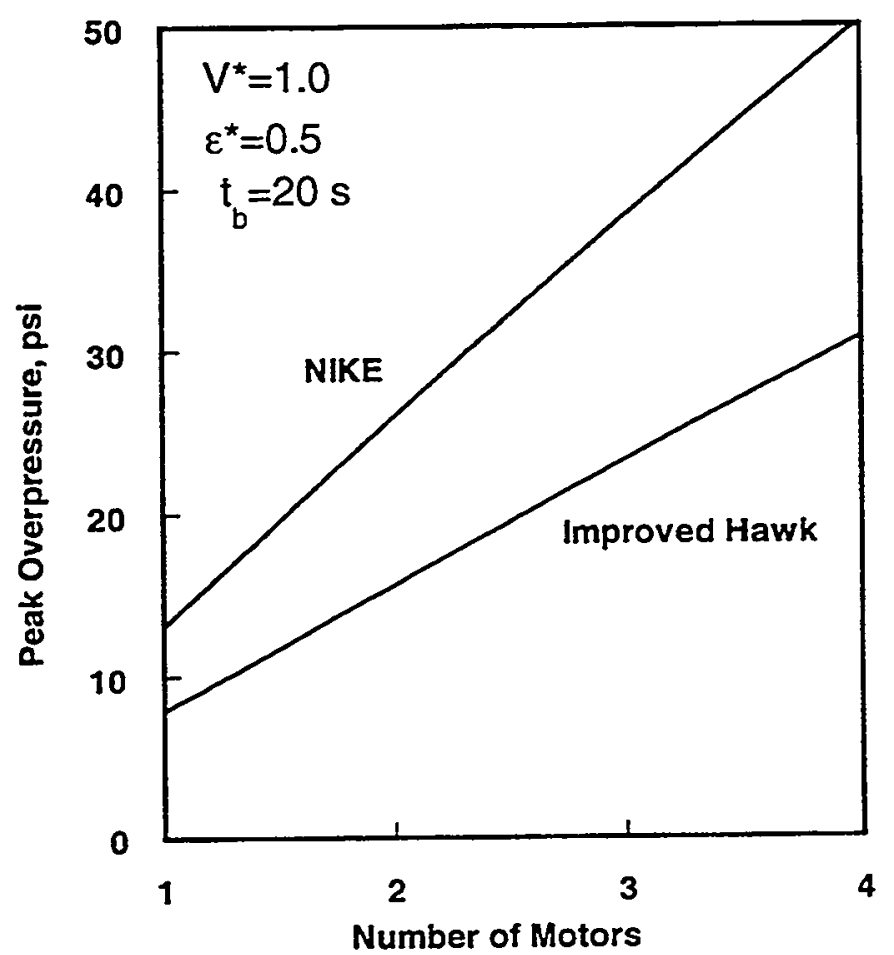

Figure 2. Computed peak pressures in test chamber, from Ref (4). 


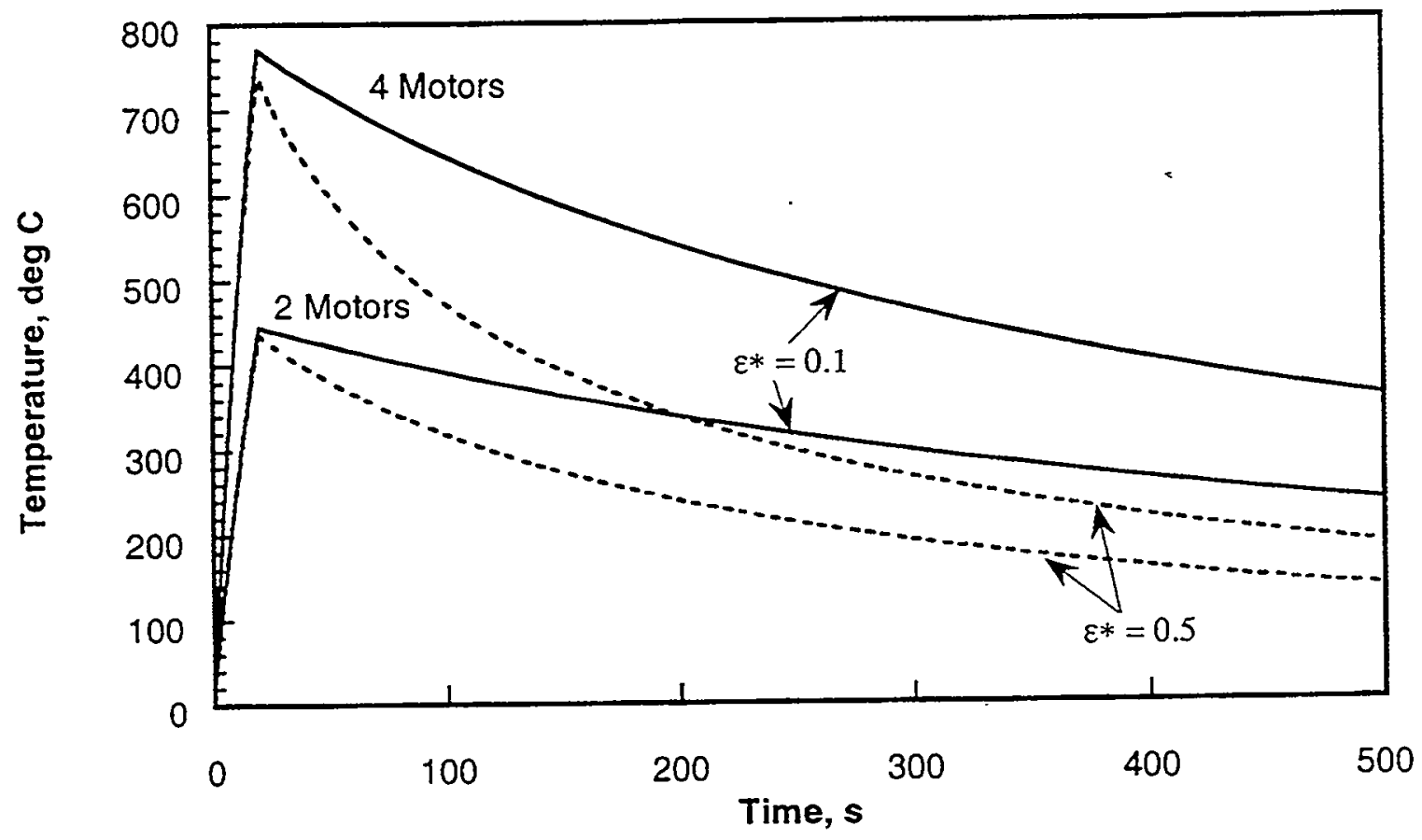

Figure 3. Computed temperature histories for combustion of NIKE rocket motor propellant in test chamber, from Ref (4).

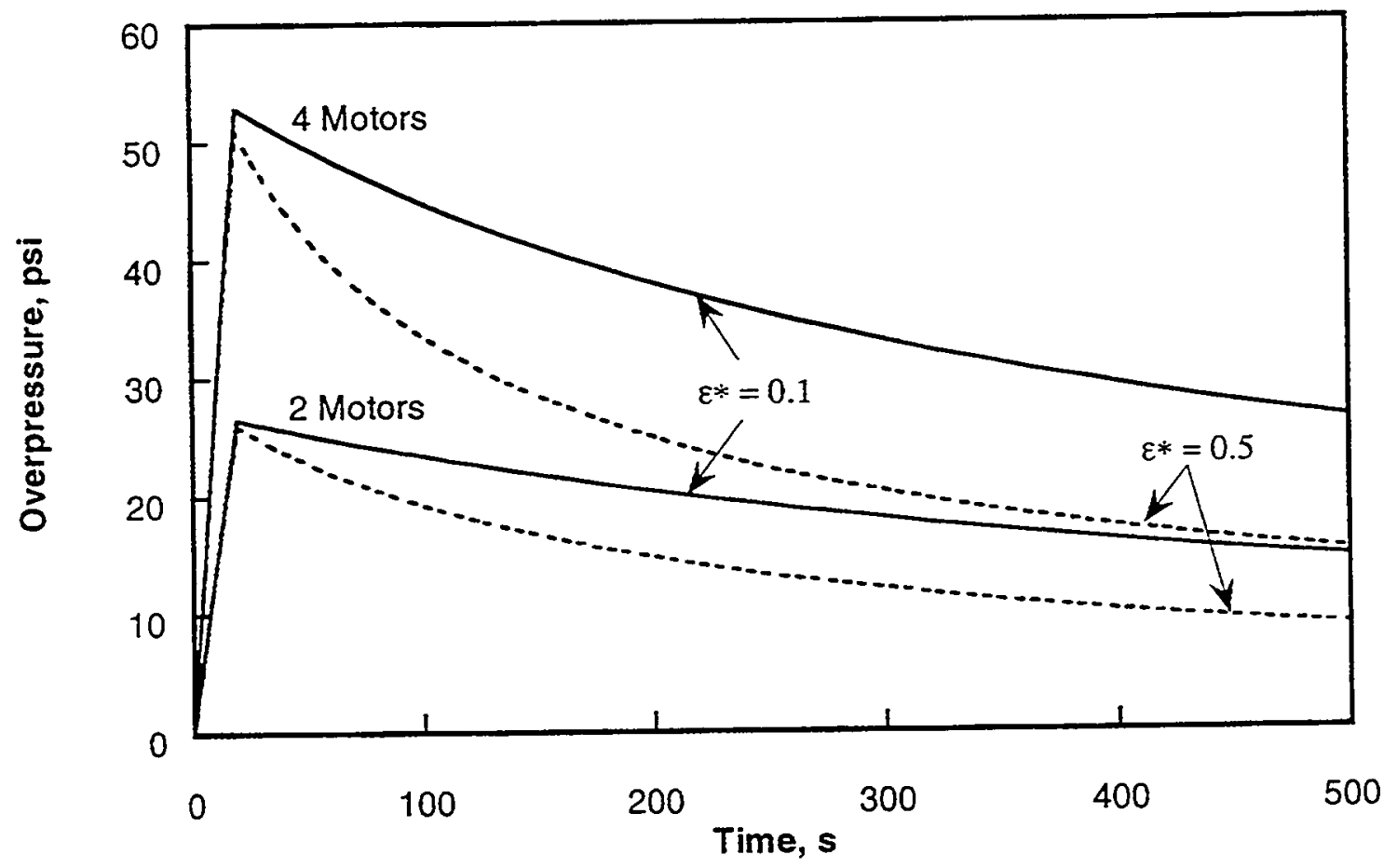

Figure 4. Computed pressure histories for combustion of NIKE rocket motor propellant in test chamber, from Ref (4). 
be either 0.1 or 0.5 in order to span a reasonable range of potential values for this parameter.

A second analysis of the temperature and pressure histories in the test chamber was carried out by Boehm and Chen (5). They developed a one-dimensional, transient heat transfer model and analyzed both the well mixed and gas stratified cases, focusing especially on results that could be expected for burning a single NIKE rocket motor. They also carried out a parameter sensitivity analysis on their results by using ranges of values for a number of different heat transfer coefficients included in their model. Such a sensitivity analysis was important because exact values of the heat transfer coefficients can not be determined in advance. In the well mixed case, and where parameters overlap, their results are similar to those shown in Figures 1-4 from (4). In the stratified model, where it is assumed that hot gases "pool" at the top of the test chamber during combustion, they calculate that both peak temperature and pressure in the test chamber are substantially reduced compared to the well mixed case. This result follows from the rapid quenching of the hot gases during the stratification process. Further analyses, and an extension of the numerical model in (5) to two-dimensions, can lead to a more thorough understanding of the complex heat transfer processes that occur in the test chamber during rocket motor burn events.

A third analysis that principally addressed containment issues for the rocket motor burn test series was carried out by Burkhard (3). Burkhard used the commercially available computer code, BLASTX (6), to estimate peak static ${ }^{2}$ and dynamic loads on the containment barrier in an assumed worst case scenario in which the propellant in 4 NIKE rocket motors detonates rather than burns. The detonation sensitivity of the NIKE rocket motor propellant is sufficiently high to warrant this concern; even though both the geometry of the propellant grain and the methods employed to split the rocket motor cases and initiate the burn make a detonation event very unlikely. An additional feature of the BLASTX code allowed Burkhard to include the effects of oxidizing the CO produced by combustion to $\mathrm{CO}_{2}$. This exothermic conversion is often referred to as an "after burn" because it proceeds somewhat more slowly than the primary combustion process. With the presence of sufficient $\mathrm{O}_{2}$ and $\mathrm{H}_{2}$, however, the CO-to- $\mathrm{CO}_{2}$ conversion occurs during combustion, as well as for some time thereafter (i.e., as long as temperatures are high enough for the reaction to proceed). Including this "after burn" process has the effect of increasing both the temperature and pressure calculated by BLASTX. The results given in (3) when there is no oxidation of $\mathrm{CO}$ agree with the peak values shown in Figures 1-2. These results change dramatically, however, when COto- $\mathrm{CO}_{2}$ conversion is included. For example, the peak static pressure in THUNDERBIRD increases from $51 \mathrm{psig}$ to $129 \mathrm{psig}$, and the peak temperature increases from roughly $700^{\circ} \mathrm{C}$ to $1700^{\circ} \mathrm{C}$. Clearly, for containment safety purposes, the conservative approach is to assume that combustion goes to completion in these tests so that all of the $\mathrm{CO}$ generated is converted to $\mathrm{CO}_{2}$. Pressure and temperature limits for the containment barrier were established using that approach.

A heat transfer calculation was also carried out in (4) to predict the temperature rise of the steel plates in the containment barrier. For this analysis, it was assumed that the combustion cloud gases reached a peak temperature of $1700^{\circ} \mathrm{C}$ followed by a

${ }^{2}$ BLASTX does not account for the combustion gas cooling that occurs due to the action of various heat transfer mechanisms. Therefore, the "static" values for pressure and temperature generated by BLASTX are effectively upper bounds on the peak values computed in (4). 
characteristic decay similar to that shown in Figure 3. The results of that calculation indicated that a 0.75 inch thick plate could reach a peak temperature on the order of $130^{\circ} \mathrm{C}$ at roughly 1200 seconds after burn initiation. This temperature is well below a thermal softening threshold for structural steel, and thus it was concluded that the thermal cycling history generated by the rocket motor burn tests series would not adversely affect the integrity of the containment barrier.

\section{Test Configurations and Arming and Firing Procedures}

In his X-tunnel test summary report (7), Peabody describes all of the test configurations as well as the arming and firing procedures that were used for the Phase $I$ and II tests in $\mathrm{X}$-tunnel. The configurations and procedures for the Phase II rocket motor burn tests are briefly summarized here.

Schematic plan views of the rocket motors in the test chamber for the SUNSPOT, THUNDERBIRD, and DAZZLER tests are show in Figures 5 and 6 . Note that the layout shown in Figure 5 is appropriate for both SUNSPOT and DAZZLER since two motors were used in each of these tests. The centers of the layouts shown in Figures 5 and 6 were roughly $19 \mathrm{~m}$ from the containment barrier. In each case, the rocket motors were secured to the concrete pad in the test chamber. This procedure prevented them from moving during the burn initiation event and the subsequent propellant burn out. The motors were offset laterally to preclude any possibility of a sympathetic detonation if the propellant in one motor were to detonate as a result of the initiation process.

In addition to using copper linear shaped charges and explosive cutting tape to initiate the propellant burns, separate copper linear shaped charge explosives were used to rapidly open standard sized tanks of compressed inert gases. These gases were released at test initiation time, and they were used as tracers for the real time gas measurements in each test. One bottle of Krypton was used in each of the SUNSPOT and THUNDERBIRD tests, and 2 bottles ( 1 each of Krypton and Neon) were used in DAZZLER. The weights of all of the explosives used in each test are summarized in Table 3.

Table 3. Explosives used to initiate low-pressure propellant burns*

\begin{tabular}{|c|c|c|c|}
\hline Explosive Source & SUNSPOT & THUNDERBIRD & DAZZLER \\
\hline \hline $\begin{array}{c}\text { Copper Linear Shaped } \\
\text { Charge }\end{array}$ & $250 \mathrm{gr} / \mathrm{ft} \times 16=0.571 \#$ & $250 \mathrm{gr} / \mathrm{ft} \times 32=1.143 \#$ & $\begin{array}{c}250 \mathrm{gr} / \mathrm{ft} X \\
16=0.571 \#\end{array}$ \\
\hline $\begin{array}{c}\text { Copper Linear Shaped } \\
\text { Charge }\end{array}$ & $600 \mathrm{gr} / \mathrm{ft} \times 5=0.429 \#$ & $600 \mathrm{gr} / \mathrm{ft} \times 5=0.429 \#$ & $\begin{array}{c}600 \mathrm{gr} / \mathrm{ft} X \\
10=0.857 \#\end{array}$ \\
\hline $\begin{array}{c}\text { Explosive Cutting Tape } \\
\text { RP1 Detonator (RDX) }\end{array}$ & $0.626 \mathrm{~g} \times 6=0.0084 \#$ & $0.626 \mathrm{~g} \times 10=0.014 \#$ & $0.626 \mathrm{~g} \times 8=0.0112 \#$ \\
\hline Total Exp. Weight (lbs) & 1.437 & $300 \mathrm{gr} / \mathrm{ft} \times$ \\
\hline
\end{tabular}

*Includes copper linear shaped charges used to cut open tanks of compressed inert tracer gas(es) 


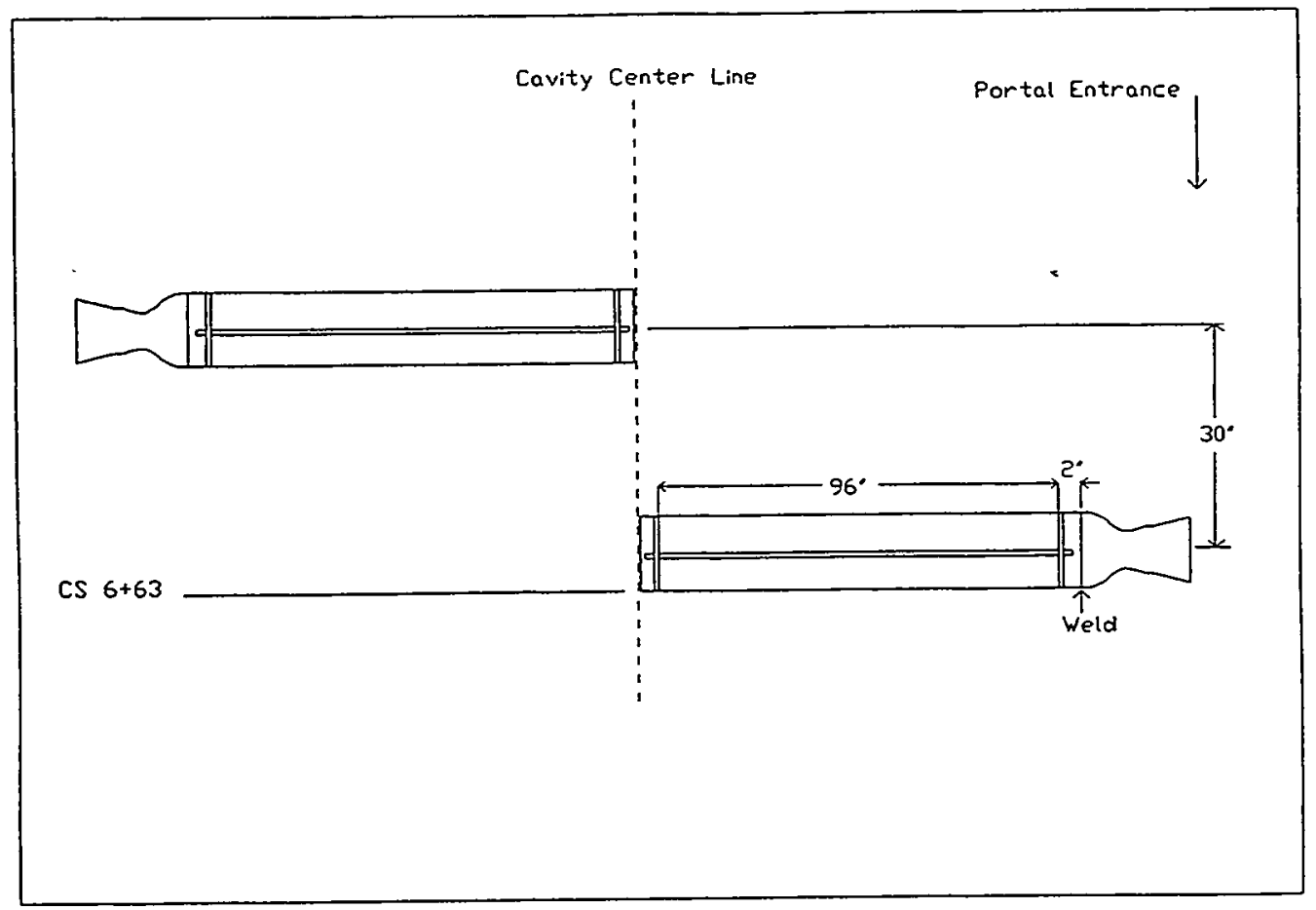

Figure 5. Plan view of rocket motor arrangement for SUNSPOT and DAZZLER tests.

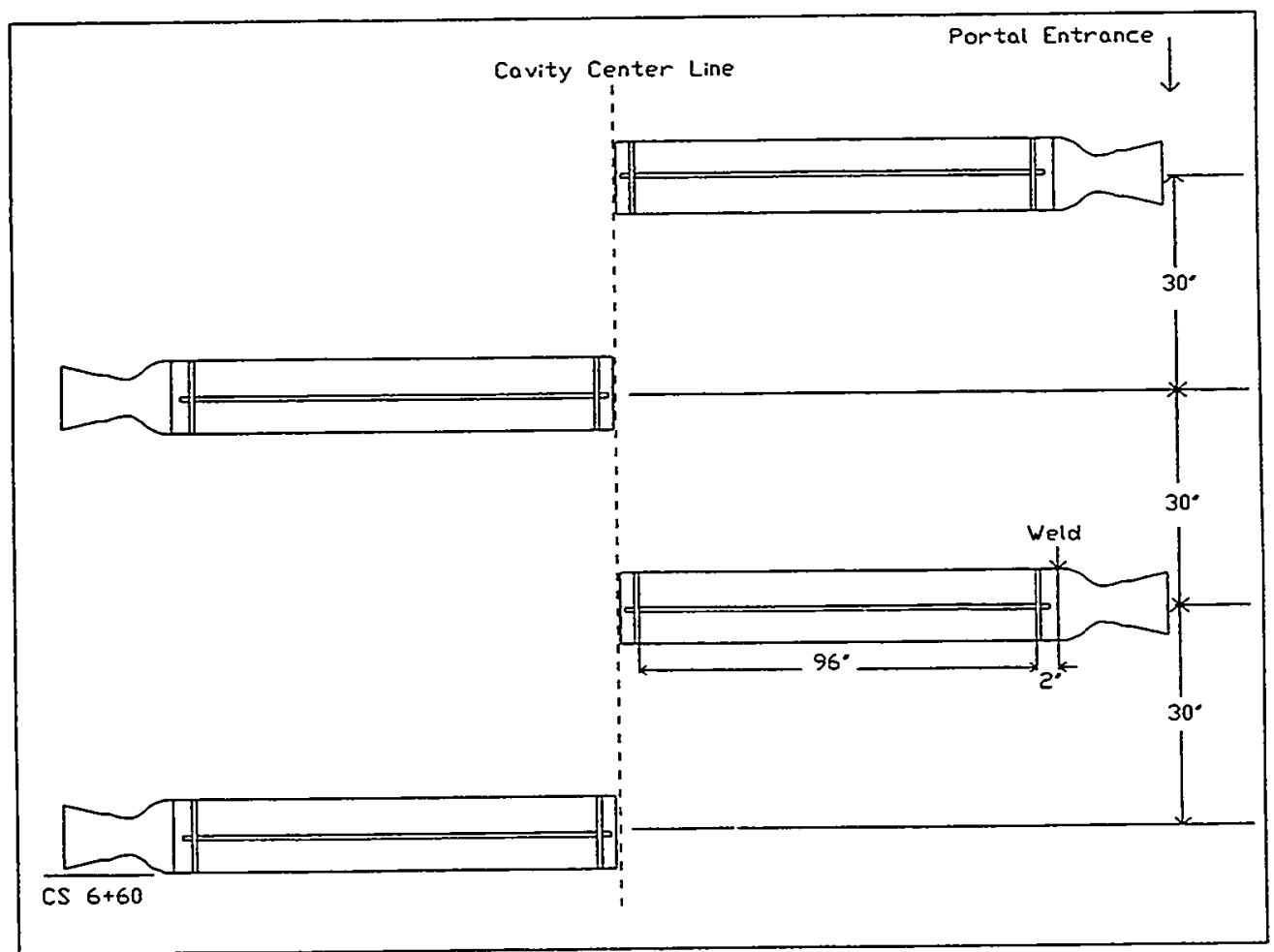

Figure 6. Plan view of rocket motor arrangement for THUNDERBIRD test. 
The arrangement of the rocket motors and the initiating explosives as well as the effectiveness of the burning process can be seen in the photographs in Figures 7 and 8 . Figures $7 \mathrm{a}$ and $8 \mathrm{a}$ show the positioning of the motors and the arrangement of the linear shaped charges and explosive cutting tape on the motors prior to the initiation of THUNDERBIRD and DAZZLER, respectively. Similarly, Figures $7 \mathrm{~b}$ and $8 \mathrm{~b}$ are views of the spent rocket motor cases after each of these tests. It is evident from Figures $7 \mathrm{~b}$ and $8 \mathrm{~b}$ that the rocket motor cases did not move during the initiation and burn processes.

\section{Test Summaries}

\section{SUNSPOT}

The first rocket motor burn in the X-tunnel test chamber was designated SUNSPOT. This test was conducted on 14 May 1997. The test consisted of cracking and burning two NIKE rocket motors containing a total of $1500 \mathrm{lbs}$ of double base propellant. In addition, a compressed gas cylinder of Krypton was explosively opened simultaneously with the initiation of the burn event. Test initiation time was 1133 hours (PDST).

Instrumentation: With the exception of the FTIR diagnostic, the complete suite of sampling methods and instrumentation given in Table 2 was employed in this test. In addition, a video camera with a view of the test chamber interior was installed behind a port on the chamber barrier at a height of roughly $3 \mathrm{~m}$ above the chamber invert (floor).

General Results: Several observations from the SUNSPOT test are reported here, and the data obtained in this test are included in Appendices A-G. From the video record of the burn event and an analysis of the temperature/pressure records, we can identify a short delay (1-3 seconds) between the initiation of the explosives and the start of the propellant burn. The burn itself lasted 20-25 seconds. Peak pressure in the chamber was measured at roughly 56 psia, and it occurred about 41 seconds after test initiation. The time delay between the apparent end of the bum and the measured pressure peak may be evidence of continued CO-to- $\mathrm{CO}_{2}$ conversion in the combustion cloud. Leaks around the containment barrier into the portal side of the tunnel were observed as pressure in the chamber increased. The particulate-laden gas cloud leaking from the test chamber obscured the view of the video camera focused on the containment barrier within 2-3 minutes after test initiation.

All of the time-resolved instrumentation performed well for the first 2-3 minutes after test initiation. At later times some of the thermocouple junctions failed, probably due to the high water content and acidic nature of the combustion products. In addition, the laser access windows in both TDL detector locations were eventually coated to a point where no laser light could be transmitted across the gas sampling volume. Peak temperatures between $550^{\circ} \mathrm{C}$ and $1200^{\circ} \mathrm{C}$ (depending on location) were measured at a time that correlates with the occurrence of peak pressure. These measurements tend to confirm that the combustion cloud gases in the chamber tend to be stratified at early times; with the highest-temperature gases observed roughly $8 \mathrm{~m}$ above the invert and $2 \mathrm{~m}$ below the chamber back (roof). The sampling ports for the Radian and LANL instrumentation were opened roughly 22 minutes after test initiation due to a concern about the initial high temperatures and pressures observed in the test chamber. 


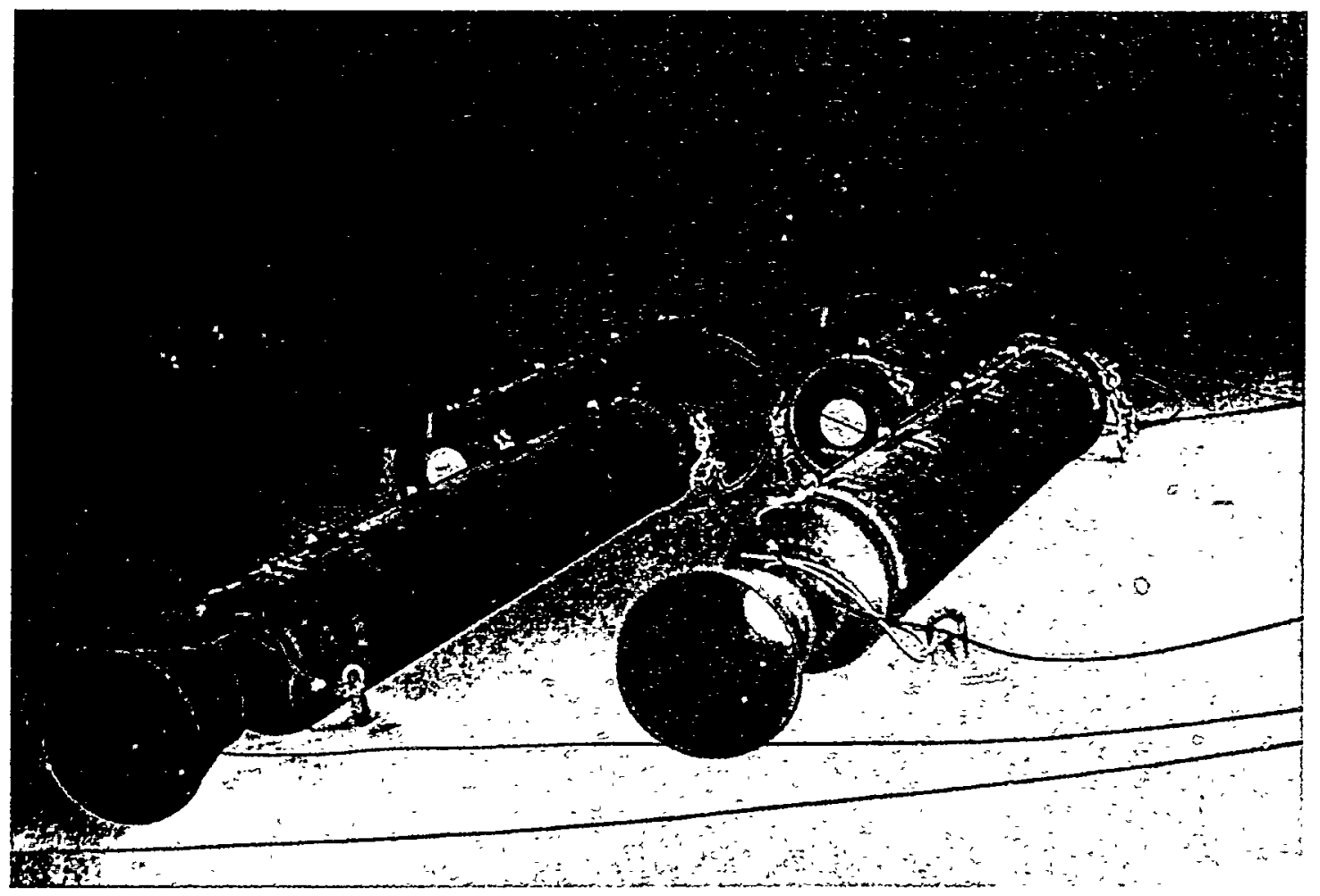

Figure 7a. View of 4 NIKE M88 rocket motors in test chamber prior to THUNDERBIRD.

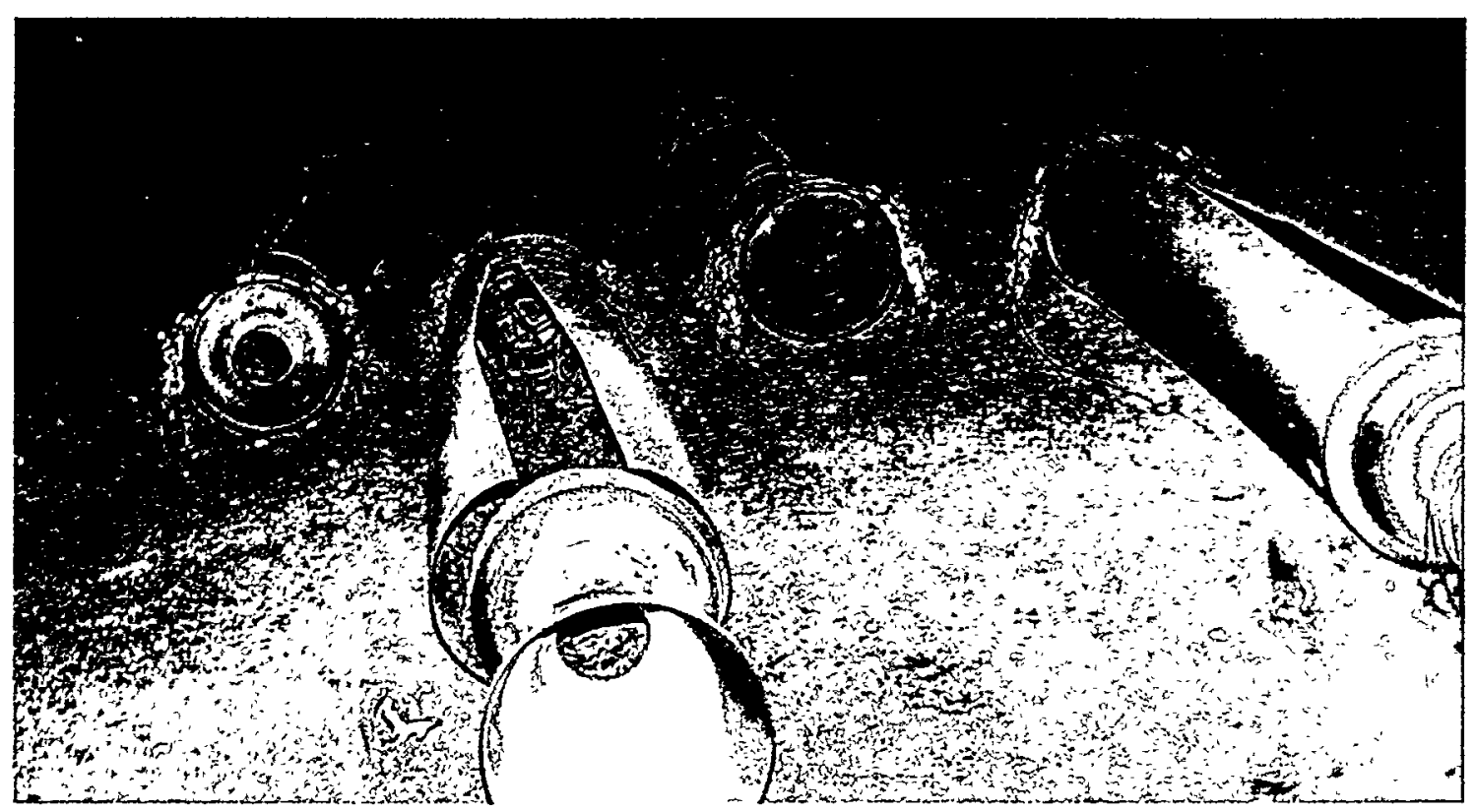

Figure $7 \mathrm{~b}$. Remnants of NIKE rocket motor cases after THUNDERBIRD. 


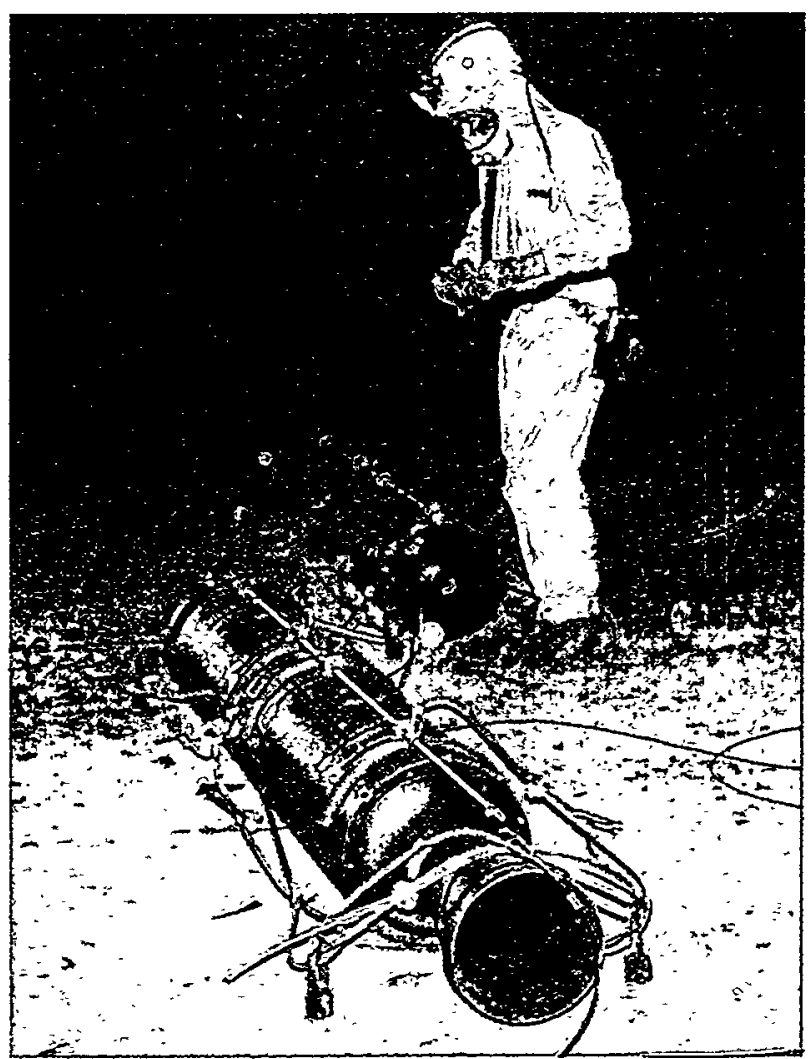

Figure 8a. View of 2 improved Hawk rocket motors in test chamber prior to DAZZLER.

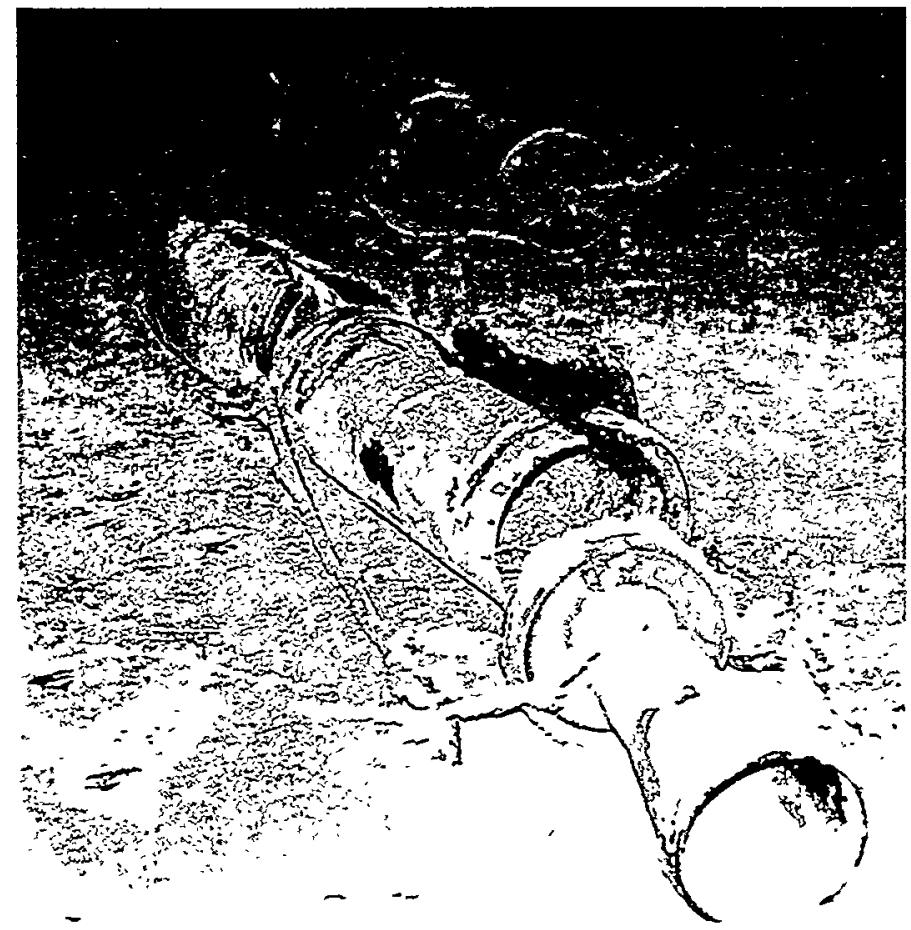

Figure $8 \mathrm{~b}$. View of improved Hawk rocket motors after DAZZLER. 
Chamber Reentry: A nominal atmosphere was monitored in the chamber after several gas exchanges over a 12-18 hour period. Reentry commenced at approximately 1030 hours on 15 May. Personnel entering the chamber were protected by tyvex suites and were required to use supplied-air respirators (SCBA). No unburned propellant was found, and the chamber was judged to be clean and relatively dust free. After off-site lab analyses revealed relatively low contamination in the chamber (particularly for lead and asbestos), the personnel protection requirement was reduced to powered air respirators.

\section{THUNDERBIRD}

The THUNDERBIRD test was performed 28 May 1997. The test consisted of cracking and burning four NIKE M88 rocket motors containing a total of $3000 \mathrm{lbs}$ of double base propellant. In addition, a compressed gas cylinder of Krypton was explosively opened simultaneously with the initiation of the burn event. Test initiation time was 1100 hours (PDST).

Instrumentation: With the exception of the SNL TDL gas species monitor, the complete suite of instrumentation identified in Table 2 was used in this test. The thermocouple array used in SUNSPOT was modified for this test. The 8-station, invert to back, array was reconfigured to 7 stations with the highest thermocouple located roughly $8 \mathrm{~m}$ above the invert. The array was also moved to a new location roughly $18 \mathrm{~m}$ from the center of the rocket motors positioned on the concrete pad. These changes were made in an effort to increase the chances of the thermocouple array surviving the high temperature environment in the chamber during THUNDERBIRD. The SNL TDL gas species monitor enclosures were insulated and sealed prior to the execution of THUNDERBIRD.

General Results: Several observations from the THUNDERBIRD test are reported here, and the data obtained in this test are included in Appendices A-G. From the video and temperature records we can see there was a short delay ( $\sim$ second) between the initiation of the explosives and the start of the propellant burn. The burn itself lasted 2025 seconds. One anomaly noted on the video, and confirmed on reentry, was that the propeliant in one of the 4 motors "burned out" more quickly than that in the others. Burn time on this motor appeared to be less than 10 seconds, and its steel case was split open more than 12 inches compared to a more typical 1-2 inches for the other motors in the test. Peak pressure in the chamber was measured at $85 \mathrm{psia}$, and it occurred roughly 32 seconds after test initiation. A significant particulate-laden cloud was observed leaking around the chamber barrier, along the invert cable/pipe trenches, and through some of the instrumentation feed-throughs.

Nearly all of the real-time instrumentation performed well during THUNDERBIRD. Gas sampling from the top of the chamber was curtailed a few minutes after test initiation due to an apparent failure of the filter on that sampling line. Six of the seven thermocouples recorded stable temperature profiles well into the chamber cool down phase. Maximum temperatures of between $650^{\circ} \mathrm{C}$ and $800^{\circ} \mathrm{C}$ were recorded depending on location. The sampling ports for the Radian and LANL instrumentation were opened approximately 10 minutes after burn initiation due to a concern about the initial high temperatures and pressures in the test chamber. Some clogging of the filters on these sampling lines due to the heavy particulate loading in the chamber reduced the total sampling time. 
Chamber Reentry: A nominal atmosphere was monitored in the chamber after several gas exchanges over night. On reentry no unburned propellant was found, and the chamber was judged to be clean and relatively dust free. The results obtained from subsequent lab analysis of contamination in the chamber (especially lead and asbestos) allowed the personnel protection requirement to be reduced to powęred air respirators for $\mathrm{x}$-tunnel test chamber operations required prior to DAZZLER.

\section{DAZZLER}

The DAZZLER test was the final rocket motor burn test performed in X-tunnel. DAZZLER was executed on 11 June 1997, and it consisted of cracking and burning two Improved HAWK rocket motors in the test chamber. The total weight of the composite propellant contained in these motors was $1294 \mathrm{lbs}$. In addition, cylinders of compressed gas, one each of Krypton and Neon, were explosively opened simultaneously with the initiation of the burn event. Test initiation time was 1100 hours (PDST).

Instrumentation: Monitoring and instrumentation for this test included the complete suite of air emission and temperature/pressure monitors identified in Table 2. Two of the thermocouples in the 7-station thermocouple array used in THUNDERBIRD were replaced, and the array was reinstalled at essentially the same location in the test chamber.

General Results: Several observations from the DAZZLER test are reported here, and the data obtained in this test are included in Appendices A-G. The first 10-12 seconds of the propellant burn was captured on the video record. The video viewing port was obscured after this time due to aluminum deposition on the surface of the glass. For this reason, the exact burn time is somewhat uncertain. The pressure peaked at roughly 42 psia and at a time of 30 seconds after test initiation. No gas leaks were noted on the portal side of the containment barrier.

All of the real-time instrumentation performed well during DAZZLER. Maximum temperatures between $500^{\circ} \mathrm{C}$ and $575^{\circ} \mathrm{C}$ were recorded on the thermocouple array, depending on location. The sampling ports for the Radian and LANL instrumentation were opened approximately 5 minutes after burn initiation. Some clogging of the filters on these sampling lines due to the heavy particulate loading in the chamber reduced the total sampling time.

Chamber Reentry: A nominal atmosphere was monitored in the chamber after several gas exchanges over night. On reentry no unburned propellant was found, and it was noted that the chamber invert was uniformly covered with a thin layer of what appeared to be aluminum oxide particulate. There was also evidence of this powdery coating on the TDL windows and the video viewing port. Analyses of the hazards in the test chamber allowed the use of powered air respirators during subsequent clean-up and shut-down operations at the X-tunnel complex.

\section{Summary of Instrumentation and Sampling/Analysis Procedures}

All of the sampling methods and instrumentation used in these tests are described in this section: abstracted data obtained for each test can be found in appendices A-G, and complete data sets are available in the referenced documents. 


\section{Time-Averaged Measurements-Radian International, LLC (Appendix A)}

Radian was contracted to use EPA methods to obtain time-averaged samples that were subsequently analyzed using EPA laboratory procedures. Results of their

measurements are given in Appendix A where species concentrations are expressed as either ppbv or $\mathrm{mg} / \mathrm{m}^{3}$ at a standard pressure of 29.92 inches $\mathrm{Hg}$ and $68^{\circ} \mathrm{F}$. A detailed report can be obtained from the author.

The samples Radian extracted from the combustion cloud were analyzed for:

- total suspended particulates (TSP),

- particulate matter with an aerodynamic diameter $\leq 10 \mu \mathrm{m}\left(\mathrm{PM}_{10}\right)$,

- volatile organic compounds (VOCs),

- semivolatile organic compounds (SVOCs),

- polychlorinated dibenzo-p-dioxins/polychlorinated dibenzofurans (PCDD/PCDF) (DAZZLER test only),

- hydrogen chloride $(\mathrm{HCl})$ /chlorine $\left(\mathrm{Cl}_{2}\right)$ (DAZZLER test only),

- metals, and

- hydrogen cyanide (HCN).

In addition, post-test residue samples were collected and analyzed for:

- residual energetics and other organic compounds to assess destruction effectiveness, and

- metals (total and leachable).

The metals analysis of the residue helped provide information about appropriate waste disposal of debris from the test chamber. Two types of samples were collected for residue analyses: solid samples that settled out of the combustion cloud and were recovered from 4 separate, $1 \mathrm{~m}^{2}$ areas on the horizontal surface of the concrete pad, and residue washed from the surfaces of 2 aluminum plates using a water and alcohol mixture. These plates were positioned vertically in the test chamber, roughly $3 \mathrm{~m}$ above the invert, and they had a total surface area of $0.75 \mathrm{~m}^{2}$.

The gas samples Radian extracted from the combustion cloud passed through several hollow probes that went into the test chamber through the containment barrier. These probes were isolated from their sampling equipment by remotely operated valves that were closed prior to test initiation. The isolation valves were only opened after it is determined that the temperature and pressure in the test chamber are within safe limits for the sampling equipment. Nominal safe temperature and pressure limits were set at $100^{\circ} \mathrm{C}$ and $50 \mathrm{psig}$, respectively. As noted above, these valves were opened at roughly 22, 10 and 5 minutes after test initiation in SUNSPOT, THUNDERBIRD, and DAZZLER, respectively. The delay in opening the sampling valves for SUNSPOT was excessive, and that delay most likely compromised the quality of the time averaged data Radian and LANL obtained in that test. The observation of inconsistent temperature data reported from the thermocouples the test chamber during SUNSPOT was the source of this 22 minute delay. The problem was resolved in THUNDERBIRD and DAZZLER by revising the thermocouple array location and by using a dedicated thermocouple located near the sampling ports in the test chamber.

In some cases, Radian acquired replicate samples because the heavy particulate loading of the combustion clouds in these tests could cause some of the samples collection trains to be voided. For those situations where replicate samples were 
collected and analyzed, the replicate results were averaged together to calculate a single result for the test. If an analyte was detected in one sample but not detected in a replicate sample, the nondetected sample was ignored in calculating the average result for the test.

\section{Time-Resolved Bulk Gas Analyses-LLNL/Bechtel Nevada (Appendix B)}

Results obtained from the bulk gas sampling of the combustion products generated in these tests are summarized in Appendix B. A detailed description of the measurement procedures and data analyses used is given in (8). Continuous analysis of gas extracted from the test chamber-as well as discrete sampling into 1 -liter containers for post-test analysis at LLNL - were used to determine time-resolved ${ }^{3}$ combustion cloud gas compositions in each test. These data were also analyzed to calculate carbon balances for each test.

On-line composition analyses of the gas samples extracted from the test chamber were obtained for each test. Where possible, duplicate measurements were made in an effort to ensure that viable composition data were obtained. Measurements for product gases were also obtained from two different types of instruments as an internal check on performance. These instruments were located in the "Mobile Noble" trailer positioned on the apron outside the tunnel portal. The gas samples from the test chamber were piped into the trailer where the line pressure was regulated manually. The gas samples were then distributed to the various analytical measurement units in the trailer. Several different continuous emission monitors sampling the incoming gas for $\mathrm{CO}, \mathrm{CO}_{2}, \mathrm{O}_{2}, \mathrm{NO}_{2}$, and $\mathrm{NOx}$ were accessible for reading the displays or changing meter ranges. The gas chromatograph (GC), sample processor lines, and quadrupole mass spectrometer (QMS) made up the other main unit in the trailer. All equipment associated with the Mobile Noble gas analysis trailer was computer controlled. A Macintosh running Labview was used for the QMS, and another Macintosh interfaced all the vacuum and sampling hardware. An IBM-type PC monitored and maintained a log file of Mobile Noble control actions for each experiment, and was also used to log the data from the NOx and CO monitor. A laptop PC controlled and recorded data from the portable GC.

\section{Real-Time and Time-Averaged Aerosol Analyses-LANL (Appendix C)}

The Los Alamos Aerosol Sampling System (LAASS) was specially developed to measure aerosol concentrations as well as to collect aerosol samples during these tests. After the propellant burn was complete in each test, sampling port valves were opened remotely and the LAASS collected representative aerosol samples from the combustion cloud. These samples were obtained by drawing aerosol-laden gas through the containment barrier into two parallel sampling systems. One system (impactor) was used to collect aerosol samples from 0.1 to $10 \mu \mathrm{m}$ in aerodynamic diameter and measure their mass concentrations $\left(\mu \mathrm{g} / \mathrm{m}^{3}\right)$ in real time. The second system (streaker) collected three aerosol size fractions, $>10 \mu \mathrm{m}, 2.5-10 \mu \mathrm{m}$, and $<2.5 \mu \mathrm{m}$. The latter two size fractions were collected on rotating substrates thereby providing a time history of the aerosols in the test chamber. The streaker samples were subsequently analyzed using Proton-Induced X-ray Emission (PIXE) Spectroscopy to determine the aerosol

\footnotetext{
${ }^{3}$ The finite transit time for a gas sample from the test chamber to reach the on-site analytical instrumentation introduces an essentially constant time shift of roughly 2 minutes between the test initiation time and the time-resolved concentration measurements obtained by these techniques.
} 
elemental composition for elements with atomic numbers greater then 11. Data obtained from the LAASS instrument are summarized in Appendix C. A summary report describing the LAASS instrument and its performance in these tests is available from the author.

The impactor is a cascade impactor that separates particles by aerodynamic diameter into 7 size bins with particle separation points of $10,5,2.5,1.2,0.6,0.3$, and $0.12 \mu \mathrm{m}$. Particles larger than the separation points are successively removed as the air stream passes through the collector. Particle mass at each stage is measured by depositing the particles onto quartz crystal micro-balances (QCMs) that change frequency as particles are deposited on them. QCM frequencies are recorded every second in the LAASS. The rate of frequency change with time at the set mass flow rate is a measurement of aerosol mass concentration $\left(\mu \mathrm{g} / \mathrm{m}^{3}\right)$ for each size bin.

The streaker collector separates particles by aerodynamic size with separation points of 10 and $2.5 \mu \mathrm{m}$. Particles larger than $10 \mu \mathrm{m}$ are collected on a fixed collector while particles between 2.5 and $10 \mu \mathrm{m}$ are collected on a moving impact surface. Particles less than $2.5 \mu \mathrm{m}$ are collected on a moving filter. The streaker sampler thus collects a time series of aerosol samples that are analyzed using the PIXE analytical technique for elemental concentrations. The chemical state, or solid phases, within the particles is not measured. Operating the streaker and impactor collectors in conjunction allows both size distributions and high quality samples to be obtained for analysis.

Each sampler is attached to a $100 \mathrm{~mm}$ diameter flange and tube that penetrates the containment barrier. A high pressure and temperature $50 \mathrm{~mm}$ barrier valve, located on the low pressure side of the barrier, isolates each sampling system from the atmosphere in the test chamber. From each sampling valve a $50 \mathrm{~mm}$ diameter sampling probe penetrates through the barrier and extends $0.6 \mathrm{~m}$ into the chamber to isolate the sampled air from the chamber walls. In order to insure that the LAASS instrument remains within its design limits, the barrier valves are not opened until the gas temperature and pressure in the test chamber fall below $200^{\circ} \mathrm{C}$ and $100 \mathrm{psig}$, respectively. For the rocket motor tests, the barrier valves were opened and the first sample taken at 27, 19, and 10 minutes after the ignition time for the SUNSPOT, THUNDERBIRD, and DAZZLER tests, respectively. Because of the high particle levels experienced in these tests, it was necessary to operate the samplers in a "grab sample" mode. That is, samples were taken for short periods ( $<5$ minutes) every 10-15 minutes for at least one hour after test initiation.

LAASS operations were controlled by a multi-level computer system. A programmable logic controller (PLC) was located in a purged cabinet on the portal side of the containment barrier. The PLC controlled the operation of the valves and flow controllers, and collected data from the aerosol and other sensors. The PLC was in turn controlled by a computer located in the instrumentation trailer that was situated outside the tunnel portal. The PLC and controlling computer are connected by fiber optic lines that were used to transmit both the LAASS instrument commands and the measured data.

\section{Real-Time Gas Species Analyses Using FTIR-LANL (Appendix D)}

A Fourier Transform Infrared Spectroscopy (FTIR) diagnostic was deployed for analyzing the gas species that evolved during the THUNDERBIRD and DAZZLER rocket motor burn tests. This diagnostic was designed and deployed on a short time 
scale during the third quarter of FY97 principally to detect and quantify the evolution of the $\mathrm{HCl}$ gas that was generated in the DAZZLER test.

The effectiveness of the FTIR diagnostic depends on the design of the sampling system and its ability to provide a representative sample. The system in X-tunnel was implemented so that a gas sample extracted from the test chamber would only have to travel a relatively short distance to the instrument's absorption cell. The FTIR cell itself was chosen to be $10 \mathrm{~cm}$ long in order to provide optimum detection of $\mathrm{HCl}$ at concentrations of $2 \%$ mole fraction. The system was designed to minimize sampling effects by using teflon tubing which provides less wall reaction and absorption than steel. The tubing for the longest run of the sample line-roughly $30 \mathrm{~m}$-was $12.5 \mathrm{~mm}$ diameter to minimize its surface-to-volume ratio. Based on previous experience, the system was also designed to use a flow rate of $28.3 \mathrm{l} / \mathrm{min}$ to minimize wall effects during sampling. A cyclone filter is included to remove particles larger than $10 \mu \mathrm{m}$. In addition, a sintered metal filter downstream of the cyclone filter removed particles larger than $0.5 \mu \mathrm{m}$. Finally, the sample line and FTIR absorption cell were heated to minimize the effects of water condensation. The sample line was also instrumented with pressure transducers and flow meters to assess system performance remotely. Data obtained from the FTIR diagnostic instrument are summarized in Appendix D. A summary report describing the FTIR diagnostic instrument and its performance in these tests is available from the author.

\section{Post-Test Metal Residue Analyses-UNLV (Appendix E)}

The Harry Reid Center for Environmental Studies at the University of Nevada, Las Vegas (UNLV) was contracted to analyze water/alcohol (50/50) rinse samples collected by Radian International. These samples were taken from two aluminum coupons (plates) that were exposed to the combustion clouds in the test chamber. The total surface area of the coupons was $0.75 \mathrm{~m}^{2}$. The coupons were cleaned before each test and fixed vertically in the chamber at a height of roughly $3 \mathrm{~m}$ above the invert (floor). After exposure to the combustion cloud, the coupons were recovered and washed down with the water/alcohol mixture that UNLV analyzed. Samples were dried, digested, and analyzed using EPA method 200.8 (ICP-MS). The analyses were preformed using an Inductively Coupled Plasma Mass Spectrometer (ICP-MS). In this way, UNLV was able to identify metal residues that collected on the surface of the aluminum during each test. The results of these analyses are given in Appendix E.

\section{In Situ, Laser-Based Measurements of Gas Species Concentrations-SNL (Appendix F)}

A modified commercial gas monitor based on tunable diode laser (TDL) spectroscopy was used to make in situ, real time measurements of several gas species in the test chamber during the SUNSPOT and DAZZLER rocket motor burn tests. The development, installation and application of the TDL gas monitoring system were the responsibilities of SNL. A detailed description of this diagnostic method and its performance in these tests is given in (9). A summary of the results obtained from it is included in Appendix F.

The TDL monitor employed in this application operates in the near-infrared portion of the electromagnetic spectrum; and it detects molecular species using optical absorption by vibration transitions in overtone and combination modes at wavelengths near 1.30 $\mu \mathrm{m}$ and $1.55 \mu \mathrm{m}$. The monitor is capable of providing the time-varying concentrations of 
two different gas species in the test chamber (i.e., using two separate TDL modules). These data are obtained essentially simultaneously and in real time at a sampling rate on the order of $1 \mathrm{~Hz}$. For the rocket motor burn tests, the gas species monitored included $\mathrm{HCN}, \mathrm{CO} / \mathrm{CO}_{2}$ and $\mathrm{H}_{2} \mathrm{O}$. A TDL monitoring system of this type is especially suitable for detecting reactive gases because it can provide gas species concentration measurements that are in-situ (i.e., no sample extraction required) and probe free. Along with the gas species concentration measurements, the TDL monitors also provide quantitative, time-resolved information about the particulate loading in the combustion clouds produced by the rocket motor burns. This occurs because the intensity of TDL near-infrared light that reaches the detector is proportional to the particulate size and concentration in the portion of the combustion cloud continuously sampled by the monitor.

Two fixed sites in the test chamber were chosen for installation of the TDL detectors and sampling volumes. One site was located in the invert of the chamber, and a second site was built into the rib (side wall) of the chamber at a height of $4.9 \mathrm{~m}$ above the invert location. Both sites were roughly $15 \mathrm{~m}$ from the working point of the rocket motor burn tests. The path length of the TDL "light" for each of the two monitors in each sampling volume was $0.5 \mathrm{~m}$. The TDL modules themselves (i.e., the laser light sources) and their associated electronic control hardware and data logging computer were located in the instrumentation trailer on the apron outside the X-tunnel portal. Suitably modulated light from the modules was transmitted to the sampling volumes in the test chamber using commercial, communications-grade optical fibers. The lowvoltage electrical signals generated by the TDL light detectors at the measurement sites contain the transmitted laser power and gas species concentration data. These signals were returned to the instrumentation trailer using coaxial cable.

\section{Time-Resolved Measurements of Test Chamber Pressure and Temperature-LLNL and Bechtel Nevada (Appendix G)}

LLNL and Bechtel NV were responsible for measuring and recording a variety of physical parameters in each test. Data obtained from these measurements are summarized in Appendix G. Complete data sets are available from the author. In addition to early-time shock, ground motion and strain gage measurements on the containment barrier, the data for each test included temperature measurements from a linear array of K-type thermocouples and the gas pressure history in the test chamber. These data were recorded prior to test initiation (baseline data) and for roughly two hours after the propellant burn was complete. Long-term data were sampled at $1-\mathrm{Hz}$ using the NTS Special Measurements integrated Data System (SMIDS). Both the rapid rise and relatively slow decay in pressure and the transient gas temperatures associated with the propellant burning and the gas cool down after the burn were recorded in this way. Depending on the test, there were seven or eight thermocouples in a thermocouple array. These thermocouples were equally spaced in the array in an effort to measure gas temperature as a function of height in the test chamber. The array was positioned between the invert and the back of the test chamber for SUNSPOT and between the invert and the mid-height of the chamber in THUNDERBIRD and DAZZLER.

Comparison of Measured Data with Containment Analyses: As described previously, prior to the execution of these tests, three different numerical simulations were used to predict the peak pressures and temperatures that might be expected in 
the test chamber (3-5). Figures 9 and 10 show comparisons of the calculated temperature and pressure histories, respectively, for THUNDERBIRD [from reference (4)] with the measured data from that test. These comparisons suggest that the analytical heat transfer models developed in references (4) and (5) provide reasonable simulations of the gross effects of propellant combustion and subsequent gas cooling in the nominally sealed test chamber. The discrepancies that do exist, however, can be qualitative explained by limitations in both the simulations and measurements. An example is the failure to include the heat release associated with $\mathrm{CO}$-to- $\mathrm{CO}_{2}$ conversion in the simulation. As discussed above, this conversion tends to increase both the gas temperature and pressure in the chamber. A pressure increase is evident (as shown in Figure 10), but a corresponding significant temperature increase is not apparent (Figure 9). We speculate, however, that the location of the thermocouple array in THUNDERBIRD did not permit an unambiguous measurement of the actual peak temperature in that test. This suggestion is consistent with temperature measurements in SUNSPOT where an invert-to-back thermocouple array location made it clear that early-time temperature histories tend to be spatially non-uniform in the chamber. A second discrepancy that can be noted in the comparisons show in Figures 9 and 10 relates to the cooling rate of the gases in the test chamber. The measured temperature and pressure profiles for THUNDERBIRD both indicate that the hot gasses in the chamber cooled more rapidly than predicted. This observation can be reconciled if we speculate that the actual emissivity of the gases is higher than assumed in the calculations. Such a speculation is reasonable since it was necessary to treat the magnitude of the combustion gas emissivity as an unknown parameter in the simulations carried out in references (4) and (5).

\section{Summary and Conclusions}

These tests provided a unique opportunity to identify propellant combustion processes and effluents from full-scale rocket motor burns both in real time and by capturing representative products for subsequent analysis. In general, we feel that the time resolved and time averaged data in Appendices A-G reveal important information about those effluents. However, several operational difficulties should be recognized when reviewing these results. These difficulties include:

- the quality of the time-averaged data from Radian and LANL measurements for the SUNSPOT test is likely compromised due to the delayed opening of the valves that isolated their equipment from the test chamber, making it difficult to compare gas and particulate data sampling results between the two NIKE rocket motor tests (SUNSPOT and THUNDERBIRD);

- some measurements of non-volatile compounds obtained for THUNDERBIRD and DAZZLER are ambiguous due to cross contamination from the residues of previous tests in the chamber-the UNLV test methods and residue measurements are least affected by this problem; and 


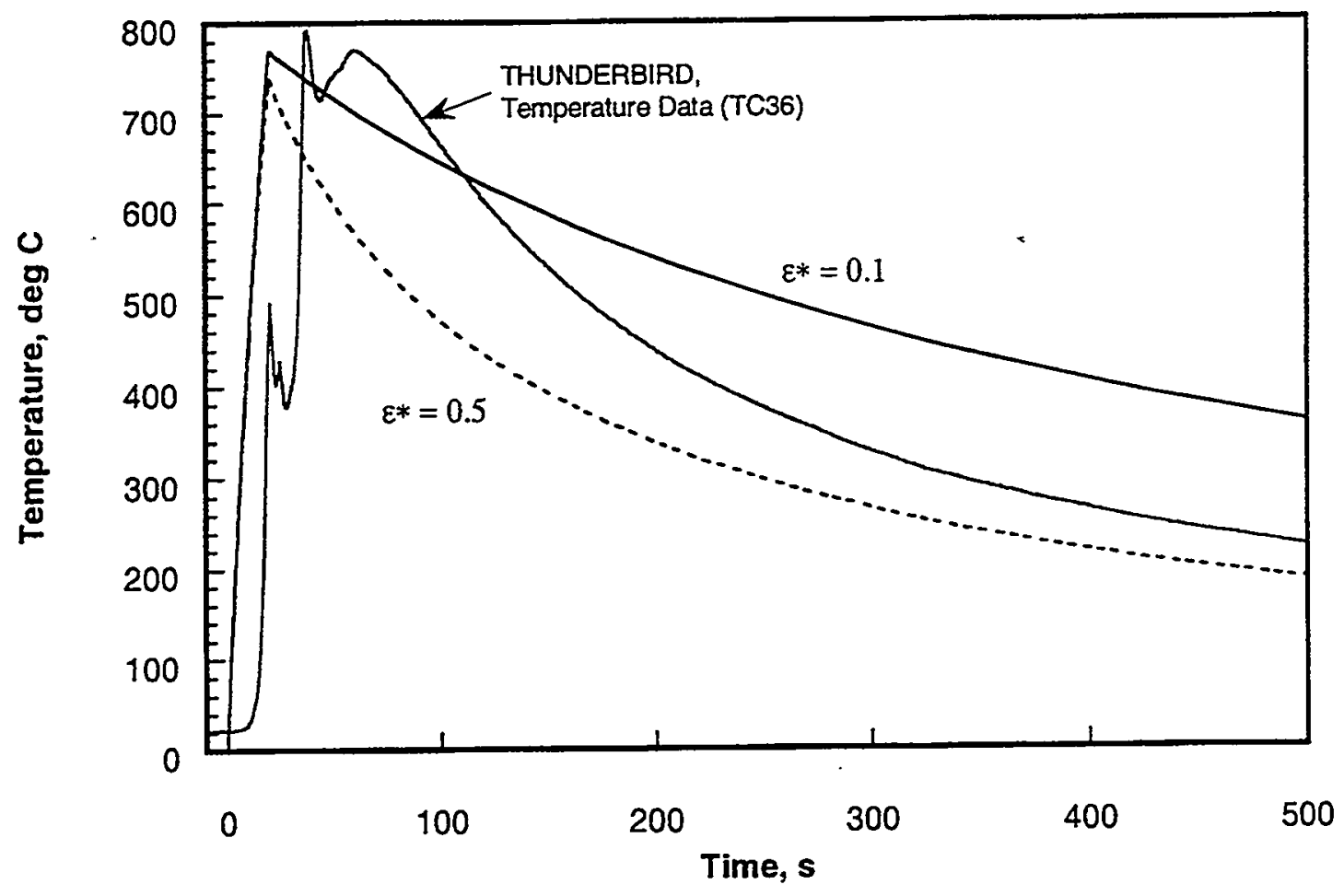

Figure 9. Overlay of computed temperature history for THUNDERBIRD [from Ref (4)] with data from TC36 (thermocouple located $6.4 \mathrm{~m}$ above the test chamber invert).

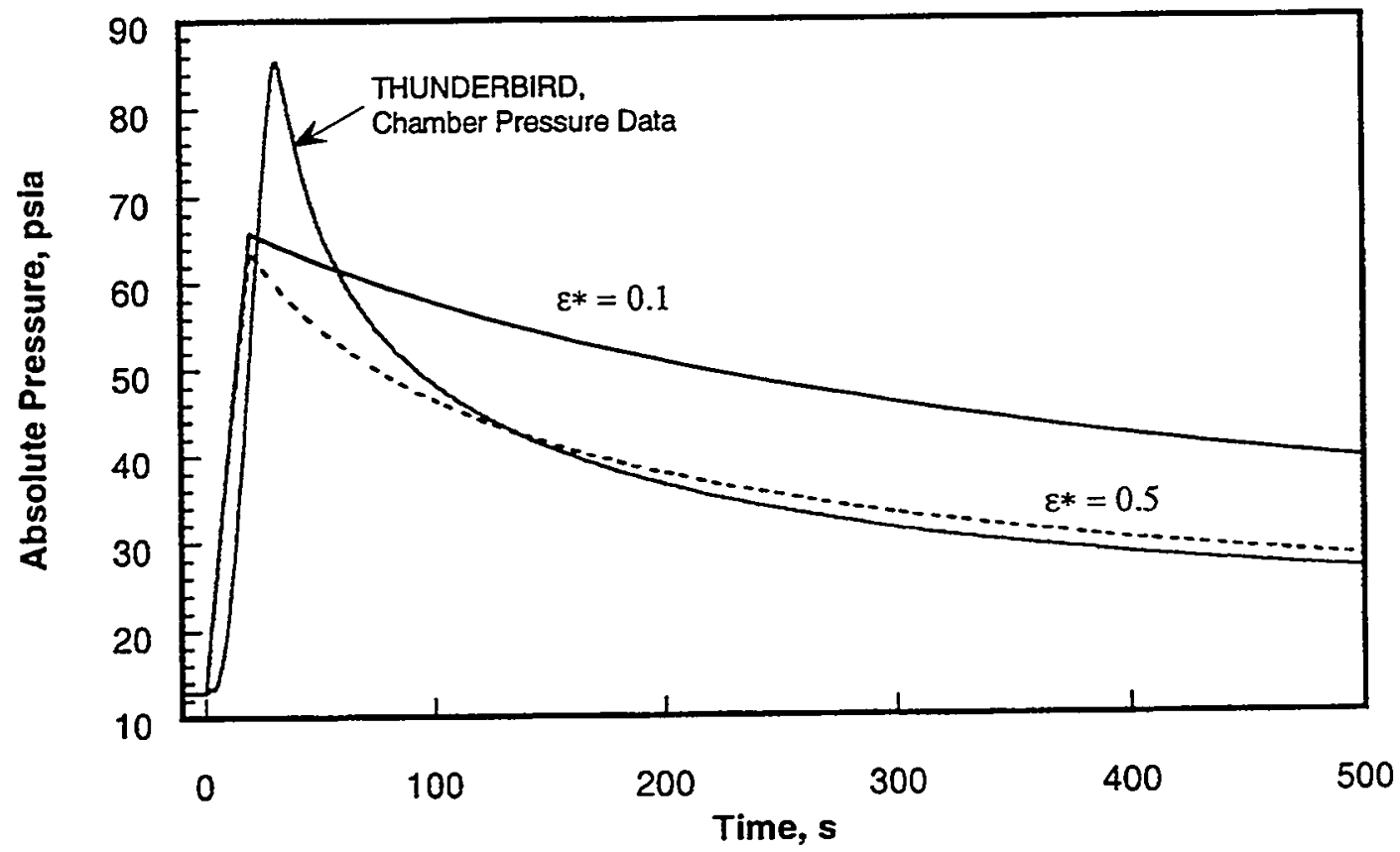

Figure 10. Overlay of computed pressure history for THUNDERBIRD [from Ref (4)] with test data. 
- there is evidence that the leak paths that developed between the test chamber and the tunnel drift during SUNSPOT and THUNDERBIRD allowed an in flow of fresh air into the test chamber-it is likely that these gas leaks substantially reduced measured bulk gas concentrations in the test chamber at late times (i.e., greater than about 80 minutes after test initiation)(10).

Nevertheless, the data provided by these tests are an invaluable source of information on the $O B$ process. In addition, it is likely that further analyses of these data can be used to improve the execution and understanding of future munition testing campaigns in X-tunnel.

The data in Appendices A-G indicate that significant amounts of some organic and inorganic compounds are emitted when double base and composite rocket motor propellants are burned. In addition, the combustion clouds generated in these events are characterized by high concentrations of particulates and aerosols. Nevertheless, the carbon balance data summarized in Appendix $B$, and the residue analyses in Appendix $A$, suggest that there was nearly complete combustion in each of these tests. We therefore conclude that the crack and burn demilitarization procedure followed by low pressure propellant combustion are safe, efficient and relatively clean disposal operations for excess rocket motors. 


\section{References}

1. "Executive Summary of Phase I Demonstrations: Detonation of Conventional Weapons: 155-mm High-Explosive M107 Projectiles", Lawrence Livermore Laboratory Report \# UCRL-ID-131252, July 1998

2. "Executive Summary of Phase II Demonstration: The Low-Pressure Rocket Motor Burns in X-tunnel", Sandia National Laboratories Report \#SAND2000-8202, January 2000

3. "Safety Factors and Design Criteria for U25x Complex (BANSHEE)", July 1996; and "NIKE Rocket Motor Burns - Revised", April 1997, N. Burkhard, Lawrence Livermore National Laboratories, Memoranda to Distribution

4. R. Nilson and S. Griffiths, Sandia National Laboratories, Private Communication, 1996-1997

5. "Analysis Support for the Sandia Rocket Burn Project", R. Boehm and Y.-T. Chen, University of Nevada Las Vegas Contract Report, February 1997

6. "Internal Blast and Thermal Environmental for Internal and External Explosions: A User's Guide for the BLASTX Code, Version 3.0", J. Britt and M Lumsden, Science Applications International Corp., SAIC 405-94-2, May 1994

7. "Final A\&F Report on FY1997 Demil Tests at X-tunnel", R. Peabody, Sandia National Laboratories A\&F Report AF706, August 1997

8. "Gas Sampling and Analysis Results for Low-Pressure Burn Demilitarization of Rocket Motors", C. Velsko, Lawrence Livermore Laboratory Report \# UCRL-ID136582, December 1998

9. "Tunable Diode Laser Spectroscopy: Report on JDT Contained Rocket Motor Burn Tests", S. W. Allendorf, et al., Sandia Report SAND98-8247, September 1998.

10. "Chamber Leakage Effects on Measured Gas Concentrations During Contained Demilitarization Test at NTS X-Tunnel", C. R. Shaddix and J. Lipkin, Sandia Report, SAND2000-8209, December 1999. 
This page intentionally left blank 


\section{APPENDIX A}

Time-Averaged Measurements-Radian International, LLC

Data obtained by Radian International LLC from post-test, laboratory analyses of samples extracted from the test chamber are summarized in Tables A1-A7. Particulate, HCN, and metal species concentrations in the combustion clouds for SUNSPOT and THUNDERBIRD (NIKE rocket motor tests) are summarized in Table A1. Table A2 summarizes measured concentrations of these same analytes, plus $\mathrm{HCl}$ and $\mathrm{Cl}_{2}$, for DAZZLER (Improved HAWK rocket motor test).

Total nonmethane hydrocarbons and selected VOC concentrations for the NIKE and Improved HAWK rocket motor tests are presented in Tables A3 and A4, respectively. The VOCs presented in these tables were detected at concentrations $>15 \mathrm{ppbv}$ in the NIKE tests and $>5 \mathrm{ppbv}$ in the Improved HAWK test. These cutpoints for inclusion in Tables A3 and A4 were chosen because they represent levels nominally five times greater than the sample detection limit.

Tables A5 and A6 present results for SVOCs for the NIKE and Improved HAWK rocket motor tests, respectively. Table A7 presents the PCDD and PCDF results for the Improved HAWK rocket motor test. Also included in Table A7 is the calculated 2,3,7,8-TCDD toxicity equivalence of the sample. These toxic equivalencies were calculated using procedures contained in Appendix IX of 40 CFR 266. 
Table A1. Particulate Matter, HCN, and metal concentrations - NIKE rocket motor

\begin{tabular}{|c|c|c|c|}
\hline \multirow{2}{*}{\multicolumn{2}{|c|}{ Compound }} & \multicolumn{2}{|c|}{ Concentrations, $\mathrm{mg} / \mathrm{m}^{3}$} \\
\hline & & THUNDERBIRD & Average \\
\hline \multicolumn{4}{|l|}{ Particulates } \\
\hline TSP & $9.08 \mathrm{E}+02$ & $1.36 E+03$ & $1.13 E+03$ \\
\hline $\mathrm{PM}_{10}$ & $7.22 \mathrm{E}+01$ & $4.84 E+02$ & $2.78 \mathrm{E}+02$ \\
\hline $\mathrm{HCN}$ & $2.63 \mathrm{E}+01$ & N/A & $2.63 \mathrm{E}+01$ \\
\hline \multicolumn{4}{|l|}{ Metals } \\
\hline \multicolumn{4}{|c|}{ Average Concentrations $>1.0 \mathrm{E}+02$} \\
\hline Lead & $2.58 \mathrm{E}+02$ & $2.86 \mathrm{E}+02$ & $2.72 \mathrm{E}+02$ \\
\hline Antimony & $1.42 E+02$ & $9.88 \mathrm{E}+01$ & $1.21 \mathrm{E}+02$ \\
\hline \multicolumn{4}{|c|}{ Average Concentrations $>1.0 \mathrm{E}+01$ but $<1.0 \mathrm{E}+02$} \\
\hline Phosphorus & $4.36 \mathrm{E}+01$ & $5.13 E+01$ & $4.75 E+01$ \\
\hline Calcium & $1.52 E+01$ & $3.07 \mathrm{E}+01$ & $2.30 \mathrm{E}+01$ \\
\hline Potassium & $4.75 \mathrm{E}+00$ & $3.52 \mathrm{E}+01$ & $2.00 E+01$ \\
\hline Iron & $1.03 \mathrm{E}+01$ & $2.71 \mathrm{E}+01$ & $1.87 \mathrm{E}+01$ \\
\hline Sodium & $4.97 \mathrm{E}+00$ & $1.66 \mathrm{E}+01$ & $1.08 \mathrm{E}+01$ \\
\hline \multicolumn{4}{|c|}{ Average Concentrations $>1.0 \mathrm{E}+00$ but $<1.0 \mathrm{E}+01$} \\
\hline Cadmium & $6.88 \mathrm{E}+00$ & $7.84 \mathrm{E}+00$ & $7.36 \mathrm{E}+00$ \\
\hline Aluminum & $4.74 \mathrm{E}+00$ & $6.61 E+00$ & $5.68 \mathrm{E}+00$ \\
\hline Zinc & $3.57 \mathrm{E}+00$ & $6.72 \mathrm{E}+00$ & $5.14 \mathrm{E}+00$ \\
\hline Copper & $3.65 \mathrm{E}+00$ & $4.72 \mathrm{E}+00$ & $4.19 E+00$ \\
\hline Magnesium & $2.27 \mathrm{E}+00$ & $4.42 \mathrm{E}+00$ & $3.34 \mathrm{E}+00$ \\
\hline Titanium & $1.02 \mathrm{E}+00$ & $1.92 \mathrm{E}+00$ & $1.47 \mathrm{E}+00$ \\
\hline \multicolumn{4}{|c|}{ Average Concentrations $>1.0 \mathrm{E}-01$ but $<1.0 \mathrm{E}+00$} \\
\hline Chromium & $2.03 \mathrm{E}-01$ & $3.22 \mathrm{E}-01$ & $2.62 \mathrm{E}-01$ \\
\hline Manganese & $1.14 \mathrm{E}-01$ & $2.73 \mathrm{E}-01$ & $1.94 \mathrm{E}-01$ \\
\hline Barium & $1.30 \mathrm{E}-01$ & $2.20 \mathrm{E}-01$ & $1.75 \mathrm{E}-01$ \\
\hline Nickel & $1.12 \mathrm{E}-01$ & $1.45 \mathrm{E}-01$ & $1.28 \mathrm{E}-01$ \\
\hline Strontium & $8.86 \mathrm{E}-02$ & 1.64E-01 & $1.26 \mathrm{E}-01$ \\
\hline \multicolumn{4}{|c|}{ Average Concentrations $>1.0 \mathrm{E}-02$ but $<1.0 \mathrm{E}-01$} \\
\hline Arsenic & $7.83 \mathrm{E}-02$ & 9.52E-02 & 8.67E-02 \\
\hline Selenium & $3.38 \mathrm{E}-02$ & $5.48 \mathrm{E}-02$ & $4.43 \mathrm{E}-02$ \\
\hline Molybdenum & $3.90 \mathrm{E}-02$ & $3.09 \mathrm{E}-02$ & $3.50 \mathrm{E}-02$ \\
\hline Cobalt & $1.63 \mathrm{E}-02$ & $2.56 \mathrm{E}-02$ & $2.09 \mathrm{E}-02$ \\
\hline Vanadium & $1.51 \mathrm{E}-02$ & $1.35 \mathrm{E}-02$ & $1.43 \mathrm{E}-02$ \\
\hline Mercury & $5.84 E-03$ & $2.05 \mathrm{E}-02$ & $1.32 \mathrm{E}-02$ \\
\hline Beryllium & $4.54 \mathrm{E}-03$ & $1.61 E-02$ & $1.03 \mathrm{E}-02$ \\
\hline
\end{tabular}

$\mathrm{N} / \mathrm{A}=$ not available 
Table A2. Particulate Matter, $\mathrm{HCN}, \mathrm{HCl}, \mathrm{Cl}_{2}$, and Metal Concentrations -Improved $\mathrm{HAWK}$ rocket motor

\section{Compound \\ Concentrations, $\mathrm{mg} / \mathrm{m}^{3}$}

DAZZLER

\begin{tabular}{lc}
\hline Particulates & $1.18 \mathrm{E}+03$ \\
$\mathrm{TSP}$ & $1.04 \mathrm{E}+03$ \\
$\mathrm{PM}_{10}$ & $\mathrm{ND}$ \\
$\mathrm{HCN}$ & $1.43 \mathrm{E}+04$ \\
$\mathrm{HCl}$ & \\
Chlorine & $1.13 \mathrm{E}+02$
\end{tabular}

Metals
Aluminum
Lead
$3.17 \mathrm{E}+02$
Iron
$1.92 \mathrm{E}+01$
Copper
Antimony
Sodium
$1.04 \mathrm{E}+01$
Potassium
Phosphorus
Chromium
Calcium
Zinc
Average Concentrations $>1.0 \mathrm{E}+00$ but
$<\mathbf{1 . 0 E}+01$
$7.42 \mathrm{E}+00$
$4.28 \mathrm{E}+00$
$2.71 \mathrm{E}+00$
$1.45 \mathrm{E}+00$
$1.26 \mathrm{E}+00$
$1.06 \mathrm{E}+00$
Average Concentrations $>1.0 \mathrm{E}-01$ but $<1.0 \mathrm{E}+00$
Titanium
Nickel
Cadmium
$8.60 \mathrm{E}-01$
$6.22 \mathrm{E}-01$
$3.78 \mathrm{E}-01$
$2.78 \mathrm{E}-01$
$2.02 \mathrm{E}-01$
Magnesium
$1.65 \mathrm{E}-01$
Manganese
Vanadium
$1.29 \mathrm{E}-01$
Average Concentrations $>1.0 \mathrm{E}-02$ but $<1.0 \mathrm{E}-01$
Molybdenum
4.53E-02
Thallium
$3.95 \mathrm{E}-02$
Cobalt
2.81E-02
Barium
$2.19 \mathrm{E}-02$
$1.77 \mathrm{E}-02$
Mercury
$5.93 \mathrm{E}-03$
Strontium
$3.11 \mathrm{E}-03$
Silver
2.42E-03
Selenium
2.32E-03
Beryllium
8.13E-04

Average Concentrations $>1.0 \mathrm{E}+01$

$\mathrm{ND}=$ not detected 
Table A3. Selected VOC Concentrations - NIKE rocket motors

\begin{tabular}{|c|c|c|c|}
\hline \multirow{2}{*}{ Compound } & \multicolumn{3}{|c|}{ Concentrations, ppby } \\
\hline & CrINCPOT & THINAFRPRD & Aromong \\
\hline \multicolumn{4}{|c|}{ Average Concentrations $>1.0 \mathrm{E}+04$} \\
\hline Total Nonmethane Hydrocarbons & $2.91 \mathrm{E}+04$ & $9.18 \mathrm{E}+04$ & $6.04 \mathrm{E}+04$ \\
\hline Acetone & $5.96 \mathrm{E}+03$ & $4.63 E+04$ & $2.61 E+04$ \\
\hline Ethanol & $3.82 E+03$ & $2.94 \mathrm{E}+04$ & $1.66 \mathrm{E}+04$ \\
\hline Benzene & $1.07 \mathrm{E}+04$ & $1.66 \mathrm{E}+04$ & $1.36 \mathrm{E}+04$ \\
\hline Acetaldehyde & $7.14 \mathrm{E}+03$ & $1.98 \mathrm{E}+04$ & $1.35 \mathrm{E}+04$ \\
\hline \multicolumn{4}{|c|}{ Average Concentrations $>1.0 \mathrm{E}+03$ but $<1.0 \mathrm{E}+04$} \\
\hline Chloromethane & $1.08 \mathrm{E}+04$ & $6.64 \mathrm{E}+03$ & $8.69 E+03$ \\
\hline Acetonitrile & $4.69 E+03$ & $9.29 E+03$ & $6.99 E+03$ \\
\hline Propylene & $1.82 E+03$ & $6.13 E+03$ & $3.97 \mathrm{E}+03$ \\
\hline Chloroethane & $1.25 \mathrm{E}+03$ & $5.45 \mathrm{E}+03$ & $3.35 \mathrm{E}+03$ \\
\hline Benzaldehyde & $1.08 \mathrm{E}+03$ & $2.37 \mathrm{E}+03$ & $1.72 E+03$ \\
\hline 1-Butene/Isobutene & $5.56 \mathrm{E}+02$ & $2.60 \mathrm{E}+03$ & $1.58 \mathrm{E}+03$ \\
\hline \multicolumn{4}{|c|}{ Average Concentrations $>1.0 \mathrm{E}+02$ but $<1.0 \mathrm{E}+03$} \\
\hline Naphthalene & $1.14 \mathrm{E}+03$ & $7.70 \mathrm{E}+02$ & $9.55 \mathrm{E}+02$ \\
\hline Acrylonitrile & $1.42 \mathrm{E}+03$ & $4.61 E+02$ & $9.40 \mathrm{E}+02$ \\
\hline 2-Butanone & $3.01 E+02$ & $1.44 \mathrm{E}+03$ & $8.68 \mathrm{E}+02$ \\
\hline 1-Butanol & $5.15 E+02$ & $1.22 E+03$ & $8.67 \mathrm{E}+02$ \\
\hline Methylene chloride & $1.88 \mathrm{E}+01$ & $1.58 \mathrm{E}+03$ & $7.97 \mathrm{E}+02$ \\
\hline Toluene & $5.21 \mathrm{E}+02$ & $1.02 E+03$ & $7.72 E+02$ \\
\hline Chlorobenzene & $3.89 E+02$ & $4.14 \mathrm{E}+02$ & $4.02 E+02$ \\
\hline Vinyl acetate & $1.56 \mathrm{E}+02$ & $5.77 \mathrm{E}+02$ & $3.66 \mathrm{E}+02$ \\
\hline trans-2-Butene & $1.06 E+02$ & $5.04 \mathrm{E}+02$ & $3.05 E+02$ \\
\hline Propane & $1.16 \mathrm{E} \div 02$ & $4.58 \mathrm{E}+02$ & $2.87 \mathrm{E}+02$ \\
\hline Vinyl chloride & $2.85 \mathrm{E}+02$ & $1.76 \mathrm{E}+02$ & $2.30 \mathrm{E}+02$ \\
\hline Diethyl ether & $1.97 \mathrm{E} \div 02$ & $2.42 E+02$ & $2.20 \mathrm{E}+02$ \\
\hline cis-2-Butene & $7.21 E+01$ & $3.39 E+02$ & $2.05 E+02$ \\
\hline Butyraldehyde & $1.31 E+02$ & $2.26 \mathrm{E}+02$ & $1.78 \mathrm{E}+02$ \\
\hline Ethylbenzene & $5.63 E \div 01$ & $2.11 \mathrm{E}+02$ & $1.33 E+02$ \\
\hline n-Butane & $4.98 \mathrm{E} \div 01$ & $1.85 \mathrm{E}+02$ & $1.17 \mathrm{E} \div 02$ \\
\hline $\mathrm{m} / \mathrm{p}$-Xylene & $6.08 E+01$ & $1.49 E+02$ & $1.05 E+02$ \\
\hline
\end{tabular}


Table A3. (Continued)

\begin{tabular}{|c|c|c|c|}
\hline \multirow{2}{*}{ Compound } & \multicolumn{3}{|c|}{ Concentrations, ppby } \\
\hline & SUNSPOT & THUNDERBIRD & Average \\
\hline \multicolumn{4}{|c|}{ Average Concentrations $>1.0 \mathrm{E}+01$ but $<1.0 \mathrm{E}+02$} \\
\hline Styrene & ND & $9.96 \mathrm{E}+01$ & $9.96 E+01$ \\
\hline Butyl acrylate & $5.88 \mathrm{E}+01$ & $9.66 \mathrm{E}+01$ & $7.77 \mathrm{E}+01$ \\
\hline 1,4-Dioxane & $8.50 \mathrm{E}+01$ & $6.24 \mathrm{E}+01$ & $7.37 \mathrm{E}+01$ \\
\hline o-Xylene & $3.70 \mathrm{E}+01$ & $8.90 \mathrm{E}+01$ & $6.30 \mathrm{E}+01$ \\
\hline 1-Hexene & $2.89 \mathrm{E}+01$ & $9.69 E+01$ & $6.29 E+01$ \\
\hline 1-Pentene & $2.54 \mathrm{E}+01$ & $9.96 \mathrm{E}+01$ & $6.25 \mathrm{E}+01$ \\
\hline Isoheptane & $2.27 \mathrm{E}+01$ & $9.56 \mathrm{E}+01$ & $5.91 \mathrm{E}+01$ \\
\hline Chloroform & $6.60 E+00$ & $8.02 E+01$ & $4.34 E+01$ \\
\hline 1,2,4-Trimethylbenzene & $3.69 \mathrm{E}+01$ & $4.89 E+01$ & $4.29 E+01$ \\
\hline Chlorodifluoromethane & $7.93 \mathrm{E}+01$ & $4.65 E+00$ & $4.20 \mathrm{E}+01$ \\
\hline 2-Propanol & $3.66 \mathrm{E}+01$ & $3.38 \mathrm{E}+01$ & $3.52 \mathrm{E}+01$ \\
\hline Isobutane & $1.55 \mathrm{E}+01$ & $.4 .93 E+01$ & $3.24 \mathrm{E}+01$ \\
\hline o-Dichlorobenzene & $2.25 \mathrm{E}+01$ & $3.92 E+01$ & $3.08 \mathrm{E}+01$ \\
\hline trans-2-Pentene & $9.92 \mathrm{E}+00$ & $5.11 \mathrm{E}+01$ & $3.05 \mathrm{E}+01$ \\
\hline Hexanal & $2.70 \mathrm{E}+01$ & $2.68 \mathrm{E}+01$ & $2.69 \mathrm{E}+01$ \\
\hline 1-Propanol & $2.09 E+01$ & $3.02 E+01$ & $2.55 \mathrm{E}+01$ \\
\hline 1-Heptene & $1.02 \mathrm{E} \div 01$ & $3.93 E+01$ & $2.47 \mathrm{E}+01$ \\
\hline n-Pentane & $1.04 \mathrm{E}+01$ & $3.40 \mathrm{E}+01$ & $2.22 E+01$ \\
\hline \multicolumn{4}{|c|}{ Average Concentrations $>1.0 \mathrm{E}+01$ but $<1.0 \mathrm{E}+02$ (cont.) } \\
\hline 2-Methyl-1-pentene & $2.17 \mathrm{E}+01$ & ND & $2.17 \mathrm{E}+01$ \\
\hline Cyclopentene & $1.10 \mathrm{E}+01$ & $3.00 \mathrm{E}+01$ & $2.05 \mathrm{E}+01$ \\
\hline 1-Decene & ND & $1.93 E+01$ & $1.93 E+01$ \\
\hline 1,2-Dichloroethane & $1.91 \mathrm{E}+01$ & ND & $1.91 E+01$ \\
\hline Methylcyclopentene & ND & $1.79 E+01$ & $1.79 E+01$ \\
\hline $1,2,4-$ Trichlorobenzene & $1.70 \mathrm{E}+01$ & ND & $1.70 E+01$ \\
\hline 3-Methyl-1-butene & $6.44 \mathrm{E}+00$ & $2.52 \mathrm{E}+01$ & $1.58 \mathrm{E}+01$ \\
\hline m-Ethyltoluene & $9.67 \mathrm{E}+00$ & $2.09 \mathrm{E}+01$ & $1.53 \mathrm{E}+01$ \\
\hline cis-2-Pentene & $4.87 \mathrm{E}+00$ & $2.35 \mathrm{E}+01$ & $1.42 E+01$ \\
\hline n-Hexane & $7.49 \mathrm{E}+00$ & $1.57 \mathrm{E}+01$ & $1.16 \mathrm{E}+01$ \\
\hline 1-Octene & $5.12 \mathrm{E}+00$ & $1.74 \mathrm{E}+01$ & $1.12 E+01$ \\
\hline n-Heptane & $4.71 E+00$ & $1.78 \mathrm{E}+01$ & $1.12 \mathrm{E}+01$ \\
\hline n-Propylbenzene & $5.80 \mathrm{E}+00$ & $1.63 \mathrm{E}+01$ & $1.10 \mathrm{E}+01$ \\
\hline 1-Nonene & $5.43 E+00$ & $1.61 \mathrm{E}+01$ & $1.07 \mathrm{E}+01$ \\
\hline \multicolumn{4}{|c|}{ Average Concentrations $>1.0 \mathrm{E}+00$ but $<1.0 \mathrm{E}+01$} \\
\hline trans-2-Hexene & $3.64 \mathrm{E}+00$ & $1.61 \mathrm{E}+01$ & $9.87 \mathrm{E}+00$ \\
\hline
\end{tabular}

$\mathrm{ND}=$ not detected 
Table A4. Selected VOC Concentrations-Improved HAWK rocket motor

Concentrations, ppbv

\section{Compound}

\section{DAZZLER}

Average Concentrations $>1.0 \mathrm{E}+03$

Methylene chloride

$1.46 \mathrm{E}+03$

Total Nonmethane Hydrocarbons

$2.57 \mathrm{E}+03$

Benzene

Concentrations $>1.0 \mathrm{E}+02$ but $<1.0 \mathrm{E}+03$

Ethanol

$5.62 \mathrm{E}+02$

Acetaldehyde

$2.69 \mathrm{E}+02$

Chloromethane

$1.87 \mathrm{E}+02$

2-Propanol

$1.86 \mathrm{E}+02$

Acetonitrile

$1.44 \mathrm{E}+02$

Acetone

1-Butanol

Carbon tetrachloride

Propylene

Chloroform

Isobutane

Benzaldehyde

$1.41 \mathrm{E}+02$

$1.33 \mathrm{E}+02$

Concentrations $>1.0 \mathrm{E}+01$ but $<1.0 \mathrm{E}+02$

$1.16 \mathrm{E}+02$

Tetrachloroethene

$9.46 \mathrm{E}+01$

$8.56 \mathrm{E}+01$

$7.85 \mathrm{E}+01$

$6.62 \mathrm{E}+01$

$6.50 \mathrm{E}+01$

Propane

$6.47 E+01$

Toluene

$6.13 E+01$

Vinyl chloride

o-Dichlorobenzene

$5.63 \mathrm{E}+01$

Chlorobenzene

$3.13 \mathrm{E}+01$

$2.76 \mathrm{E}+01$

Acrylonitrile

Isopentane

Naphthalene

Butyraldehyde

$2.74 \mathrm{E}+01$

$2.64 \mathrm{E}+01$

$2.38 \mathrm{E} \div 01$

n-Butane

$2.14 \mathrm{E}+01$

Chloroethane

$2.13 \mathrm{E}+01$

$2.01 \mathrm{E}+01$

$\mathrm{m} / \mathrm{p}$-Xylene

$2.00 \mathrm{E}+01$

1-Butene/Isobutene

$1.92 \mathrm{E}+01$

Trichloroethene

$1.62 \mathrm{E}+01$

Concentrations $>1.0 \mathrm{E}+00$ but $<1.0 \mathrm{E}+01$

$1.12 \mathrm{E}+01$

1,2-Dichloropropane

1-Propanol

$9.70 \mathrm{E}+00$

1,2-Dichloroethane

$9.56 \mathrm{E}+00$

2-Butanone

$7.92 \mathrm{E}+00$

n-Pentane

$7.62 \mathrm{E}+00$

Chlorodifluoromethane

$7.43 \mathrm{E}+00$

Ethylbenzene

$7.42 \mathrm{E}+00$

$6.96 \mathrm{E}+00$

Benzyl chloride

$6.70 \mathrm{E}+00$ 
Table A5. SVOC Concentrations - NIKE rocket motor

\begin{tabular}{|c|c|c|c|}
\hline \multirow{2}{*}{ Compound } & \multicolumn{2}{|c|}{ Concentrations, $\mathrm{mg} / \mathrm{m}^{3}$} & \multirow[b]{2}{*}{ Average } \\
\hline & SUNSPOT & THUNDERBIRD & \\
\hline \multicolumn{4}{|c|}{ Average Concentrations $>1.0 \mathrm{E}+01$} \\
\hline Diethylphthalate & $9.46 \mathrm{E}+01$ & $4.63 \mathrm{E}+01$ & $7.05 \mathrm{E}+01$ \\
\hline 2-Nitrophenol & $1.85 \mathrm{E}+01$ & $2.04 \mathrm{E}+01$ & $1.95 E+01$ \\
\hline \multicolumn{4}{|c|}{ Average Concentrations $>1.0 \mathrm{E}+00$ but $<1.0 \mathrm{E}+01$} \\
\hline Phenol & $1.21 \mathrm{E}+00$ & $1.20 \mathrm{E}+01$ & $6.58 \mathrm{E}+00$ \\
\hline Benzoic acid & $5.66 \mathrm{E}+00$ & $6.44 \mathrm{E}+00$ & $6.05 E+00$ \\
\hline 4-Nitrophenol & $3.59 E+00$ & $6.94 \mathrm{E}+00$ & $5.27 \mathrm{E}+00$ \\
\hline Naphthalene & $7.06 \mathrm{E}+00$ & $1.85 \mathrm{E}+00$ & $4.45 \mathrm{E}+00$ \\
\hline 2,4-Dinitrophenol & ND & $3.45 \mathrm{E}+00$ & $3.45 E+00$ \\
\hline Dimethylphthalate & $2.26 \mathrm{E}+00$ & $3.85 E+00$ & $3.06 \mathrm{E}+00$ \\
\hline Acetophenone & $1.27 \mathrm{E}+00$ & $3.55 \mathrm{E}+00$ & $2.41 E+00$ \\
\hline Dibenzofuran & $2.48 \mathrm{E}+00$ & $.1 .43 \mathrm{E}+00$ & $1.96 \mathrm{E}+00$ \\
\hline \multicolumn{4}{|c|}{ Average Concentrations $>1.0 \mathrm{E}-01$ but $<1.0 \mathrm{E}+00$} \\
\hline Nitrobenzene & 3.37E-01 & $6.67 \mathrm{E}-01$ & 5.02E-01 \\
\hline Phenanthrene & $4.79 \mathrm{E}-01$ & $1.11 \mathrm{E}-01$ & $2.95 \mathrm{E}-01$ \\
\hline bis(2-Ethylhexyl)phthalate & $3.88 E-01$ & $8.45 \mathrm{E}-02$ & $2.36 \mathrm{E}-01$ \\
\hline 2-Methylnaphthalene & $3.18 \mathrm{E}-01$ & $1.41 \mathrm{E}-01$ & 2.29E-01 \\
\hline Chrysene & $2.16 \mathrm{E}-01$ & ND & $2.16 \mathrm{E}-01$ \\
\hline 1,2-Dichlorobenzene & $2.37 \mathrm{E}-01$ & $1.28 \mathrm{E}-01$ & $1.82 E-01$ \\
\hline 1,2,4-Trichlorobenzene & $1.65 \mathrm{E}-01$ & ND & $1.65 \mathrm{E}-01$ \\
\hline 4-Methylphenol/3-Methylphenol & 7.47E-02 & $1.59 \mathrm{E}-01$ & $1.17 \mathrm{E}-01$ \\
\hline Benzyl alcohol & $1.10 \mathrm{E}-01$ & ND & $1.10 \mathrm{E}-01$ \\
\hline 1,4-Dichlorobenzene & $1.02 E-01$ & ND & $1.02 \mathrm{E}-01$ \\
\hline 1,3-Dichlorobenzene & $1.01 \mathrm{E}-01$ & ND & $1.01 \mathrm{E}-01$ \\
\hline \multicolumn{4}{|c|}{ Average Concentrations $>1.0 \mathrm{E}-02$ but $<1.0 \mathrm{E}-01$} \\
\hline Fluoranthene & 8.70E-02 & ND & 8.70E-02 \\
\hline 2,4,6-Trichlorophenol & ND & $7.49 \mathrm{E}-02$ & 7.49E-02 \\
\hline 2-Chlorophenol & $3.10 \mathrm{E}-02$ & $1.17 \mathrm{E}-01$ & $7.42 \mathrm{E}-02$ \\
\hline Benzo(b)fluoranthene & $7.30 \mathrm{E}-02$ & ND & $7.30 \mathrm{E}-02$ \\
\hline Benzo(k)fluoranthene & $7.30 \mathrm{E}-02$ & ND & 7.30E-02 \\
\hline Fluorene & $7.23 \mathrm{E}-02$ & $2.66 \mathrm{E}-02$ & $4.95 E-02$ \\
\hline $1,2,4,5$-Tetrachlorobenzene & $2.30 \mathrm{E}-02$ & ND & $2.30 \mathrm{E}-02$ \\
\hline Di-n-butylphthalate & $1.87 \mathrm{E}-02$ & $1.99 \mathrm{E}-02$ & 1.93E-02 \\
\hline Acenaphthylene & $1.68 \mathrm{E}-02$ & ND & $1.68 \mathrm{E}-02$ \\
\hline Anthracene & $1.39 \mathrm{E}-02$ & ND & $1.39 E-02$ \\
\hline \multicolumn{4}{|c|}{ Average Concentrations $>1.0 \mathrm{E}-03$ but $<1.0 \mathrm{E}-02$} \\
\hline Pyrene & $6.18 \mathrm{E}-03$ & ND & $6.18 \mathrm{E}-03$ \\
\hline
\end{tabular}


Table A6. SVOC Concentrations - Improved HAWK rocket motor

\section{Compound}

\section{Concentrations, $\mathrm{mg} / \mathrm{m}^{3}$}

\section{DAZZLER}

Benzoic acid

Diethylphthalate

2-Nitrophenol

2,4,6-Trichlorophenol

1,2-Dichlorobenzene

Naphthalene

Hexachlorobenzene

Pentachlorobenzene

4-Nitrophenol

1,2,4,5-Tetrachlorobenzene

Phenol

Dibenzofuran

1,2,4-Trichlorobenzene

Dimethylphthalate

4-Chloro-3-methylphenol

2-Chloronaphthalene

2,4-Dichlorophenol

1,3-Dichlorobenzene

Hexachlorobutadiene

Concentrations $>1.0 \mathrm{E}+00$

2-Chlorophenol

\begin{tabular}{cc} 
Concentrations $>1.0 \mathrm{E}+\mathbf{0 0}$ & $1.43 \mathrm{E}+00$ \\
$1.05 \mathrm{E}+00$ \\
Concentrations $>\mathbf{1 . 0 E}-\mathbf{0 1}$ but $<\mathbf{1 . 0 E}+\mathbf{0 0}$ \\
$9.44 \mathrm{E}-01$ \\
$6.56 \mathrm{E}-01$ \\
$3.30 \mathrm{E}-01$ \\
$2.81 \mathrm{E}-01$ \\
$2.40 \mathrm{E}-01$ \\
$1.94 \mathrm{E}-01$ \\
$1.60 \mathrm{E}-01$ \\
Concentrations $>\mathbf{1 . 0 E}-\mathbf{0 2}$ but $<1.0 \mathrm{E}-\mathbf{0 1}$ \\
$9.68 \mathrm{E}-02$ \\
$8.46 \mathrm{E}-02$ \\
$7.58 \mathrm{E}-02$ \\
$6.10 \mathrm{E}-02$ \\
$6.00 \mathrm{E}-02$ \\
$4.46 \mathrm{E}-02$ \\
$4.36 \mathrm{E}-02$ \\
$4.13 \mathrm{E}-02$ \\
$3.53 \mathrm{E}-02$ \\
$3.47 \mathrm{E}-02$ \\
$3.37 \mathrm{E}-02$ \\
$3.35 \mathrm{E}-02$ \\
$1.94 \mathrm{E}-02$ \\
$1.03 \mathrm{E}-02$ \\
\hline
\end{tabular}

4,6-Dinitro-2-methylphenol

1,4-Dichlorobenzene

Phenanthrene

$1.03 \mathrm{E}-02$ 
Table A7. PCDD and PCDF Concentrations-Improved HAWK rocket motor

\begin{tabular}{|c|c|}
\hline Compound & $\begin{array}{c}\text { Concentrations, } \mathrm{mg} / \mathrm{m}^{3} \\
\text { DAZZLER }\end{array}$ \\
\hline $\begin{array}{l}\text { Polychlorinated dibenzo-p-dioxin } \\
\text { 2,3,7,8-TCDD } \\
\text { 1,2,3,7,8-PeCDD } \\
\text { 1,2,3,4,7,8-HxCDD } \\
1,2,3,6,7,8-\mathrm{HxCDD} \\
1,2,3,7,8,9-\mathrm{HxCDD} \\
1,2,3,4,6,7,8-\mathrm{HpCDD} \\
1,2,3,4,6,7,8,9-\mathrm{OCDD} \\
\text { Total TCDD } \\
\text { Total PeCDD } \\
\text { Total HxCDD } \\
\text { Total HpCDD }\end{array}$ & $\begin{array}{l}7.60 \mathrm{E}-05 \\
1.20 \mathrm{E}-04 \\
8.46 \mathrm{E}-05 \\
1.42 \mathrm{E}-04 \\
1.47 \mathrm{E}-04 \\
4.95 \mathrm{E}-04 \\
1.11 \mathrm{E}-03 \\
1.86 \mathrm{E}-03 \\
1.35 \mathrm{E}-03 \\
1.49 \mathrm{E}-03 \\
8.82 \mathrm{E}-04\end{array}$ \\
\hline $\begin{array}{l}\text { Polychlorinated dibenzofurans } \\
2,3,7,8-\mathrm{TCDF} \\
1,2,3,7,8-\mathrm{PeCDF} \\
2,3,4,7,8-\mathrm{PeCDF} \\
1,2,3,4,7,8-\mathrm{HxCDF} \\
1,2,3,6,7,8-\mathrm{HxCDF} \\
2,3,4,6,7,8-\mathrm{HxCDF} \\
1,2,3,7,8,9-\mathrm{HxCDF} \\
1,2,3,4,6,7,8-\mathrm{HpCDF} \\
1,2,3,4,7,8,9-\mathrm{HpCDF} \\
1,2,3,4,6,7,8,9-\mathrm{OCDF} \\
\text { Total TCDF } \\
\text { Total PeCDF } \\
\text { Total HxCDF } \\
\text { Total HpCDF }\end{array}$ & $\begin{array}{l}1.62 \mathrm{E}-03 \\
1.05 \mathrm{E}-03 \\
7.52 \mathrm{E}-04 \\
3.32 \mathrm{E}-03 \\
9.04 \mathrm{E}-04 \\
7.09 \mathrm{E}-04 \\
1.92 \mathrm{E}-04 \\
4.81 \mathrm{E}-05 \\
2.55 \mathrm{E}-03 \\
9.62 \mathrm{E}-05 \\
1.38 \mathrm{E}-02 \\
8.56 \mathrm{E}-03 \\
1.01 \mathrm{E}-02 \\
1.30 \mathrm{E}-02\end{array}$ \\
\hline 2,3,7,8-TCDD Toxicity Equivalence ${ }^{a}$ & $1.31 E-03$ \\
\hline
\end{tabular}

${ }^{\mathrm{a} C}$ Calculated using procedures in Appendix IX of 40 CFR 266. 
Samples of solid residue collected from the concrete pad on the invert of the test chamber after each test were analyzed for energetics, SVOC's and metals. These data are summarized in Tables A8-A11. Table A8 summarizes the results of the residue energetics analyses. SVOCs found in the residue.samples are summarized in Table A9.

The concentrations of metals found in the residue samples are summarized in Table A10. The results of subjecting the residue to the Toxicity Characteristic Leaching Procedure (TCLP) are summarized in Table A11. For the residue from the SUNSPOT and THUNDERBIRD test burns, all the TCLP metals were detected at a level lower than their respective regulatory levels. For the DAZZLER residue, cadmium and lead from the TCLP exceeded the regulatory level for defining the material as "toxic." Since the total metals concentrations of cadmium and lead were similar in all residue samples, the TCLP results for the DAZZLER residue were somewhat unexpected. A possible explanation for the greater leachability of cadmium and lead from the DAZZLER residue is the high $\mathrm{HCl}$ content of the combustion gases from the DAZZLER test. Some of the $\mathrm{HCl}$ undoubtedly was absorbed on the residue. The acidity associated with the $\mathrm{HCl}$ could have caused the metals in the residue to be more readily leached by the TCLP.

Table A8. Energetics in residue samples

\begin{tabular}{lccc}
\hline \multicolumn{1}{c}{ Analyte } & \multicolumn{3}{c}{ Concentration, ppb } \\
& SUNSPOT & THUNDERBIRD & DAZZLER \\
\cline { 2 - 4 } $\begin{array}{l}\text { Octahydro-1,3,5,7-tetranitro-1,3,5,7- } \\
\text { tetrazocine (HMX) }\end{array}$ & $\mathrm{ND}$ & $\mathrm{ND}$ & 411 \\
Hexahydro-1,3,5-trinitro-1,3,5-triazine (RDX) & 14950 & 7350 & $\mathrm{ND}$ \\
1,3,5-Trinitrobenzene & $\mathrm{ND}$ & $\mathrm{ND}$ & 1040 \\
2-amino-4,6-dinitrotoluene & $\mathrm{ND}$ & $\mathrm{ND}$ & 20 \\
& & & \\
Net Explosive Weight (NEW), Ib & 1501.6 & 3002.8 & 1211 \\
\hline $\mathrm{ND}=$ not detected & &
\end{tabular}


Table A9. SVOCs in residue samples

\begin{tabular}{|c|c|c|c|}
\hline \multirow{2}{*}{ SVOC } & \multicolumn{3}{|c|}{ Concentration in Residue Samples, $\mu \mathrm{g} / \mathrm{kg}$} \\
\hline & SUNSPOT & THUNDERBIRD & DAZZLER \\
\hline 2,4-Dinitrophenol & 2020 & 1130 & 903 \\
\hline 2-Methylnaphthalene & 98 & 80 & 168 \\
\hline 2-Nitrophenol & 2550 & 5150 & 1540 \\
\hline 4,6-Dinitro-2-methylphenol & 205 & ND & ND \\
\hline 4-Nitrophenol & 2080 & 8540 & 1360 \\
\hline Anthracene & 37 & ND & ND \\
\hline Benzo(b)fluoranthene & 959 & ND & ND \\
\hline Benzoic Acid & 852 & 999 & 3410 \\
\hline bis(2-Ethylhexyl)phthalate & 4450 & 283 & 1040 \\
\hline Butylbenzylphthalate & 1410 & ND & ND \\
\hline Chrysene & 2270 & ND & ND \\
\hline Dibenzofuran & 998 & 359 & 302 \\
\hline Diethylphthalate & 87500 & 15500 & 44200 \\
\hline Dimethylphthalate & 1710 & 657 & 3620 \\
\hline Di-n-butylphthalate & 513 & 82 & ND \\
\hline Fluoranthene & 368 & 15 & ND \\
\hline Fluorene & 51 & ND & ND \\
\hline Hexachlorobutadiene & 65 & ND & ND \\
\hline Naphthalene & 288 & 480 & 90 \\
\hline Nitrobenzene & ND & 58 & ND \\
\hline Phenanthrene & 728 & 50 & 106 \\
\hline Phenol & 11100 & 3930 & ND \\
\hline
\end{tabular}

$\mathrm{ND}=$ not detected 
Table A10. Total metals in residue samples

\begin{tabular}{|c|c|c|c|}
\hline & \multicolumn{3}{|c|}{ Concentration in Residue Samples, $\mathrm{mg} / \mathrm{kg}$} \\
\hline & SUNSPOT & THUNDERBIRD & DAZZLER \\
\hline Aluminum & NR & NR & 19500 \\
\hline Antimony & 2370 & 514 & 993 \\
\hline Arsenic & 9.5 & 14.2 & 4.37 \\
\hline Barium & 291 & 169 & 110 \\
\hline Beryllium & ND & 0.464 & ND \\
\hline Cadmium & 121 & 53.7 & 87.3 \\
\hline Cobalt & 5.23 & 7.04 & 2.95 \\
\hline Chromium & 42 & 24.7 & 68.9 \\
\hline Lead & 14800 & 5880 & 8770 \\
\hline Manganese & 283 & 176 & 163 \\
\hline Mercury & 0.429 & 0.114 & 0.435 \\
\hline Nickel & 23.5 & 11.0 & 12.2 \\
\hline Phosphorus & 2360 & 1050 & 983 \\
\hline Selenium & 1.89 & 1.15 & 1.44 \\
\hline Silver & ND & 0.207 & 0.254 \\
\hline Thallium & 1.39 & 2.18 & 1.04 \\
\hline Zinc & 208 & 140 & 344 \\
\hline
\end{tabular}


Table A11. TCLP metals analysis of residue samples

\begin{tabular}{lcccc}
\hline \multicolumn{1}{c}{ Metal } & \multicolumn{2}{c}{ Concentration in Residue Leachate, mg/L } & $\begin{array}{c}\text { Regulatory } \\
\text { Level, } \mathbf{m g} / \mathbf{L}\end{array}$ \\
Arsenic & SUNSPOT & THUNDERBIRD & DAZZLER & \\
\cline { 2 - 4 } Barium & 0.049 & 0.0185 & 0.007 & 5 \\
Cadmium & 0.237 & 0.215 & 0.313 & 100 \\
Chromium & 0.0325 & 0.001 & 1.94 & 1 \\
Lead & 0.0035 & $\mathrm{ND}$ & 0.0985 & 5 \\
Mercury & 2.80 & 0.155 & 29.0 & 5 \\
Selenium & 0.0063 & $\mathrm{ND}$ & 0.00065 & 5.2 \\
Silver & 0.0075 & $\mathrm{ND}$ & $\mathrm{ND}$ & 1 \\
\hline
\end{tabular}

$\mathrm{ND}=$ not detected 
This page intentionally left blank 


\section{APPENDIX B}

\section{Time-Resolved Bulk Gas Analyses-LLNL/Bechtel Nevada}

An inventory of the propellant and explosive materials consumed in each rocket motor burn test is shown in Table B1. This inventory indicates the carbon content of these materials. All of the carbon-bearing materials in each test must be identified in order to calculate the final distribution of carbon (i.e., the carbon balance) in all of the gaseous combustion products that were measured by LLNL and $\mathrm{BN}$.

Assuming that the low pressure burns in the test chamber represent complete combustion, we can use the inventory information in Table B1 to estimate how much of each product gas will be produced in a given test. The calculated moles of the product gases are shown in Table B2 along with the quantities of inert tracer gas released in each test. Note that the results given in Table B2 generally depend on the assumptions that are made about the composition of the reaction products in a test. For example, the bottom two rows in Table B2 show how two different assumptions on the formation of $\mathrm{HCl}$ and $\mathrm{Cl}_{2}$ affect the calculated moles of $\mathrm{H}_{2} \mathrm{O}$ and $\mathrm{O}_{2}$ in DAZZLER.

The combustion product gas concentrations expected for each test are obtained by using the estimated gas quantities in Table B2 and the initial gas composition in the test chamber. These concentrations are shown in the column labeled "Expect" in Table B3. Table B3 also includes a summary of all of the bulk gas species concentration data measured in the rocket motor burn test series.

Table B1. Inventory of materials consumed in rocket motor burns ${ }^{\star}$.

\begin{tabular}{|c|c|c|c|}
\hline \multirow[b]{2}{*}{ Item Description } & \multicolumn{3}{|c|}{ Test ID } \\
\hline & SUNSPOT & THUNDERBIRD & DAZZLER \\
\hline $\begin{array}{c}\text { Total weight of } \\
\text { carbon-containing materials }\end{array}$ & $\begin{array}{c}1606 \mathrm{lb},(2 \mathrm{NIKE}) \\
(29.34 \mathrm{wt} \% \text { carbon })\end{array}$ & $\begin{array}{l}3212 \mathrm{lb},(4 \mathrm{NIKE}) \\
(29.34 \text { wt\% carbon })\end{array}$ & $\begin{array}{c}1334 \text { lb (2 Imp. } \\
\text { HAWK) } \\
\text { (14.11 wt\% carbon) }\end{array}$ \\
\hline $\begin{array}{l}\text { carbon-containing materials in } \\
\text { each motor }\end{array}$ & $\begin{array}{l}\text { OIO propellant, } \\
\text { cellulose acetate liner }\end{array}$ & $\begin{array}{c}\text { OIO propellant, } \\
\text { cellulose acetate liner }\end{array}$ & $\begin{array}{l}\text { composite propellant, } \\
\text { liner, insert }\end{array}$ \\
\hline $\begin{array}{l}\text { RDX in Copper Linear Shaped } \\
\text { Charge (CLSC) (for rocket } \mathrm{mtr} \text { ) }\end{array}$ & $250 \mathrm{gr} / \mathrm{ft} \times 16=0.571 \mathrm{lb}$ & $250 \mathrm{gr} / \mathrm{ft} \times 32=1.143 \mathrm{lb}$ & $250 \mathrm{gr} / \mathrm{ft} \times 16=0.571 \mathrm{lb}$ \\
\hline RDX in CLSC (for gas btl) & $600 \mathrm{gr} / \mathrm{ft} \times 5=0.429 \mathrm{lb}$ & $600 \mathrm{gr} / \mathrm{ft} \times 5=0.429 \mathrm{lb}$ & $600 \mathrm{gr} / \mathrm{ft} \times 10=0.857 \mathrm{lb}$ \\
\hline RDX in Cutting Tape & $300 \mathrm{~g} / \mathrm{ft} \times 10=0.429 \mathrm{lb}$ & $300 \mathrm{gr} / \mathrm{ft} \times 20=0.857 \mathrm{lb}$ & $300 \mathrm{gr} / \mathrm{ft} \times 13=0.571 \mathrm{lb}$ \\
\hline RDX in RP1 Detonator & $0.626 \mathrm{~g} \times 6=0.00841 \mathrm{~b}$ & $0.626 \mathrm{~g} \mathrm{x} 10=0.014 \mathrm{lb}$ & $0.626 \mathrm{~g} \times 8=0.0112 \mathrm{lb}$ \\
\hline $\begin{array}{l}\text { Total RDX Weight } \\
\left(\mathrm{C}_{3} \mathrm{H}_{6} \mathrm{O}_{6} \mathrm{~N}_{6}\right)\end{array}$ & $1.437 \mathrm{lb}$ & $2.443 \mathrm{lb}$ & $2.010 \mathrm{lb}$ \\
\hline
\end{tabular}

*From R. L. Peabody, Sandia National Laboratories, Albuquerque, NM, and SPIA Data Sheets and T. Moore, Chemical Propulsion Information Agency, John Hopkins University, MD. 
Table B2. Expected rocket burn combustion products and tracer gas amounts. ${ }^{*}$

\begin{tabular}{|l|c|c|c|c|c|c|c|}
\hline \multicolumn{1}{|c|}{ Test ID } & $\begin{array}{c}\text { Test } \\
\text { Weight, lbs }\end{array}$ & $\begin{array}{c}\mathrm{H}_{2} \mathrm{O}, \\
\text { moles }\end{array}$ & $\begin{array}{c}\mathrm{N}_{2}, \\
\text { moles }\end{array}$ & $\begin{array}{c}\mathrm{CO}_{2}, \\
\text { moles }\end{array}$ & $\begin{array}{c}\mathrm{O}_{2}{ }^{* *} \\
\text { moles }\end{array}$ & $\begin{array}{c}\text { Neon, } \\
\text { moles }\end{array}$ & $\begin{array}{c}\text { Krypton, } \\
\text { moles }\end{array}$ \\
\hline SUNSPOT & 1606 & 12095 & 3018 & 17796 & -11277 & & 412 \\
\hline THUNDERBIRD & 3212 & 24186 & 6033 & 35590 & -22553 & & 379.8 \\
\hline DAZZIER $(\mathrm{HCl})$ & 1334 & 12107 & 2530 & 7115 & -6830 & 446 & 380.8 \\
\hline DAZZLER $\left(\mathrm{Cl}_{2}\right)$ & 1334 & 13755 & 2530 & 7115 & -7654 & 446 & 380.8 \\
\hline
\end{tabular}

* Assume all metals are completely oxidized (i.e., $\mathrm{PbO}, \mathrm{Al}_{2} \mathrm{O}_{3}, \mathrm{Fe}_{3} \mathrm{O}_{4}$ ), all nitrogen goes to $\mathrm{N}_{2}$, all $\mathrm{CO}$ goes to $\mathrm{CO}_{2}$, all hydrogen goes to $\mathrm{H}_{2} \mathrm{O}$ or $\mathrm{H}_{2} \mathrm{O}$ and $\mathrm{HCl}$ [in DAZZLER ( $\mathrm{HCl}$ )], and all chlorine (in the two DAZZLER assumptions) reacted to either $\mathrm{Cl}_{2}$ (1648 moles) or $\mathrm{HCl}$ ( 3295 moles).

** Negative values indicate consumption of atmospheric $\mathrm{O}_{2}$ after all the oxygen in the carbon-bearing items (propellant+explosives+motor parts) is consumed.

Table B3. Data summary-comparison of computed and measured bulk gas species concentrations in the test chamber at the end of each burn *

\begin{tabular}{|c|c|c|c|c|c|c|c|c|c|}
\hline \multirow[b]{2}{*}{ Gas Species } & \multicolumn{3}{|c|}{ SUNSPOT, \% Vol, } & \multicolumn{3}{|c|}{ THUNDERBIRD, \% Vol } & \multicolumn{3}{|c|}{ DAZZLER, \% Vol } \\
\hline & Expect & Meas'd & $\pm \% \mathrm{~V}$ & Expect & Meas'd & $\pm \% \mathrm{~V}$ & Expect & Meas'd & $\pm \% \mathrm{~V}$ \\
\hline Nitrogen & 75.42 & 75.63 & 0.10 & 73.20 & 75.13 & 0.5 & 76.45 & 77.10 & 0.1 \\
\hline Oxygen & 13.45 & 13.14 & 0.10 & 6.75 & 4.48 & 0.5 & 16.22 & 16.20 & 0.1 \\
\hline Carbon Dioxide & 10.01 & 9.95 & 0.10 & 19.00 & 19.01 & 0.5 & 4.10 & 4.17 & 0.1 \\
\hline Argon & 0.88 & 0.87 & 0.02 & 0.84 & 0.85 & 0.02 & 0.90 & 0.90 & 0.02 \\
\hline Krypton & 0.23 & 0.22 & 0.01 & 0.20 & 0.20 & 0.01 & 0.218 & 0.204 & 0.002 \\
\hline Neon & & & & & & & 0.238 & 0.206 & 0.0006 \\
\hline Hydrogen Chloride & & & & & & & 1.88 & -- & \\
\hline & & ppmv & $\pm p p m v$ & & ppmv & $\pm p p m v$ & & ppmv & $\pm p p m v$ \\
\hline Carbon Monoxide & & 682 & 42 & & 1692 & 100 & & 234 & 42 \\
\hline Hydrogen & & 64 & 6 & & 299 & 20 & & 497 & 6 \\
\hline Nitrogen oxides: NOx & & & & & & & & & \\
\hline & & 1169 & 50 & & 1324 & 50 & & 1425 & 50 \\
\hline NO & & 1017 & 50 & & 1164 & 50 & & 1292 & 50 \\
\hline $\mathrm{NO}_{2}$, by difference & & 152 & 50 & & 159 & 50 & & 133 & \\
\hline Methane & & 50 & 10 & & 70 & 20 & & $<10$ & 10 \\
\hline Net Test Weight, $1 b^{\circ 0}$ & & 1606 & & & 3212 & & & 1334 & \\
\hline
\end{tabular}

* Expect assumes only $\mathrm{CO}_{2}, \mathrm{~N}_{2}, \mathrm{H}_{2} \mathrm{O}$, metal oxides and $\mathrm{HCl}$ (in DAZZLER) are formed and added to an initial atmosphere at $20^{\circ} \mathrm{C}, 60 \%$ relative humidity, and a pressure of 0.88 atmosphere with a volume of $4644 \mathrm{~m}^{3}$; note that initial $\mathrm{CO}_{2}$ concentration was 200ppmv for SUNSPOT and THUNDERBIRD and 325ppmv for DAZZLER

* Meas'd values are obtained by extrapolating time-resolved gas concentration measurements back to test initiation time plus 60 s (i.e., $T=60$ s). These values are normalized to $100 \%$ on a water-free basis. Data from the sampling port on the tunnel back were used for obtaining the SUNSPOT and DAZZLER measurements. For THUNDERBIRD, the data shown represent an average from two measurements taken at the back and invert ports at 5 and 9 minutes, respectively. For this reason, it is assumed that the SUNSPOT and DAZZLER measurements represent maximum values, whereas the THUNDERBIRD measurements are an average.

$* \pm \% \mathrm{~V}$ indicates the precision of the measured values except for values of $\mathrm{NO}_{2}$, by difference and DAZZLER $\mathrm{Kr}$ and Ne. The uncertainty on $\mathrm{NO}_{2}$ is the square root of the squared errors for NOx and NO. The uncertainty on the DAZZLER $\mathrm{Kr}$ and $\mathrm{Ne}$ values is the uncertainty on the intercept of a linear regression data fit.

${ }^{\circ}$ Initial weight of carbon bearing materials in the test 
The gas species concentrations in Table B3 were measured in each test by extracting samples from the test chamber. These samples, composed of combustion product gases mixed with ambient air and tracer gas, were extracted from the test chamber using two sampling ports. One port was at the invert, and the second one was located on the back of the chamber. Stainlèss steel sampling lines from each port were routed out of the test chamber and over a distance of roughly $300 \mathrm{~m}$ to a pumping station located on the apron of the $X$ tunnel complex. The combustion gases were analyzed in real time by standard analytical instruments located near the pumping station. The transit time of the gases between the test chamber and the analysis station was roughly $120 \mathrm{~s}$.

Since the gases in the test chamber tend to become stratified (i.e., hotter gases collecting near the tunnel back), we instituted a general procedure focused on analyzing the gas stream from the port on the chamber back. In general, this gas stream was analyzed for roughly 30 minutes before switching to the invert port for roughly 10 minutes before returning to the port at the chamber back. The one exception to this procedure occurred in the THUNDERBIRD test where we found the sampling port on the back of the chamber was non-operable roughly 7 minutes after the test was initiated. This failure was probably caused by high debris loading in the combustion cloud that clogged the sample port inlet filter. After the back sampling port became clogged, the invert port was used exclusively for gas sampling in THUNDERBIRD.

The histories of the $\mathrm{O}_{2}$ and $\mathrm{CO}_{2}$ concentrations during the first 20 minutes after initiation of the SUNSPOT test as given in Figure B1 are examples of the data obtained from these measurements. Similarly, the time histories of the NOx species for 250 minutes in SUNSPOT are shown in Figure B2. It is evident from Figure $\mathrm{B} 1$ that, once the propellant burn is completed, the concentrations of the relatively stable $\mathrm{O}_{2}$ and $\mathrm{CO}_{2}$ gas species are essentially constant. It can also be seen that the measured concentrations of these species depend somewhat on sampling location. The full data record for the $\mathrm{CO}_{2}$ concentration history in SUNSPOT is given in Figure B3. This record shows a gradual decrease in $\mathrm{CO}_{2}$ concentration over the 3-4 hour sampling period for the test. In contrast, we see in Figure B2 over a comparable time scale that the concentration histories of the highly reactive NOx species in the combustion cloud are characterized by:

strong peaks followed by rapid decreases, and

long-term molecular stratification in the chamber.

The occurrence of the concentration peaks in Figure B2 correlates well with the end of the propellant burn. The stratification is evident from the persistent factor of 2 difference in the NOx gas concentrations measured at the invert and back sampling locations. However, in the interest of reporting conservative data in Table B3, we list only the highest values of the measured nitrogen oxide concentrations at the end of each test burn (i.e., derived from samples taken at the chamber back). 
A summary of the carbon burn efficiency (overall carbon balance) computed from the test results is given in Table B4. These results suggest that the conversion of the carbon materials inventory in each test to carbon-containing gas species is complete. In the NIKE rocket motor burn tests, the $\mathrm{CO}_{2}$ values are slightly greater than $100 \%$, but within the 1-sigma uncertainty of the result. In contrast, the data from DAZZLER suggest the presence of excess $\mathrm{CO}_{2}$ in the test chamber. A possible explanation for this anomaly is that some of the $\mathrm{CO}_{2}$ absorbed in the chamber walls from previous tests may have been released in DAZZLER due to the elevated temperatures and the high concentration of acid gases in that test. Note also that less than $1 \%$ of the carbon was converted to $\mathrm{CO}$ and $\mathrm{CH}_{4}$ in every test. This observation suggests that the combustion process in the test chamber proceeded very nearly to completion, which is consistent with the assumptions used above in calculating the expected gas species concentrations shown in Table B3.

Table B4. Carbon balance

\begin{tabular}{|c|c|c|c|c|c|c|}
\hline & \multicolumn{2}{|c|}{ SUNSPOT } & \multicolumn{2}{|c|}{ THUNDERBIRD } & \multicolumn{2}{|c|}{ DAZZLER } \\
\hline & $\%$ Total C & $\pm \% \mathrm{TC}$ & \% Total C & $\pm \% \mathrm{TC}$ & $\%$ Total C & $\pm \% \mathrm{TC}$ \\
\hline $\mathrm{CO} 2$ & 103.89 & 3.85 & 101.89 & 5.75 & 108.85 & 2.80 \\
\hline $\mathrm{CO}$ & 0.71 & 0.05 & 0.91 & 0.07 & 0.62 & 0.11 \\
\hline $\mathrm{CH} 4$ & 0.05 & 0.01 & 0.04 & 0.01 & & \\
\hline Gas sum & 105 & 4 & 103 & 6 & 109 & 3 \\
\hline
\end{tabular}

$\%$ Total $\mathrm{C}=100 \times$ (moles carbon in gas product) / (initial total moles carbon in the test materials) 


\section{Sunspot}

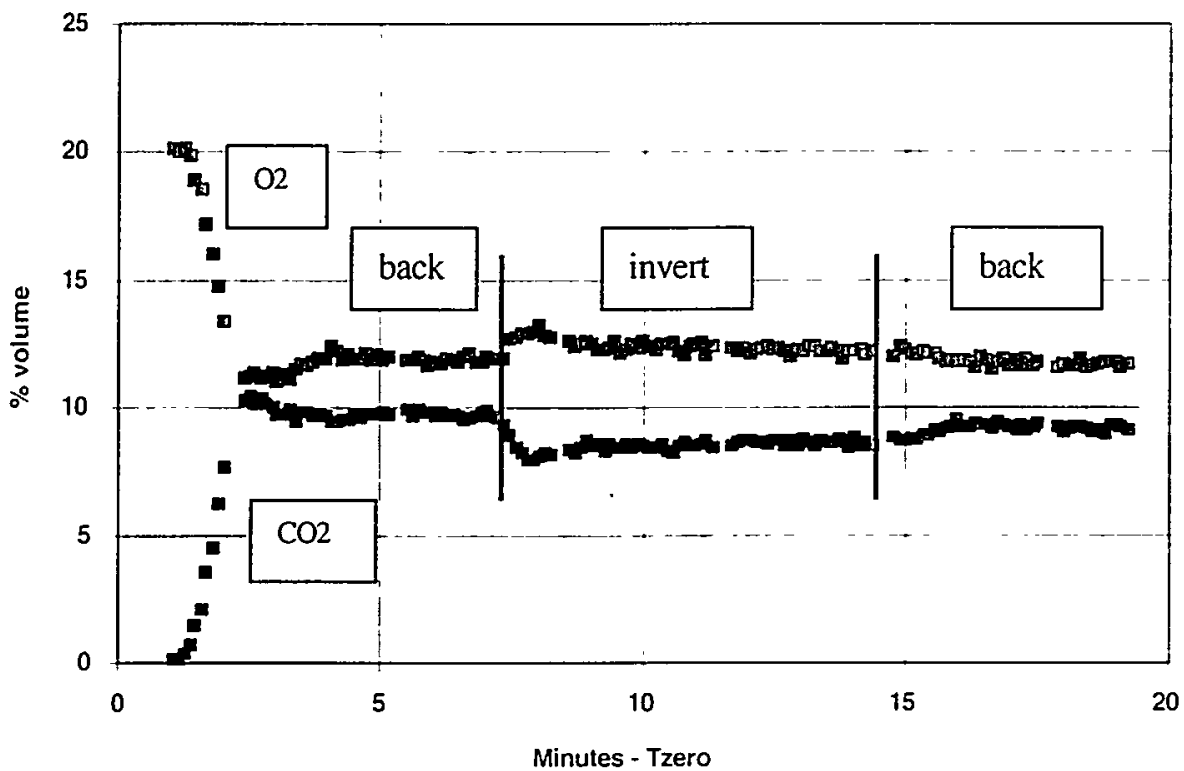

Figure B1. Early-time variation of $\mathrm{O}_{2}$ and $\mathrm{CO}_{2}$ gas concentrations in test chamber during SUNSPOT test. Samples extracted from chamber back and invert as indicated.

\section{Sunspot NOx data}

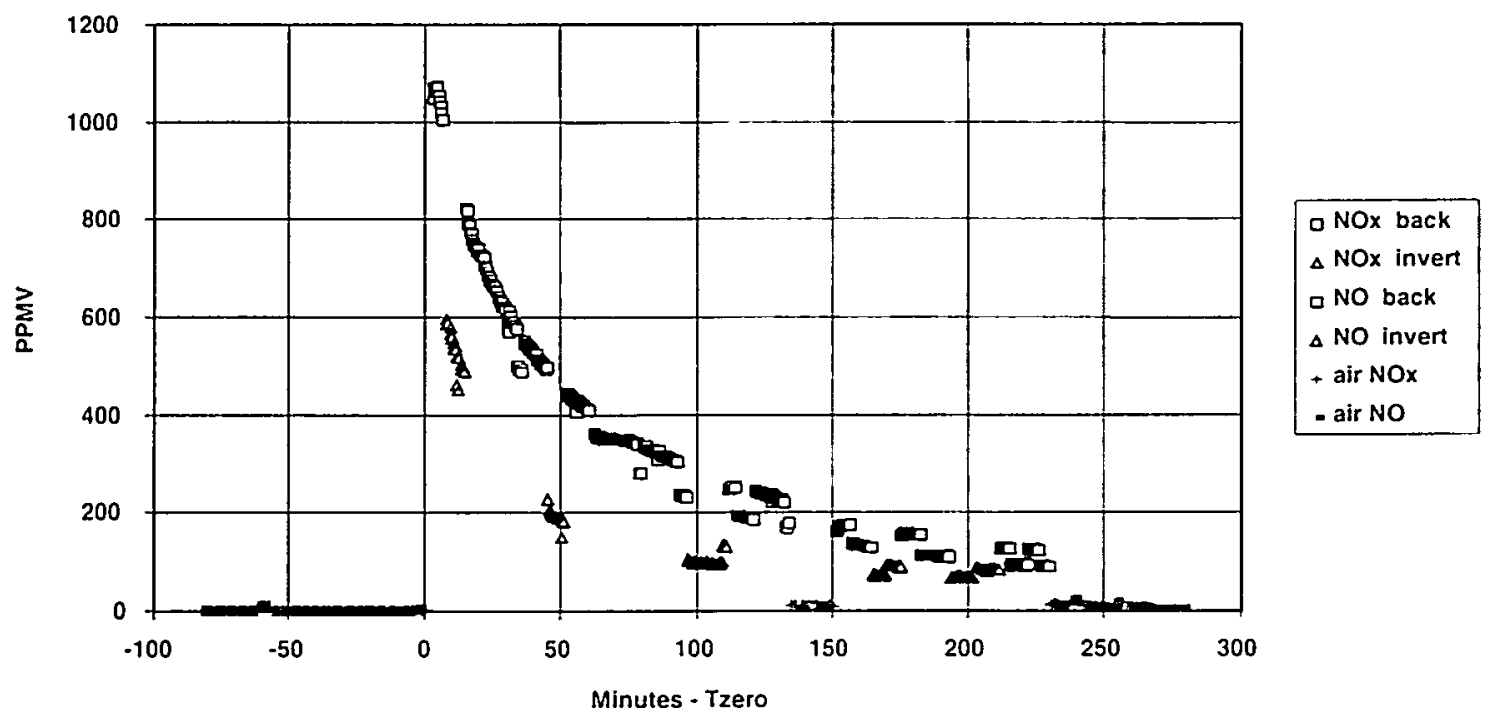

Figure B2. Variation of NOx gas concentrations in test chamber during SUNSPOT test (samples taken from invert and back). 


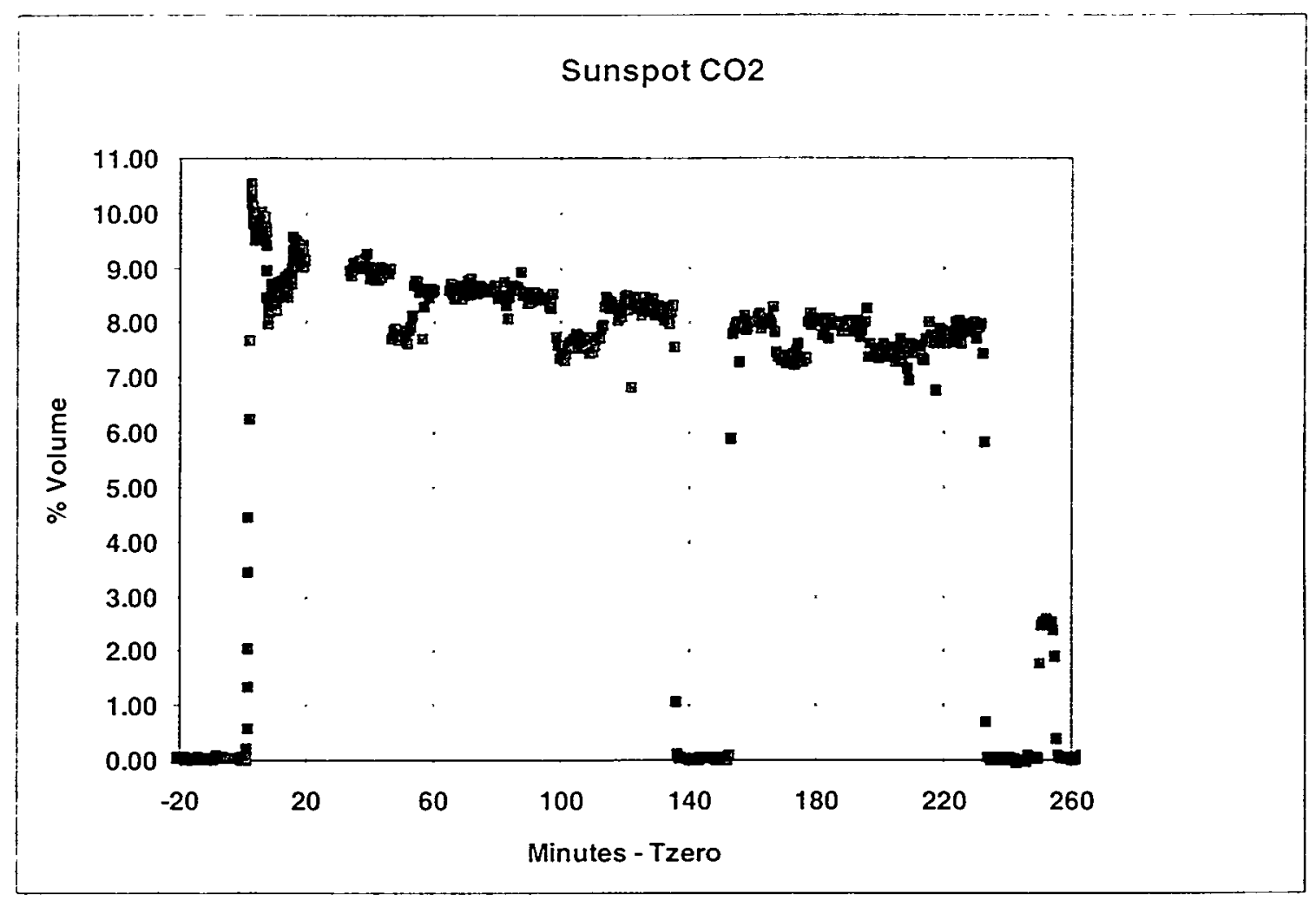

Figure B3. Complete history of $\mathrm{CO}_{2}$ concentration in SUNSPOT. 


\section{APPENDIX C}

\section{Real-Time and Time-Averaged Aerosol Analyses-LANL}

The LAASS impactor and streaker aerosol measurement elements provided data on the evolution, size distribution and composition of the particulate in the combustion cloud after each rocket motor bum test. Time-resolved elemental analyses (i.e., PIXE results) from the streaker are summarized in Tables C1-C6. Data from SUNSPOT are given in Tables $\mathrm{C} 1$ and $\mathrm{C} 2$ for the total $(<10 \mu \mathrm{m})$ and fine $(<2.5 \mu \mathrm{m})$ aerosol fractions, respectively. The same aerosol size distinction is used for streaker data obtained from the THUNDERBIRD (Tables C3 and C4) and DAZZLER (Tables C5 and C6) tests. These data also give us an indication of the evolution of the total aerosol concentrations in the test chamber. The sums of the elemental concentrations at each sampling time for the two aerosol size categories provide this information. These results for the SUNSPOT, THUNDERBIRD and DAZZLER tests are presented in Figures C1-C3, respectively. The rapid changes in the elemental concentration data shown in Figure $\mathrm{C} 3$ are physically unrealistic and may be the result of a measurement error. Additional analyses are required to resolve this issue.

The time histories of the aerosol size distributions obtained from the LAASS impactor measurements are reported in Figures C4-C6 for the SUNSPOT, THUNDERBIRD and DAZZLER tests, respectively. Figure $C 4$ shows the aerosol size distribution obtained from the impactor 27 minutes after initiation of the motor burn in SUNSPOT. One of the impactor channels $(1.2-2.5 \mu \mathrm{m})$ was inoperative during this test. In addition, because of an error in operating the flow controllers for the impactor, the impactor was not operated in an isokinetic condition for this sample. The aerosol concentration data therefore represent a lower limit to the actual aerosol concentration. Figure $\mathrm{C} 5$ shows the impactor data obtained for the first two sampling times in the THUNDERBIRD test. Note that dynamic processes in the test chamber (e.g., particle coagulation and thermally driven turbulence) likely affect the aerosol concentrations reported here. Thus, even though the quantities of propellant consumed in the SUNSPOT and THUNDERIRD tests differ by a factor of two, the aerosol concentration in a given bin size will not show a similar scale dependence. A more meaningful testto-test comparison is the aerosol mass integrated over all sizes. Finally, Figure C6 shows impactor data for the first three sampling times in the DAZZLER test. Unlike the comparable data from SUNSPOT and THUNDERBIRD, the results in Figure 66 suggest a shift in aerosol size distribution from larger to smaller sizes over the three sampling times. This shift may reflect propellant differences in the tests (smaller aerosols showing less coagulation than in previous tests), or it may be associated with the differing sample delay times in each test. The decrease in aerosol concentration observed for latter samples is also consistent with the streaker results for DAZZLER. 
Table C1. Total $(<10 \mu \mathrm{m})$ Elemental Concentrations- $\left(\mu \mathrm{g} / \mathrm{m}^{3}\right)$ for SUNSPOT

\begin{tabular}{|c|c|c|c|c|c|c|}
\hline Sample Time & (minutes): & 26 & 39 & 62 & 79 & 101 \\
\hline \multirow{2}{*}{$\begin{array}{l}\text { Atomic } \\
\text { Number }\end{array}$} & Element & \multicolumn{5}{|c|}{ Concentration } \\
\hline & & Sample 1 & Sample 2 & Sample 3 & Sample 4 & Sample 5 \\
\hline 11 & $\mathrm{Na}$ & 0 & 0 & 0 & 0 & 0 \\
\hline 12 & $\mathrm{Mg}$ & 0 & 0 & 0 & 0 & 0 \\
\hline 13 & $\mathrm{Al}$ & 0 & 0 & 0 & 0 & 0 \\
\hline 14 & $\mathrm{Si}$ & 3179.69 & 2176.42 & 2011.35 & 1583.43 & 1553.79 \\
\hline 15 & $P$ & 10372.5 & 7601.45 & 7956.44 & 5660.62 & 5794.44 \\
\hline 16 & $\mathrm{~S}$ & 0 & 0 & 0 & 1174.75 & 750.849 \\
\hline 17 & $\mathrm{Cl}$ & 5759.18 & 5176.61 & 4804.79 & 2941.69 & 2905.63 \\
\hline 18 & $\mathrm{Ar}$ & 0 & 0 & 0 & 0 & 0 \\
\hline 19 & K & 992.051 & 779.297 & 812.712 & 535.771 & 532.807 \\
\hline 20 & $\mathrm{Ca}$ & 3056.29 & 2218.89 & 1727.67 & 1292.55 & 1314.19 \\
\hline 21 & Sc & 0 & 0 & 0 & 0 & 0 \\
\hline 22 & $\mathrm{Ti}$ & 221.569 & 79.332 & 49.9231 & 87.9063 & 47.9999 \\
\hline 23 & $\mathrm{~V}$ & 0 & 0 & 0 & 0 & 0 \\
\hline 24 & $\mathrm{Cr}$ & 42.2303 & 18.7993 & 40.884 & 17.413 & 15.4818 \\
\hline 25 & $\mathrm{Mn}$ & 0 & 3.91852 & 0 & 0 & 0 \\
\hline 26 & $\mathrm{Fe}$ & 2378.36 & 1742.1 & 1835.05 & 1324.6 & 1358.26 \\
\hline 27 & Co & 0 & 0 & 0 & 0 & 0 \\
\hline 28 & $\mathrm{Ni}$ & 0 & 0 & 0 & 0 & 0 \\
\hline 29 & $\mathrm{Cu}$ & 1185.41 & 875.857 & 916.886 & 668.552 & 685.941 \\
\hline 30 & $\mathrm{Zn}$ & 1198.15 & 884.191 & 926.341 & 680.893 & 685.941 \\
\hline 31 & $\mathrm{Ga}$ & 0 & 41.8296 & 18.6711 & 0 & 15.3856 \\
\hline 32 & $\mathrm{Ge}$ & 0 & 0 & 0 & 0 & 0 \\
\hline 33 & As & 289.121 & 191.198 & 153.696 & 190.878 & 158.023 \\
\hline 34 & $\mathrm{Se}$ & 8.26175 & 37.2299 & 11.5873 & 21.3716 & 9.3756 \\
\hline 35 & $\mathrm{Br}$ & 170.444 & 134.408 & 176.053 & 117.155 & 123.566 \\
\hline 48 & $\mathrm{Cd}$ & 2600.33 & 1915.99 & 2079.46 & 1792.58 & 1708.44 \\
\hline 49 & In & 0 & 0 & 0 & 0 & 0 \\
\hline 50 & $\mathrm{Sn}$ & 0 & 0 & 0 & 0 & 0 \\
\hline 51 & $\mathrm{Sb}$ & 37622.6 & 27822.3 & 30170.2 & 21259.4 & 21900.4 \\
\hline 82 & $\mathrm{~Pb}$ & 118774 & 89541 & 96961.3 & 69804.1 & 71719.3 \\
\hline
\end{tabular}


Table C2. Fine $(<2.5 \mu \mathrm{m})$ Elemental Concentrations- $\left(\mu \mathrm{g} / \mathrm{m}^{3}\right)$ for SUNSPOT

\begin{tabular}{|c|c|c|c|c|c|c|}
\hline $\begin{array}{c}\text { Sample Time } \\
\text { Atomic }\end{array}$ & $\begin{array}{l}\text { (minutes): } \\
\text { Element }\end{array}$ & 26 & 39 & Concentra & tion & 101 \\
\hline & & Sample 1 & Sample 2 & Sample 3 & Sample 4 & Sample 5 \\
\hline 11 & $\mathrm{Na}$ & 0 & 0 & 0 & 0 & 0 \\
\hline 12 & $\mathrm{Mg}$ & 0 & 0 & 0 & 0 & 0 \\
\hline 13 & $\mathrm{Al}$ & 0 & 0 & 0 & 0 & 0 \\
\hline 14 & $\mathrm{Si}$ & 2102.7 & 1410.35 & 1173.95 & 947.977 & 893.487 \\
\hline 15 & $\mathrm{P}$ & 9023.01 & 6402.65 & 5320.85 & 4030.71 & 3966.6 \\
\hline 16 & $S$ & 0 & 0 & 0 & 1174.75 & 750.849 \\
\hline 17 & $\mathrm{Cl}$ & 5304.83 & 4623.69 & 3421.69 & 2342.3 & 2228.51 \\
\hline 18 & $\mathrm{Ar}$ & 0 & 0 & 0 & 0 & 0 \\
\hline 19 & $\mathrm{~K}$ & 769.28 & 611.417 & 512.052 & 361.401 & 344.573 \\
\hline 20 & $\mathrm{Ca}$ & 2226.91 & 1667.57 & 1065.77 & 864.639 & 860.632 \\
\hline 21 & $\mathrm{Sc}$ & 0 & 0 & 0 & 0 & 0 \\
\hline 22 & $\mathrm{Ti}$ & 133.582 & 0 & 0 & 22.1168 & 0 \\
\hline 23 & $\mathrm{~V}$ & 0 & 0 & 0 & 0 & 0 \\
\hline 24 & $\mathrm{Cr}$ & 42.2303 & 15.7061 & 32.8547 & 9.05507 & 10.6577 \\
\hline 25 & $\mathrm{Mn}$ & 0 & 3.91852 & 0 & 0 & 0 \\
\hline 26 & $\mathrm{Fe}$ & 1895.95 & 1338.23 & 1153.92 & 851.817 & 846.208 \\
\hline 27 & Co & 0 & 0 & 0 & 0 & 0 \\
\hline 28 & $\mathrm{Ni}$ & 0 & 0 & 0 & 0 & 0 \\
\hline 29 & $\mathrm{Cu}$ & 967.209 & 687.544 & 579.364 & 432.72 & 431.919 \\
\hline 30 & $\mathrm{Zn}$ & 954.388 & 669.113 & 570.549 & 426.309 & 404.673 \\
\hline 31 & $\mathrm{Ga}$ & 0 & 41.8296 & 18.6711 & 0 & 15.3856 \\
\hline 32 & $\mathrm{Ge}$ & 0 & 0 & 0 & 0 & 0 \\
\hline 33 & As & 262.036 & 130.617 & 83.3387 & 73.8829 & 70.5975 \\
\hline 34 & $\mathrm{Se}$ & 0 & 25.8029 & 0 & 8.81467 & 9.3756 \\
\hline 35 & $\mathrm{Br}$ & 138.23 & 108.741 & 110.023 & 78.8512 & 84.0599 \\
\hline 48 & $\mathrm{Cd}$ & 2314.25 & 1617.09 & 1370.28 & 1268.51 & 1123.47 \\
\hline 49 & In & 0 & 0 & 0 & 0 & 0 \\
\hline 50 & Sn & 0 & 0 & 0 & 0 & 0 \\
\hline 51 & $\mathrm{Sb}$ & 32534.1 & 23198.6 & 19889.1 & 14680.4 & 14696.5 \\
\hline 82 & $\mathrm{~Pb}$ & 102651 & 74363.7 & 63385.5 & 46958.1 & 45996.5 \\
\hline
\end{tabular}


Table C3. Total $(<10 \mu \mathrm{m})$ Elemental Concentrations $-\left(\mu \mathrm{g} / \mathrm{m}^{3}\right)$ for THUNDERBIRD

\begin{tabular}{ccccccr} 
Sample Time & (minutes): & 19 & 32 & 43 & 54 & 63 \\
Atomic Number & Element & & \multicolumn{4}{c}{ Concentration }
\end{tabular}

Sample 1 Sample 2 Sample 3 Sample 4 Sample 5

$\begin{array}{llrrrrr}14 & \mathrm{Si} & 5755.18 & 5418.62 & 3365.6 & 3197.32 & 2452.08 \\ 15 & \mathrm{P} & 9644.85 & 7712.03 & 5577.28 & 5067.63 & 4178.15 \\ 16 & \mathrm{~S} & 12563.3 & 12659.5 & 8173.6 & 8216.87 & 5288.8 \\ 17 & \mathrm{Cl} & 5806.62 & 4086.8 & 3711.78 & 3192.51 & 3024.23 \\ 18 & \mathrm{Ar} & 0 & 0 & 0 & 0 & 0 \\ 19 & \mathrm{~K} & 8308.22 & 6740.82 & 4740.69 & 4327.2 & 3557.92 \\ 20 & \mathrm{Ca} & 5158.98 & 3726.2 & 2966.54 & 2658.82 & 1971.28 \\ 21 & \mathrm{Sc} & 0 & 0 & 0 & 0 & 0 \\ 22 & \mathrm{Ti} & 376.947 & 337.522 & 228.861 & 197.128 & 204.34 \\ 23 & \mathrm{~V} & 12.9335 & 0 & 0 & 0 & 13.7509 \\ 24 & \mathrm{Cr} & 113.661 & 75.1971 & 40.3872 & 67.312 & 55.6766 \\ 25 & \mathrm{Mn} & 53.3688 & 0 & 0 & 0 & 0 \\ 26 & \mathrm{Fe} & 4870.5 & 3428.1 & 2639.59 & 2283.8 & 2149.18 \\ 27 & \mathrm{Co} & 0 & 0 & 0 & 0 & 0 \\ 28 & \mathrm{Ni} & 0 & 0 & 0 & 0 & 0 \\ 29 & \mathrm{Cu} & 1485.19 & 1089.49 & 799.09 & 716.873 & 670.716 \\ 30 & \mathrm{Zn} & 1941.95 & 1417.88 & 1064.97 & 945.253 & 840.438 \\ 35 & \mathrm{Br} & 240.833 & 183.329 & 135.441 & 127.316 & 116.45 \\ 48 & \mathrm{Cd} & 3405.03 & 2915.09 & 1716.94 & 1822.23 & 1591.45 \\ 49 & \mathrm{In} & 0 & 0 & 0 & 0 & 0 \\ 50 & \mathrm{Sn} & 0 & 0 & 0 & 0 & 0 \\ 51 & \mathrm{Sb} & 29362.5 & 21549.5 & 15741.4 & 13875.9 & 13048.9 \\ 82 & \mathrm{~Pb} & 123325 & 91159.7 & 68129.4 & 60436.6 & 56061.3\end{array}$


Table C4. Fine $(<2.5 \mu \mathrm{m})$ Elemental Concentrations $-\left(\mu \mathrm{g} / \mathrm{m}^{3}\right)$ for THUNDERBIRD $\begin{array}{lllllll}\text { Sample Time } & \text { (minutes): } & 19 & 32 & 43 & 54 & 63\end{array}$ Atomic Number Element

Concentration

Sample 1 Sample 2 Sample 3 Sample 4 Sample 5

$\begin{array}{lcrrrrr}14 & \mathrm{Si} & 4904.16 & 4707.03 & 2812.68 & 2456.89 & 1682.8 \\ 15 & \mathrm{P} & 8558.24 & 6635.04 & 4399.32 & 3682.93 & 2841.53 \\ 16 & \mathrm{~S} & 11202.6 & 11106.5 & 7356.24 & 6538.88 & 3706.97 \\ 17 & \mathrm{Cl} & 5481.12 & 3596.38 & 2875.18 & 2379.96 & 2211.68 \\ 18 & \mathrm{Ar} & 0 & 0 & 0 & 0 & 0 \\ 19 & \mathrm{~K} & 7500.48 & 5961.92 & 3923.33 & 3312.71 & 2519.39 \\ 20 & \mathrm{Ca} & 4519.52 & 3178.09 & 2456.89 & 2072.25 & 1394.32 \\ 21 & \mathrm{Sc} & 0 & 0 & 0 & 0 & 0 \\ 22 & \mathrm{Ti} & 272.614 & 260.594 & 169.242 & 129.816 & 115.873 \\ 23 & \mathrm{~V} & 0 & 0 & 0 & 0 & 0 \\ 24 & \mathrm{Cr} & 100.968 & 62.504 & 40.3872 & 47.503 & 37.262 \\ 25 & \mathrm{Mn} & 53.3688 & 0 & 0 & 0 & 0 \\ 26 & \mathrm{Fe} & 4057.95 & 2788.64 & 1947.24 & 1572.22 & 1394.32 \\ 27 & \mathrm{Co} & 0 & 0 & 0 & 0 & 0 \\ 28 & \mathrm{Ni} & 0 & 0 & 0 & 0 & 0 \\ 29 & \mathrm{Cu} & 1327.01 & 932.752 & 620.232 & 524.072 & 466.857 \\ 30 & \mathrm{Zn} & 1682.8 & 1177.96 & 793.32 & 663.504 & 548.112 \\ 35 & \mathrm{Br} & 205.302 & 154.818 & 94.7176 & 88.948 & 73.0816 \\ 48 & \mathrm{Cd} & 3048.27 & 2548.24 & 1346.24 & 1317.39 & 1081.8 \\ 49 & \mathrm{In} & 0 & 0 & 0 & 0 & 0 \\ 50 & \mathrm{Sn} & 0 & 0 & 0 & 0 & 0 \\ 51 & \mathrm{Sb} & 26155.5 & 18558.9 & 12020 & 10000.6 & 8894.8 \\ 82 & \mathrm{~Pb} & 107218 & 75966.4 & 50964.8 & 42118.1 & 36781.2\end{array}$


Table C5. Total $(<10 \mu \mathrm{m})$ Elemental Concentrations- $\left(\mu \mathrm{g} / \mathrm{m}^{3}\right)$ for DAZZLER

$\begin{array}{ccccccccc}\begin{array}{c}\text { Sample Time } \\ \text { Atomic } \\ \text { Number }\end{array} & \begin{array}{c}\text { Eleminutes): } \\ \text { Elent }\end{array} & 10 & 22 & 32 & 43 & \begin{array}{c}52 \\ \text { Concentration }\end{array} & 72 & 82 \\ & & & & & & & \end{array}$

\section{Sample 1 Sample 2 Sample 3 Sample 4 Sample 5 Sample 6 Sample 7 Sample 8}

$\begin{array}{lrrrrrrrrr}11 & \mathrm{Na} & 0 & 0 & 0 & 0 & 0 & 0 & 0 & 0 \\ 12 & \mathrm{Mg} & 1877.52 & 2769.41 & 110.344 & 1177.96 & 805.34 & 1233.25 & 935.156 & 1012.08 \\ 13 & \mathrm{Al} & 106690 & 113589 & 11419 & 67864.9 & 39666 & 35555.2 & 46829.9 & 47286.7 \\ 14 & \mathrm{Si} & 0 & 158.424 & 0 & 0 & 0 & 245.208 & 0 & 0 \\ 15 & \mathrm{P} & 0 & 0 & 0 & 0 & 0 & 0 & 0 & 0 \\ 16 & \mathrm{~S} & 644.272 & 926.982 & 0 & 399.064 & 153.616 & 163.472 & 310.116 & 147.365 \\ 17 & \mathrm{Cl} & 668.072 & 1022.9 & 123.085 & 564.219 & 428.393 & 321.174 & 426.71 & 460.126 \\ 18 & \mathrm{Ar} & 0 & 0 & 0 & 0 & 0 & 0 & 0 & 0 \\ 19 & \mathrm{~K} & 358.196 & 351.946 & 13.0537 & 205.542 & 104.814 & 99.2852 & 78.13 & 123.806 \\ 20 & \mathrm{Ca} & 410.363 & 356.994 & 57.72 & 226.938 & 114.671 & 124.046 & 80.2936 & 116.594 \\ 21 & \mathrm{Sc} & 0 & 0 & 0 & 0 & 0 & 0 & 0 & 0 \\ 22 & \mathrm{Ti} & 66.4706 & 69.7641 & 11.669 & 53.3688 & 20.5542 & 26.6844 & 12.02 & 20.3378 \\ 23 & \mathrm{~V} & 0 & 0 & 0 & 0 & 0 & 0 & 0 & 0 \\ 24 & \mathrm{Cr} & 210.614 & 199.556 & 35.8196 & 135.562 & 65.4369 & 60.8933 & 36.685 & 64.908 \\ 25 & \mathrm{Mn} & 29.0884 & 0 & 0 & 19.9292 & 6.611 & 0 & 0 & 17.6934 \\ 26 & \mathrm{Fe} & 1662.85 & 1230.37 & 169.722 & 674.562 & 360.36 & 330.31 & 189.676 & 364.206 \\ 27 & \mathrm{Co} & 0 & 0 & 0 & 0 & 0 & 0 & 0 & 0 \\ 28 & \mathrm{Ni} & 0 & 0 & 1.47125 & 1.51692 & 0 & 0 & 0 & 0 \\ 29 & \mathrm{Cu} & 1791.7 & 1658.28 & 176.454 & 965.687 & 492.339 & 442.817 & 260.594 & 495.945 \\ 30 & \mathrm{Zn} & 126.955 & 120.368 & 18.4868 & 71.0622 & 38.4159 & 34.1368 & 19.6407 & 37.9111 \\ 31 & \mathrm{Ga} & 12.6931 & 11.1786 & 0 & 1.45923 & 0 & 0 & 0 & 4.30316 \\ 32 & \mathrm{Ge} & 0 & 0 & 0 & 0 & 0 & 0 & 0 & 0 \\ 33 & \mathrm{As} & 0 & 0 & 0 & 23.415 & 0 & 0 & 0 & 0 \\ 34 & \mathrm{Se} & 0 & 0 & 0 & 0 & 0 & 0 & 0 & 0 \\ 35 & \mathrm{Br} & 0 & 0 & 0 & 0.723604 & 3.87044 & 2.42804 & 0 & 1.61789 \\ 51 & \mathrm{Sb} & 113.95 & 323.338 & 0 & 267.325 & 144 & 82.938 & 69.4756 & 157.222 \\ 82 & \mathrm{~Pb} & 1426.53 & 1361.14 & 171.165 & 764.712 & 416.132 & 372.62 & 226.938 & 432.239\end{array}$


Table C6. Fine $(<2.5 \mu \mathrm{m})$ Elemental Concentrations- $\left(\mu \mathrm{g} / \mathrm{m}^{3}\right)$ for DAZZLER

$\begin{array}{cccccccccc}\text { Sample Time } & \text { (minutes): } & 10 & 22 & 32 & 43 & \begin{array}{c}52 \\ \text { Concentration }\end{array} \\ \text { Atomic Number } & \begin{array}{c}\text { Element }\end{array} & & & & & 72 & 82\end{array}$

Sample 1 Sample 2 Sample $3 \quad$ Sample 4 Sample 5 Sample 6 Sample 7 Sample 8

$\begin{array}{lrrrrrrrrr}11 & \mathrm{Na} & 0 & 0 & 0 & 0 & 0 & 0 & 0 & 0 \\ 12 & \mathrm{Mg} & 1334.22 & 1807.81 & 110.344 & 668.312 & 425.508 & 372.62 & 480.8 & 507.244 \\ 13 & \mathrm{Al} & 85582.4 & 93275.2 & 6611 & 49522.4 & 21563.9 & 22020.6 & 30050 & 25482.4 \\ 14 & \mathrm{Si} & 0 & 0 & 0 & 0 & 0 & 0 & 0 & 0 \\ 15 & \mathrm{P} & 0 & 0 & 0 & 0 & 0 & 0 & 0 & 0 \\ 16 & \mathrm{~S} & 644.272 & 726.008 & 0 & 399.064 & 153.616 & 163.472 & 310.116 & 147.365 \\ 17 & \mathrm{Cl} & 500.032 & 798.128 & 48.08 & 377.428 & 191.839 & 174.771 & 228.861 & 188.474 \\ 18 & \mathrm{Ar} & 0 & 0 & 0 & 0 & 0 & 0 & 0 & 0 \\ 19 & \mathrm{~K} & 312.52 & 300.5 & 0 & 175.011 & 65.6292 & 68.514 & 42.3104 & 76.928 \\ 20 & \mathrm{Ca} & 365.408 & 312.52 & 34.3772 & 185.108 & 74.7644 & 87.746 & 38.7044 & 65.8696 \\ 21 & \mathrm{Sc} & 0 & 0 & 0 & 0 & 0 & 0 & 0 & 0 \\ 22 & \mathrm{Ti} & 57.9364 & 63.706 & 9.47176 & 47.3588 & 14.7125 & 20.6744 & 6.58696 & 13.4864 \\ 23 & \mathrm{~V} & 0 & 0 & 0 & 0 & 0 & 0 & 0 & 0 \\ 24 & \mathrm{Cr} & 189.195 & 179.819 & 26.9248 & 115.152 & 46.6376 & 42.7912 & 18.2704 & 40.3872 \\ 25 & \mathrm{Mn} & 29.0884 & 0 & 0 & 19.9292 & 6.611 & 0 & 0 & 17.6934 \\ 26 & \mathrm{Fe} & 1526.54 & 1110.65 & 131.499 & 569.748 & 257.228 & 233.428 & 93.5156 & 227.418 \\ 27 & \mathrm{Co} & 0 & 0 & 0 & 0 & 0 & 0 & 0 & 0 \\ 28 & \mathrm{Ni} & 0 & 0 & 0 & 0 & 0 & 0 & 0 & 0 \\ 29 & \mathrm{Cu} & 1629.91 & 1502.5 & 137.028 & 831.784 & 355.792 & 319.732 & 131.98 & 317.328 \\ 30 & \mathrm{Zn} & 115.392 & 109.622 & 14.5923 & 60.1 & 28.3672 & 24.5208 & 9.95256 & 24.7612 \\ 31 & \mathrm{Ga} & 12.6931 & 11.1786 & 0 & 0 & 0 & 0 & 0 & 2.74056 \\ 32 & \mathrm{Ge} & 0 & 0 & 0 & 0 & 0 & 0 & 0 & 0 \\ 33 & \mathrm{As} & 0 & 0 & 0 & 23.415 & 0 & 0 & 0 & 0 \\ 34 & \mathrm{Se} & 0 & 0 & 0 & 0 & 0 & 0 & 0 & 0 \\ 35 & \mathrm{Br} & 0 & 0 & 0 & 0 & 3.87044 & 2.42804 & 0 & 1.61789 \\ 51 & \mathrm{Sb} & 79.5724 & 281.268 & 0 & 233.669 & 93.9964 & 40.3872 & 25.7228 & 102.17 \\ 82 & \mathrm{~Pb} & 1281.33 & 1221.23 & 135.345 & 641.868 & 288.48 & 259.632 & 108.42 & 266.844\end{array}$




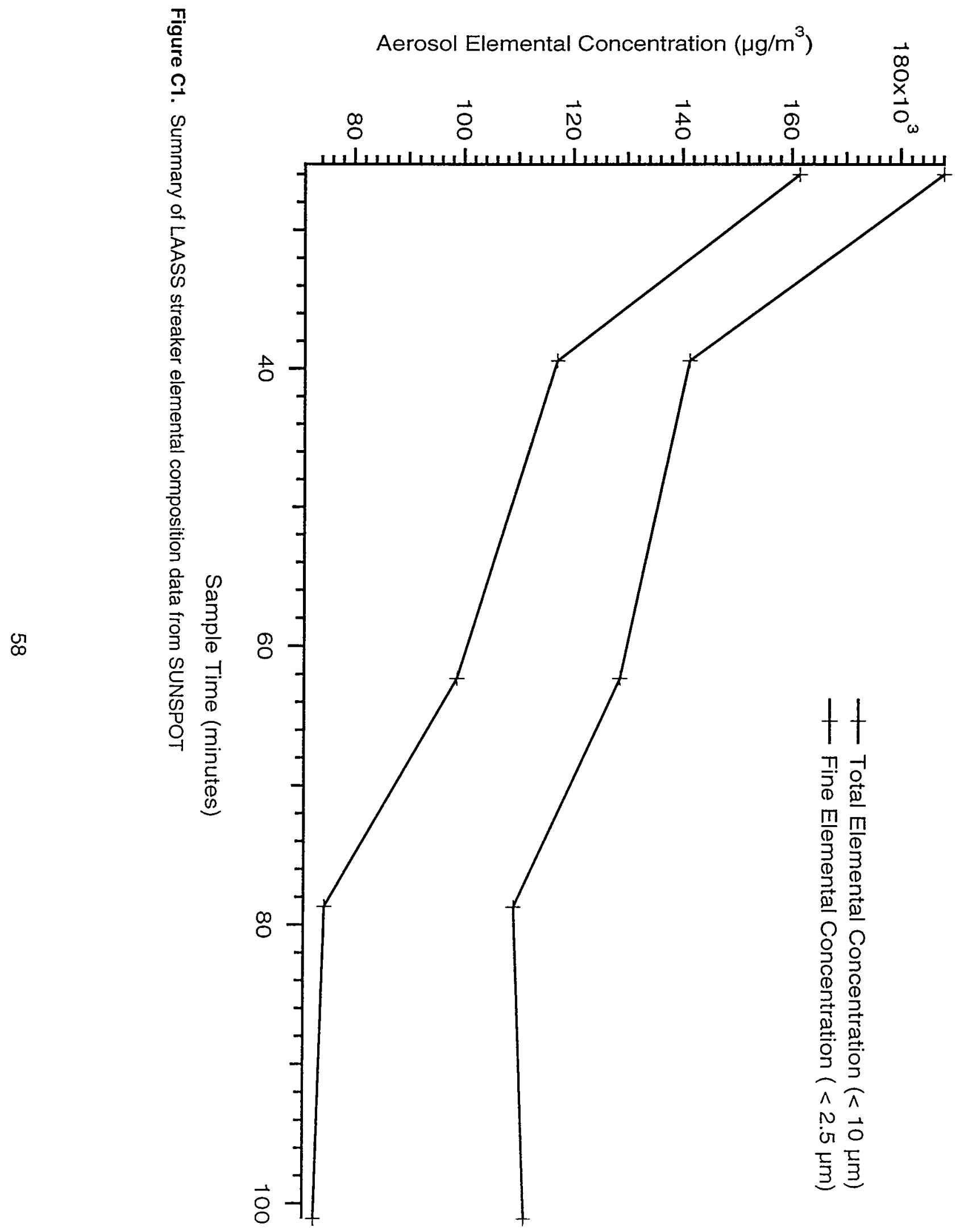




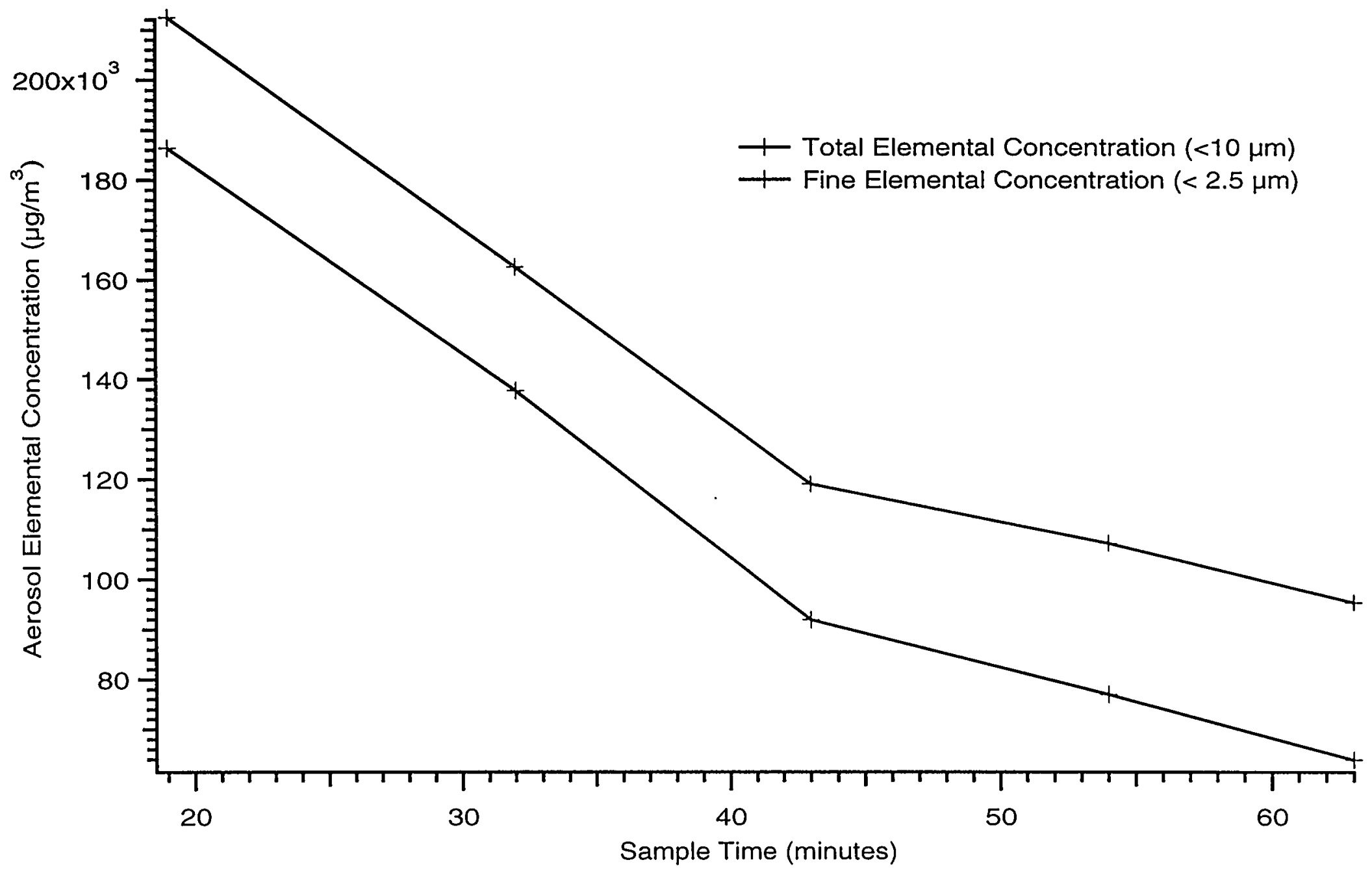

Figure C2. Summary of LAASS streaker elemental composition data from THUNDERBIRD 


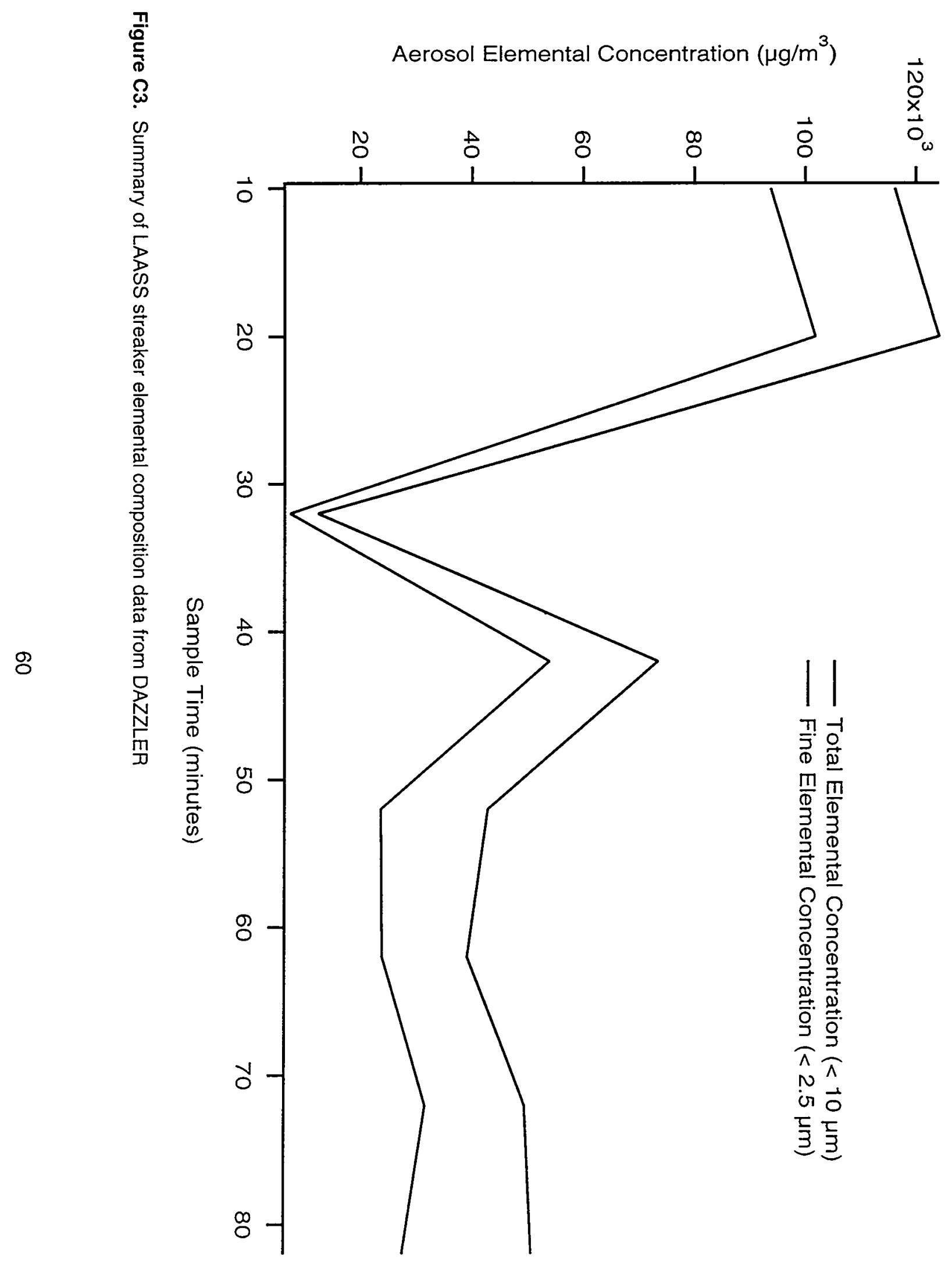




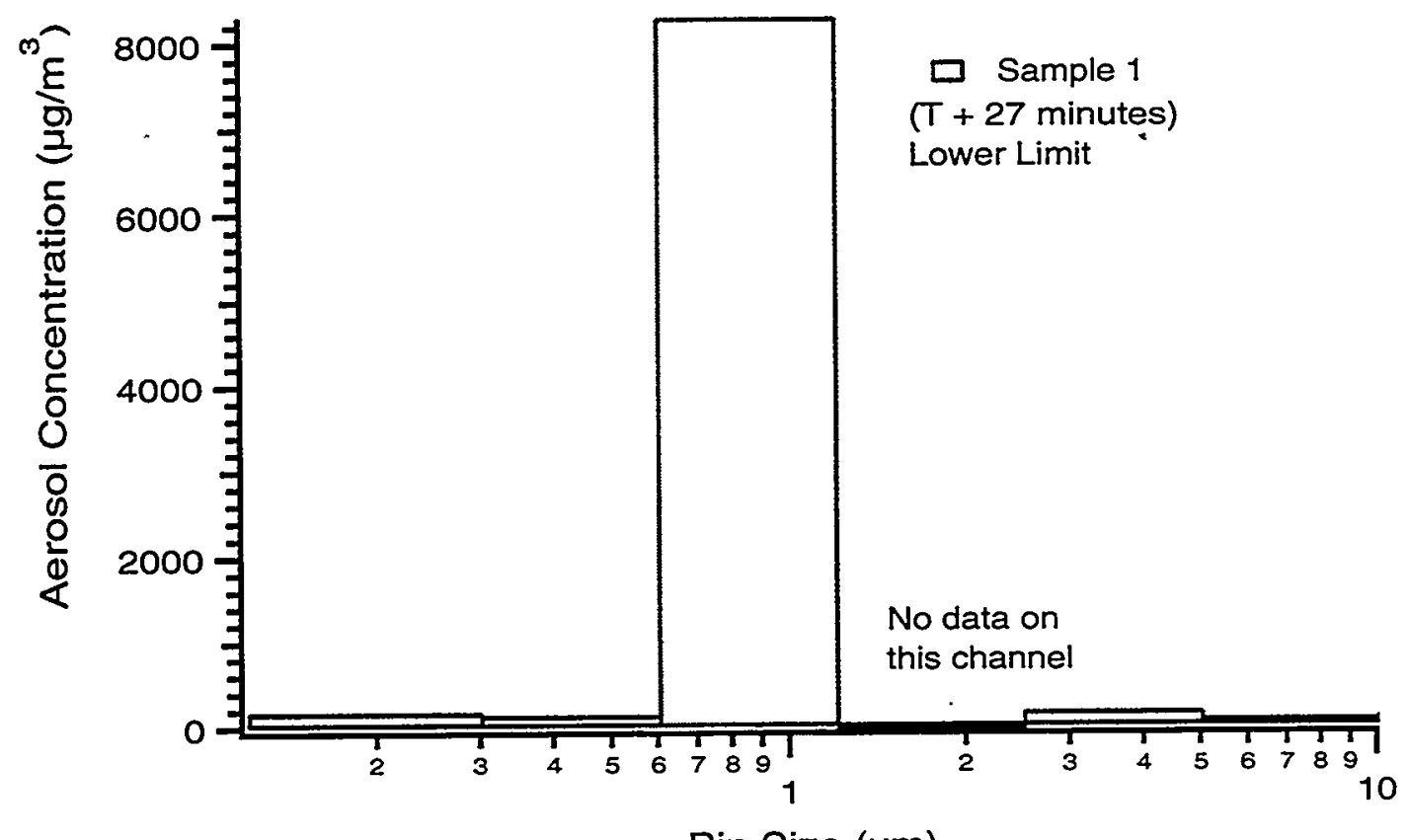

Bin Size $(\mu \mathrm{m})$

Figure C4. Summary of LAASS impactor data from SUNSPOT

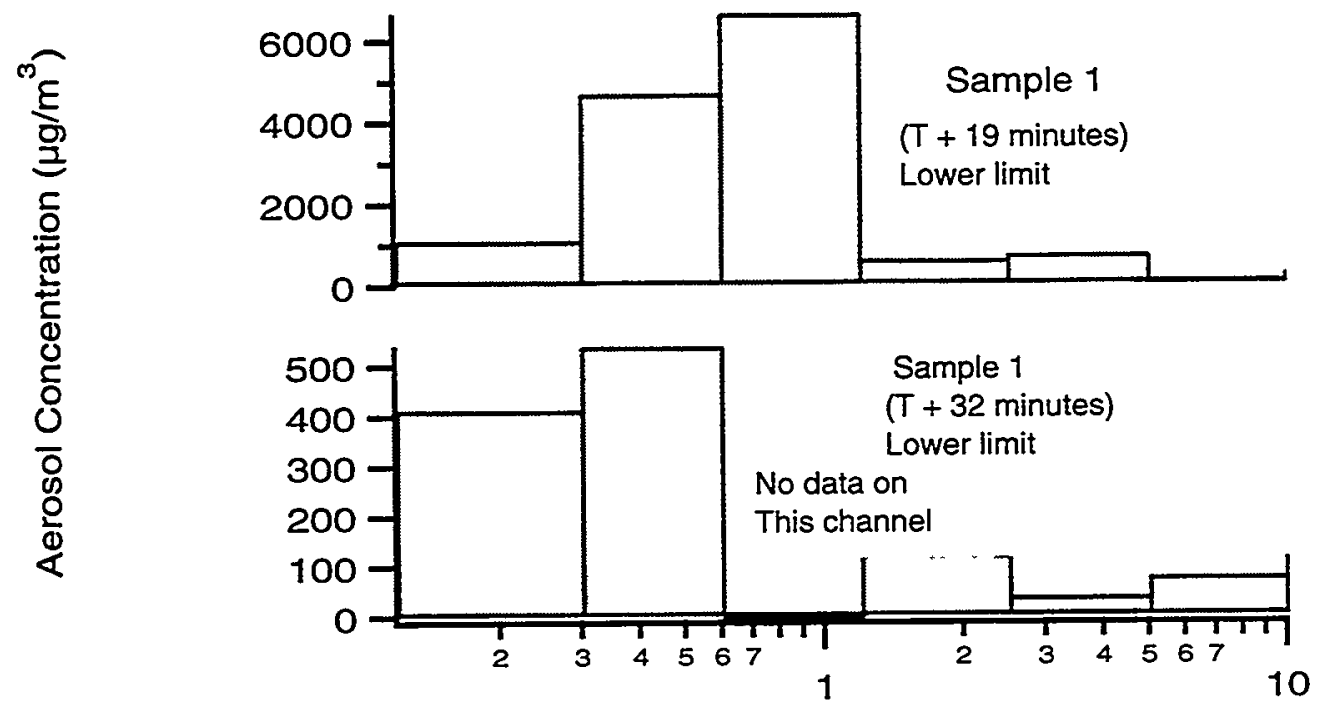

Bin Size $(\mu \mathrm{m})$

Figure C5. Summary of LAASS impactor data from THUNDERBIRD 


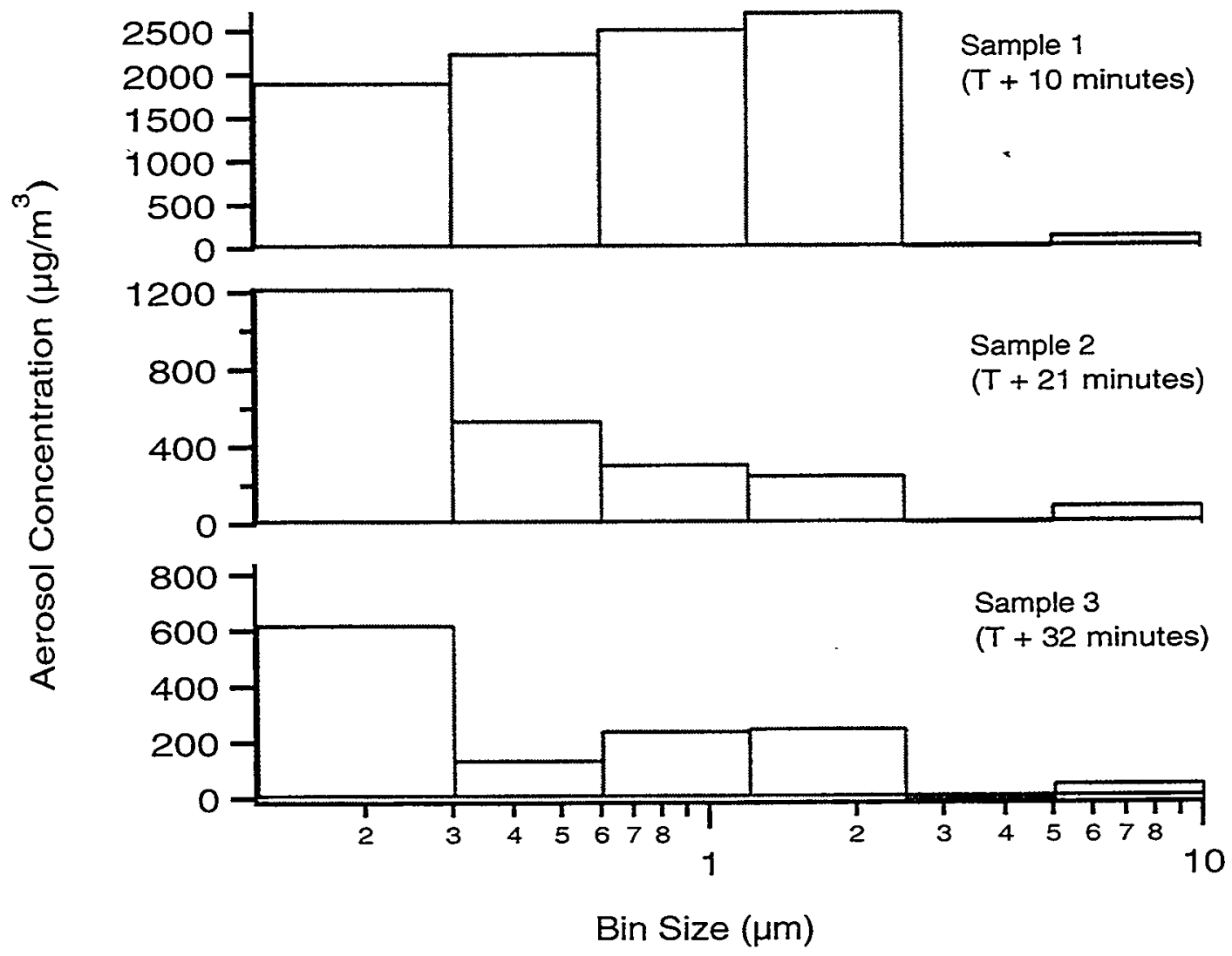

Figure C6. Summary of LAASS impactor data from DAZZLER 


\section{APPENDIX D}

\section{Real-Time Gas Species Analyses Using FTIR-LANL}

The FTIR diagnostic was implemented primarily to obtain time-resolved measurements of $\mathrm{HCl}$ gas concentrations in DAZZLER. Nevertheless, it was available to analyze gas samples extracted from the THUNDERBIRD test. The FTIR was therefore used in this test to establish operational procedures for it in $X$-tunnel, rather than for collecting critical data. Only a single FTIR spectrum was obtained in THUNDERBIRD because the substantial particulate loading in this test clogged an in-line, small-particulate filter located in the sampling line. This interruption occurred soon after the first sample was extracted from the test chamber. In addition, it appears that a water-based aerosol entered the sample cell despite the precaution of using a heated sample line.

To quantify the results for $\mathrm{CO}_{2}, \mathrm{CO}$ and $\mathrm{H}_{2} \mathrm{O}$ concentrations observed in this first scan, the background scan obtained prior to executing the THUNDERBIRD test was used as a reference to obtain the absorbance spectrum shown in Figure D1. This spectrum is a function of the concentrations of the gas species detected. We can obtain good estimates of these concentrations either by calculating the spectrum from known databases parameters or by adjusting tabulated spectra from available quantitative databases. The later was done here, using the QASOFT ${ }^{1}$ database to quantify the concentrations of $\mathrm{CO}, \mathrm{CO}_{2}$ and $\mathrm{H}_{2} \mathrm{O}$ in the sample at $0.2 \%, 10 \%$, and $10 \%$, respectively. The spectra used for these analyses are shown in Figure D2.

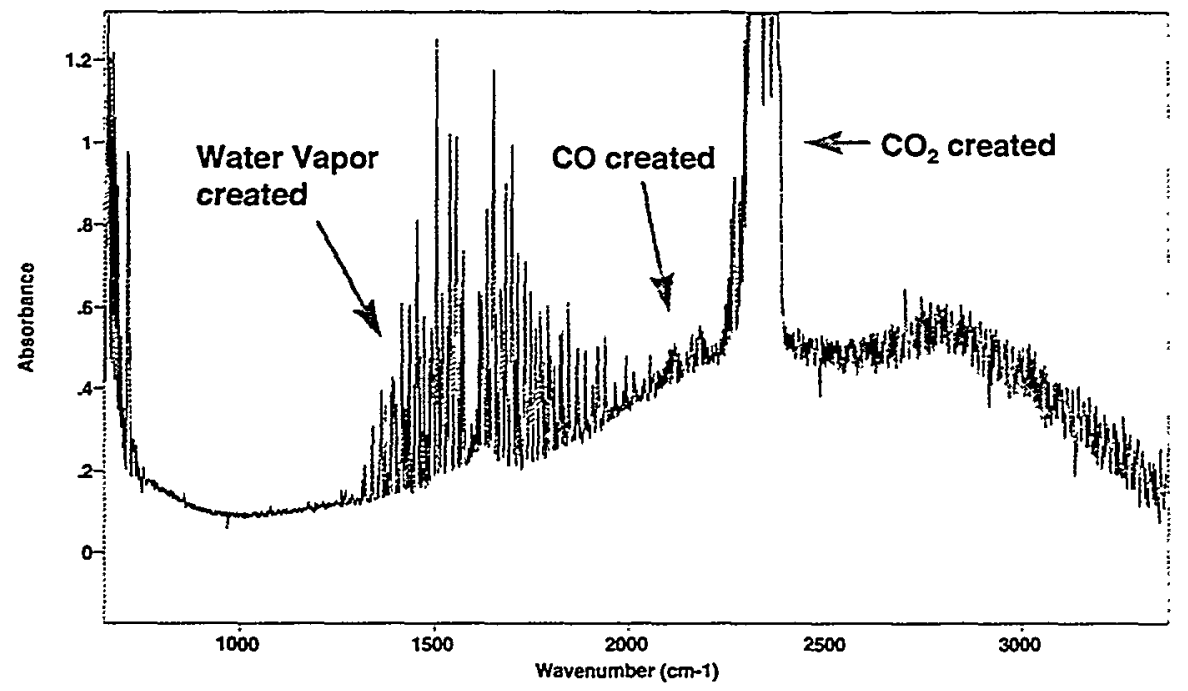

Figure D1. Absorbance spectra from first FTIR scan in THUNDERBIRD (sample taken at test initiation time +19 minutes)

\footnotetext{
${ }^{1}$ P. L. Hanst and S. T.Hanst, "Infrared Spectra for the Quantitative Analysis of Gases", Infrared Analysis, Inc., Anaheim, CA
} 

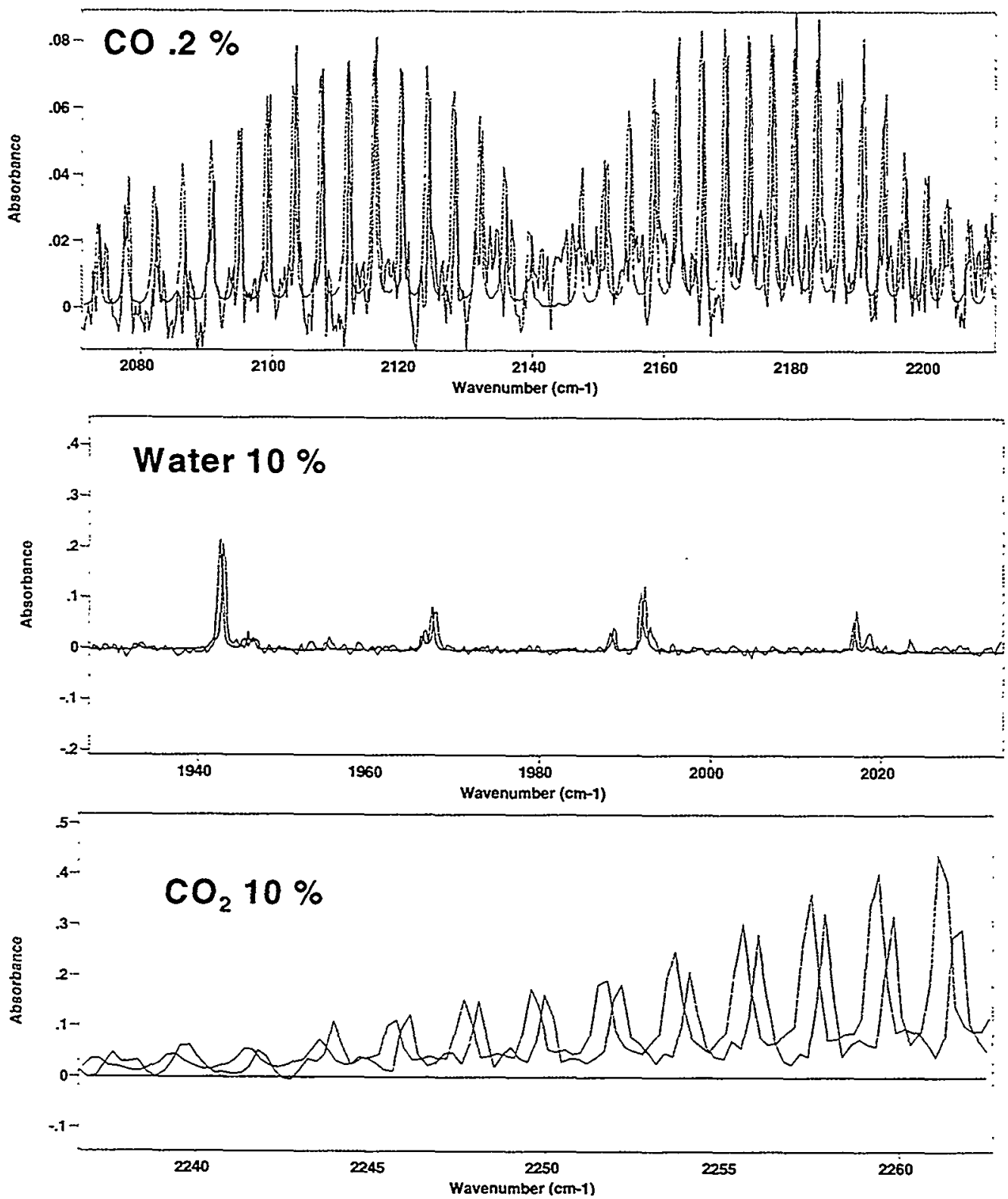

Figure D2. Comparison between measured and simulated absorption features for water, $\mathrm{CO}$ and . $\mathrm{CO}_{2}$. Simulated spectra are derived from the QASOFT database. Estimated concentrations are indicated for each simulation.

Thirteen FTIR spectra were obtained using extracted samples from the DAZZLER test. This improved performance of the FTIR diagnostic (compared to the results in THUNDERBIRD) is related to changes in the sampling procedures implemented between the tests. In addition, a different combustion cloud aerosol size distribution in DAZZLER helped reduce particulate loading in the sampling line to the FTIR. However, no $\mathrm{HCl}$ peaks were observed in the thirteen spectra. Subsequent analysis of the FTIR diagnostic and comparison to QASOFT spectra suggest that an $\mathrm{HCl}$ concentration greater than $0.2 \%$ should have been detectable by the instrument. The measurement of $\mathrm{HCl}$ concentration in 
DAZZLER obtained by Radian International from post-test analyses of extracted samples was roughly $1.1 \%$. Analyses of the FTIR spectra from DAZZLER shown in Figure D3 indicate upper limits of $0.5 \%, 0.1 \%, 0.1 \%$ and $0.05 \%$ for the concentrations of $\mathrm{NO}, \mathrm{NO}_{2}, \mathrm{~N}_{2} \mathrm{O}$, and $\mathrm{HCN}$, respectively.
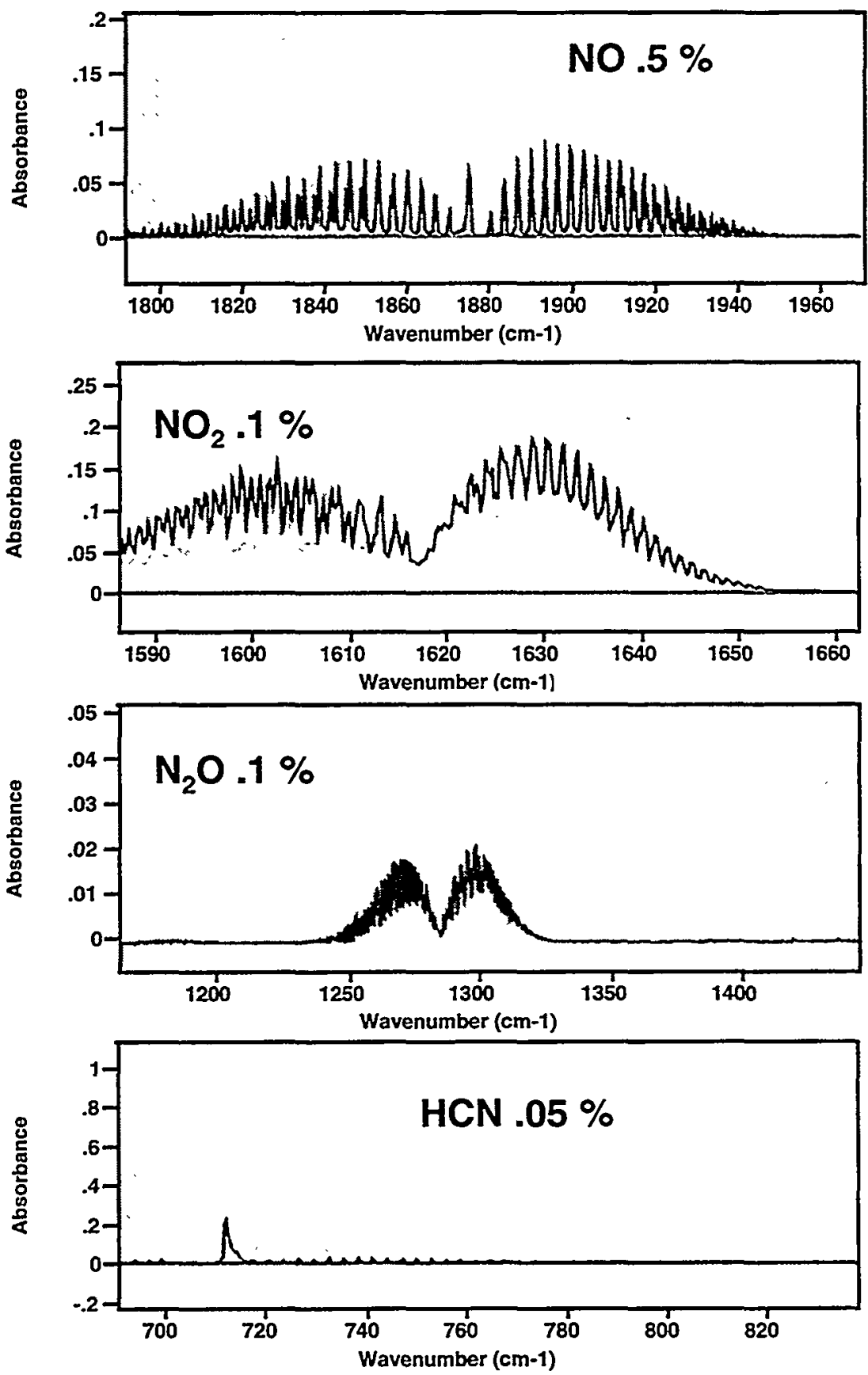

Figure D3. Representative spectra from DAZZLER (light background) compared with simulated absorption features from the QASOFT database (dark foreground). 
This page intentionally left blank 


\section{APPENDIX E}

Post-test Metal Residue Analyses-UNLV

The results of the UNLV analyses of the coupon rinse samples obtained after each rocket motor burn test are summarized in Table E1. These analyses identified the concentrations of non-volatile metal residues that remained on large aluminum plate coupons after they were exposed to the combustion clouds in the test chamber. The mounting of the plates before a test, and the recovery of the rinse solution (a 50/50 mixture of distilled water and alcohol) after a test, were the responsibility of Radian international. Since the plates were fixed vertically in the chamber at a height of roughly $3 \mathrm{~m}$ above the invert, we speculate that the residue sample obtained from them was fairly representative of the nonvolatile combustion cloud components in each test. Note that no effort was made to recover volatile or semi-volatile compounds from these samples.

Table E1. Summary of metal concentrations (in $\mathrm{ppb}$ ) found in coupon rinse solution obtained after each contained rocket motor burn test.

\begin{tabular}{|c|c|c|c|}
\hline Element & $\begin{array}{l}\text { SUNSPOT } \\
\text { M /SD }\end{array}$ & $\begin{array}{c}\text { THUNDERBIRD } \\
M / S D\end{array}$ & $\begin{array}{c}\text { DAZZLER } \\
M / S D\end{array}$ \\
\hline Be 9 & ND & ND & ND \\
\hline Al 27 & $\begin{array}{c}721 \\
15\end{array}$ & $\begin{array}{c}5411 \\
56\end{array}$ & $\begin{array}{c}1475000 \\
13030\end{array}$ \\
\hline Cr 52 & $\begin{array}{l}2.80 \\
0.11\end{array}$ & $\begin{array}{c}21.2 \\
0.2\end{array}$ & $\begin{array}{c}642 \\
3\end{array}$ \\
\hline Cr 53 & $\begin{array}{l}12.7 \\
2.3\end{array}$ & $\begin{array}{c}39.3 \\
1.4\end{array}$ & $\begin{array}{c}668 \\
2\end{array}$ \\
\hline Mn 55 & $\begin{array}{l}87.0 \\
1.5\end{array}$ & $\begin{array}{c}85.5 \\
1.5\end{array}$ & $\begin{array}{c}2683 \\
58\end{array}$ \\
\hline $\mathrm{Ni} 60$ & $\begin{array}{l}10.4 \\
0.2\end{array}$ & $\begin{array}{l}8.73 \\
0.45\end{array}$ & $\begin{array}{c}179 \\
1\end{array}$ \\
\hline $\mathrm{Ni} 62$ & $\begin{array}{l}10.8 \\
0.4\end{array}$ & $\begin{array}{c}10.1 \\
1\end{array}$ & $\begin{array}{c}179 \\
5\end{array}$ \\
\hline Cu 63 & $\begin{array}{c}78.8 \\
1.4\end{array}$ & $\begin{array}{c}640 \\
11\end{array}$ & $\begin{array}{c}1969 \\
34\end{array}$ \\
\hline Cu 65 & $\begin{array}{c}78.1 \\
2.2\end{array}$ & $\begin{array}{c}627 \\
10\end{array}$ & $\begin{array}{c}1954 \\
53\end{array}$ \\
\hline $\operatorname{Zn} 66$ & $\begin{array}{c}311 \\
7\end{array}$ & $\begin{array}{c}409 \\
14 \\
\end{array}$ & $\begin{array}{c}272 \\
3 \\
\end{array}$ \\
\hline
\end{tabular}


Table E1. (Contd.)

\begin{tabular}{|c|c|c|c|}
\hline Element & $\begin{array}{c}\text { SUNSPOT } \\
M / S D\end{array}$ & $\begin{array}{c}\text { THUNDERBIRD } \\
M / S D\end{array}$ & $\begin{array}{c}\text { DAZZLER } \\
M / S D\end{array}$ \\
\hline $\mathrm{Zn} 68$ & $\begin{array}{c}301 \\
14\end{array}$ & $\begin{array}{c}409 \\
8\end{array}$ & $\begin{array}{c}270 \\
8\end{array}$ \\
\hline As 75 & $\begin{array}{l}6.65 \\
0.81\end{array}$ & $\begin{array}{c}25.2 \\
0.7\end{array}$ & $\begin{array}{l}16 \\
0.3\end{array}$ \\
\hline Se 77 & $\begin{array}{c}38.5 \\
7.4\end{array}$ & $\begin{array}{c}93.2 \\
3\end{array}$ & $\begin{array}{c}85.5 \\
1\end{array}$ \\
\hline Se 82 & $\begin{array}{l}0.273 \\
0.889\end{array}$ & $\begin{array}{l}2.46 \\
0.78\end{array}$ & $\begin{array}{l}0.51 \\
0.55\end{array}$ \\
\hline Cd 111 & $\begin{array}{c}56.9 \\
2.1\end{array}$ & $\begin{array}{c}317 \\
11\end{array}$ & $\begin{array}{c}60.2 \\
1.7\end{array}$ \\
\hline Cd 114 & $\begin{array}{c}56.2 \\
0.6\end{array}$ & $\begin{array}{c}315 \\
6\end{array}$ & $\begin{array}{c}60.5 \\
1.5\end{array}$ \\
\hline Ba 135 & $\begin{array}{l}19.1 \\
0.4\end{array}$ & $\begin{array}{c}67.6 \\
2.5\end{array}$ & $\begin{array}{l}32.8 \\
0.8\end{array}$ \\
\hline Ba 137 & $\begin{array}{c}19.6 \\
0.2\end{array}$ & $\begin{array}{c}69.4 \\
2\end{array}$ & $\begin{array}{l}33 \\
0.5\end{array}$ \\
\hline $\mathrm{Pb} 207$ & $\begin{array}{c}2424 \\
33\end{array}$ & $\begin{array}{c}24200 \\
434\end{array}$ & $\begin{array}{c}2472 \\
22\end{array}$ \\
\hline $\mathrm{Pb} 208$ & $\begin{array}{c}2459 \\
44\end{array}$ & $\begin{array}{c}24140 \\
415\end{array}$ & $\begin{array}{c}2467 \\
33\end{array}$ \\
\hline Sb 121 & $\begin{array}{c}364 \\
5\end{array}$ & $\begin{array}{c}6574 \\
110\end{array}$ & $\begin{array}{c}807 \\
5\end{array}$ \\
\hline Sb 123 & $\begin{array}{c}360 \\
3\end{array}$ & $\begin{array}{c}6564 \\
57\end{array}$ & $\begin{array}{c}796 \\
14\end{array}$ \\
\hline
\end{tabular}

$M$ - Mean

SD -Standard Deviation 


\section{APPENDIX F}

\section{In Situ Laser-Based Measurements of Gas Species Concentrations-SNL}

The tunable diode laser gas species monitor (TDL) was used in two of the three contained rocket motor burn tests in X-tunnel: SUNSPOT and DAZZLER. The TDL monitors were not used in THUNDERBIRD because it was anticipated that the transient high air temperature and substantial number of particles generated in that test would be detrimental to this instrumentation.

In these tests, the sensitivity of the TDL instrumentation at both its invert and rib locations was limited by laser transmittance. During SUNSPOT, laser transmittances at the rib location slowly decreased after initially recovering from a prompt attenuation at test initiation time, $T=0$. Nevertheless, the optical paths for both lasers in the rib were completely blocked by $T=2000 \mathrm{~s}$. Laser transmittance in the invert sample volume during SUNSPOT was essentially zero by $T=40 \mathrm{~s}$. During DAZZLER, the overall laser transmittances increased somewhat after the initial drop-off at $T=0$; allowing some gas species concentration measurements to be made during this test. The time history of the laser transmittance in DAZZLER was qualitatively similar to that observed in the detonation test series.

The results of the TDL measurements in the rocket motor burn tests are summarized in Table F1. Molecular species measurements during SUNSPOT are sparse: $\mathrm{CO}_{2}$ and $\mathrm{H}_{2} \mathrm{O}$ signals were detected and analyzed, but the laser transmittance was very low so the signals were weak. Conversely, during DAZZLER, $\mathrm{CO}_{2}$ concentration histories were obtained in both locations, and the $\mathrm{H}_{2} \mathrm{O}$ concentration history was measured at the rib location. While the $\mathrm{CO}_{2}$ signal in the invert was characterized by a low signal: noise ratio, the measurements indicate that molecular stratification was present in DAZZLER, in qualitative agreement with results obtained in the detonation tests.

The $\mathrm{CO}_{2}$ concentration histories measured at the invert and rib locations in DAZZLER are presented in Figures F1 and F2, respectively. Both curves have been smoothed using a binomial smoothing algorithm. This was particularly necessary for the invert measurements because of low laser transmittance. The final $\mathrm{CO}_{2}$ concentrations are nominally $4 \%$ in the invert, and $6 \%$ in the rib. Equilibrium calculations for DAZZLER yield a fully-mixed final $\mathrm{CO}_{2}$ concentration of $3.6 \%$, compared to the on-line LLNL/BN measured value (early time) of $4.2 \%$. Even with the large uncertainty seen in Figs. $\mathrm{F} 1$ and $\mathrm{F} 2$, these data suggest that the $\mathrm{CO}_{2}$ concentration at the rib location is substantially higher than in the invert, even long after the combustion process is complete. 
Table F1. TDL measurement summary for rocket motor burn experiments

\begin{tabular}{|c|c|c|c|}
\hline & SUNSPOT & THUNDERBIRD & DAZZLER \\
\hline Execution date & $5 / 14 / 97$ & $5 / 28 / 97$ & $6 / 11 / 97$ \\
\hline Load & $\begin{array}{c}2 \text { Nike Rocket } \\
\text { Motors }\end{array}$ & 4 Nike Rocket Motors & $\begin{array}{c}2 \text { Hawk Rocket } \\
\text { Motors }\end{array}$ \\
\hline Species monitored & $\mathrm{HCN} ; \mathrm{CO} ; \mathrm{CO}_{2} ; \mathrm{H}_{2} \mathrm{O}$ & Did not participate. & $\mathrm{CO} ; \mathrm{CO}_{2} ; \mathrm{H}_{2} \mathrm{O}$ \\
\hline Species detected & $\mathrm{CO}_{2} ; \mathrm{H}_{2} \mathrm{O}$ & -- & $\mathrm{CO}_{2}$ and $\mathrm{H}_{2} \mathrm{O}$ \\
\hline CO concentration & -- & $\cdots$ & $\ldots$ \\
\hline $\begin{array}{c}\mathrm{CO}_{2} \text { concentration, } \\
\text { rib location } \\
\end{array}$ & $9 \%$ peak & --. & $6 \%$ \\
\hline $\begin{array}{c}\mathrm{CO}_{2} \text { concentration, } \\
\text { invert location } \\
\end{array}$ & -- & $\cdots$ & $4 \%$ \\
\hline $\begin{array}{c}\text { Fully mixed } \mathrm{CO}_{2} \\
\text { concentration }\end{array}$ & $10.01 \%$ & $19.00 \%$ & not available \\
\hline $\begin{array}{c}\mathrm{H}_{2} \mathrm{O} \text { concentration added, } \\
\text { rib location }\end{array}$ & --- & -- & $2.4 \%$ \\
\hline $\begin{array}{c}\mathrm{H}_{2} \mathrm{O} \text { concentration added, } \\
\text { invert location }\end{array}$ & $-\cdots$ & --- & -- \\
\hline $\begin{array}{c}\text { Fully mixed } \mathrm{H}_{2} \mathrm{O} \\
\text { concentration, } 75 \% \text { initial } \\
\text { relative humidity }\end{array}$ & $7.23 \%$ & --- & not available \\
\hline Final Transmittance (rib) & $0 \%$ & - & $13 \%$ \\
\hline
\end{tabular}

Water concentration measurements were also obtained at the rib location in DAZZLER. Low transmittance prevented comparable measurements at the invert location. The results are shown in Figure F3. The pre-event water concentration in the chamber ambient air was estimated at $2.1 \%$. The data in Figure F3 indicate that the total water concentration in the sealed chamber long after propellant combustion was completed was roughly $4.5 \%$, corresponding to a water concentration increase of $2.4 \%$ from the combustion products. No other measurement of water concentration history was obtained in DAZZLER. 


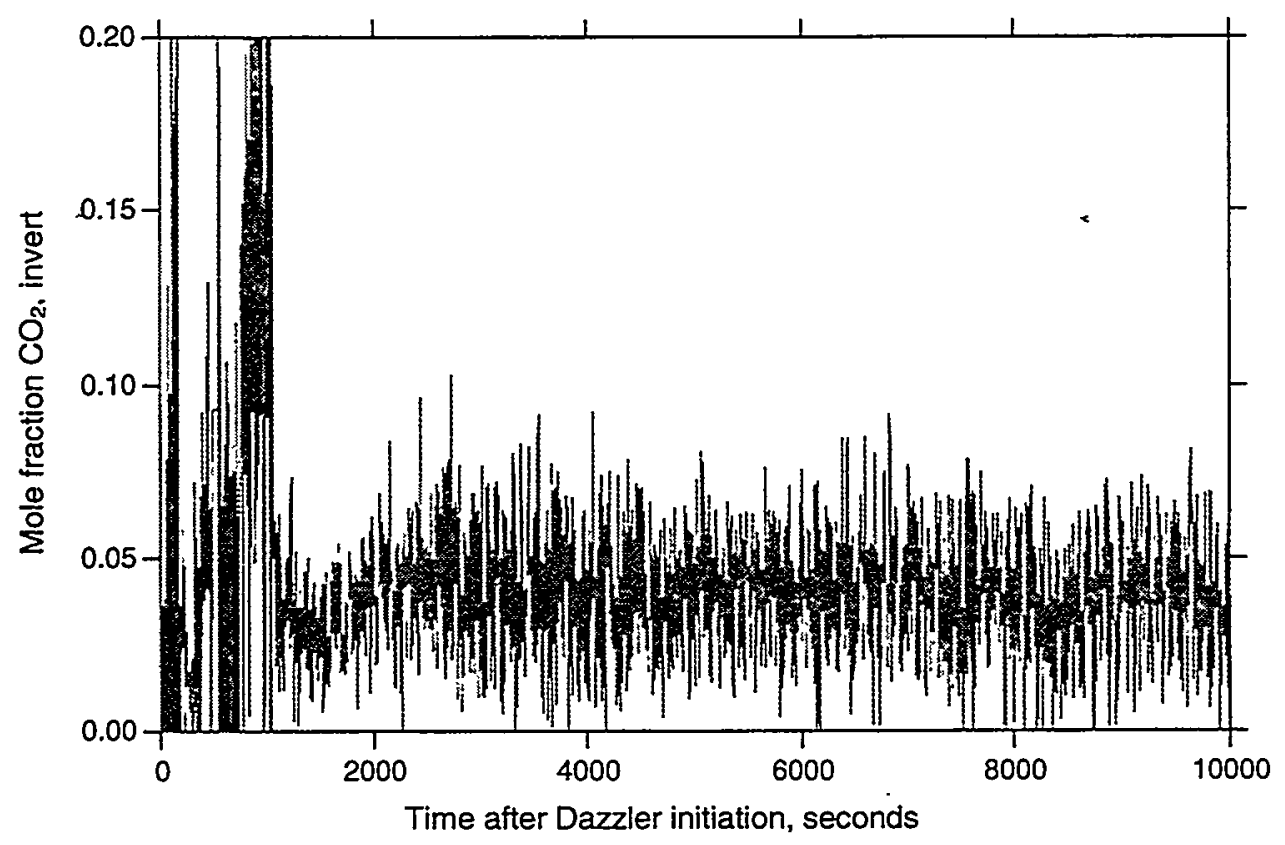

Figure F1. $\mathrm{CO}_{2}$ measured in invert during DAZZLER.

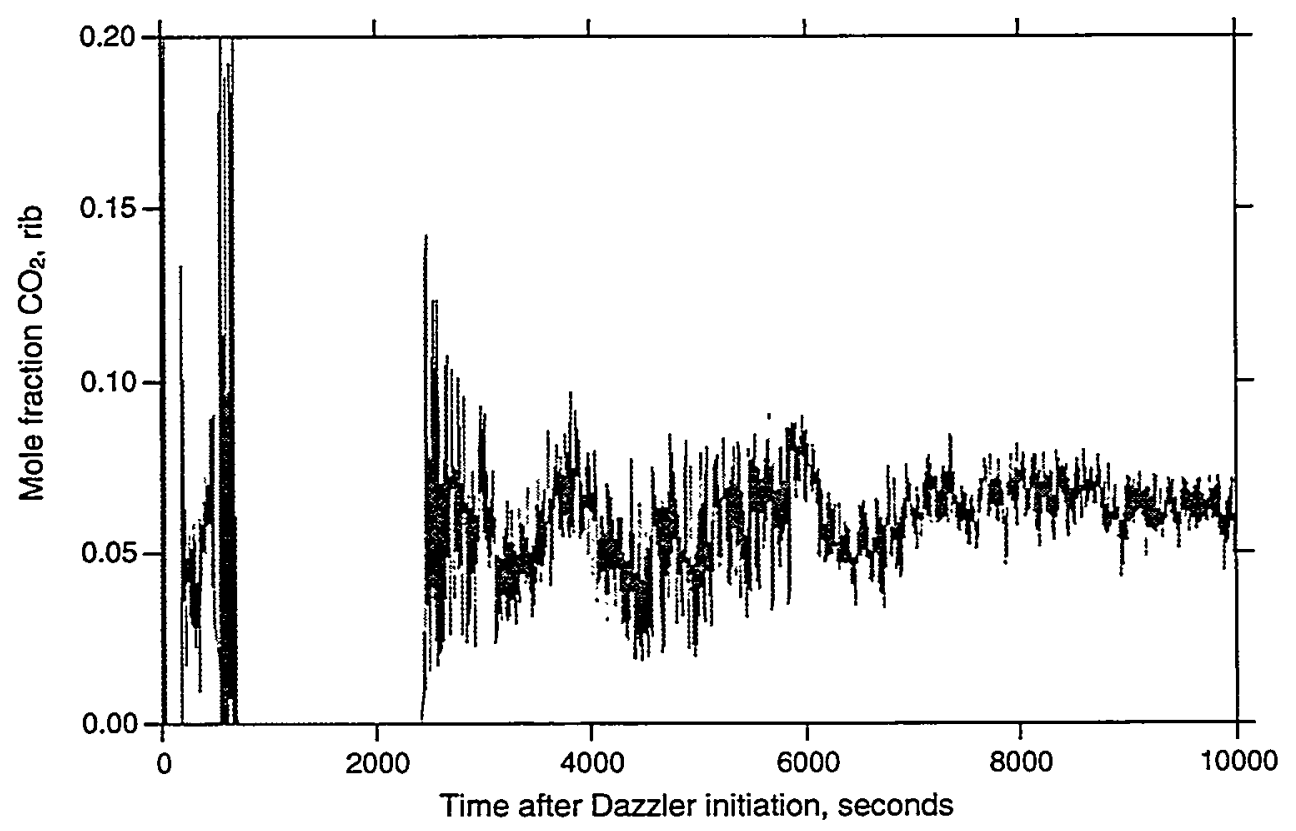

Figure F2. $\mathrm{CO}_{2}$ measured in rib during DAZZLER. 


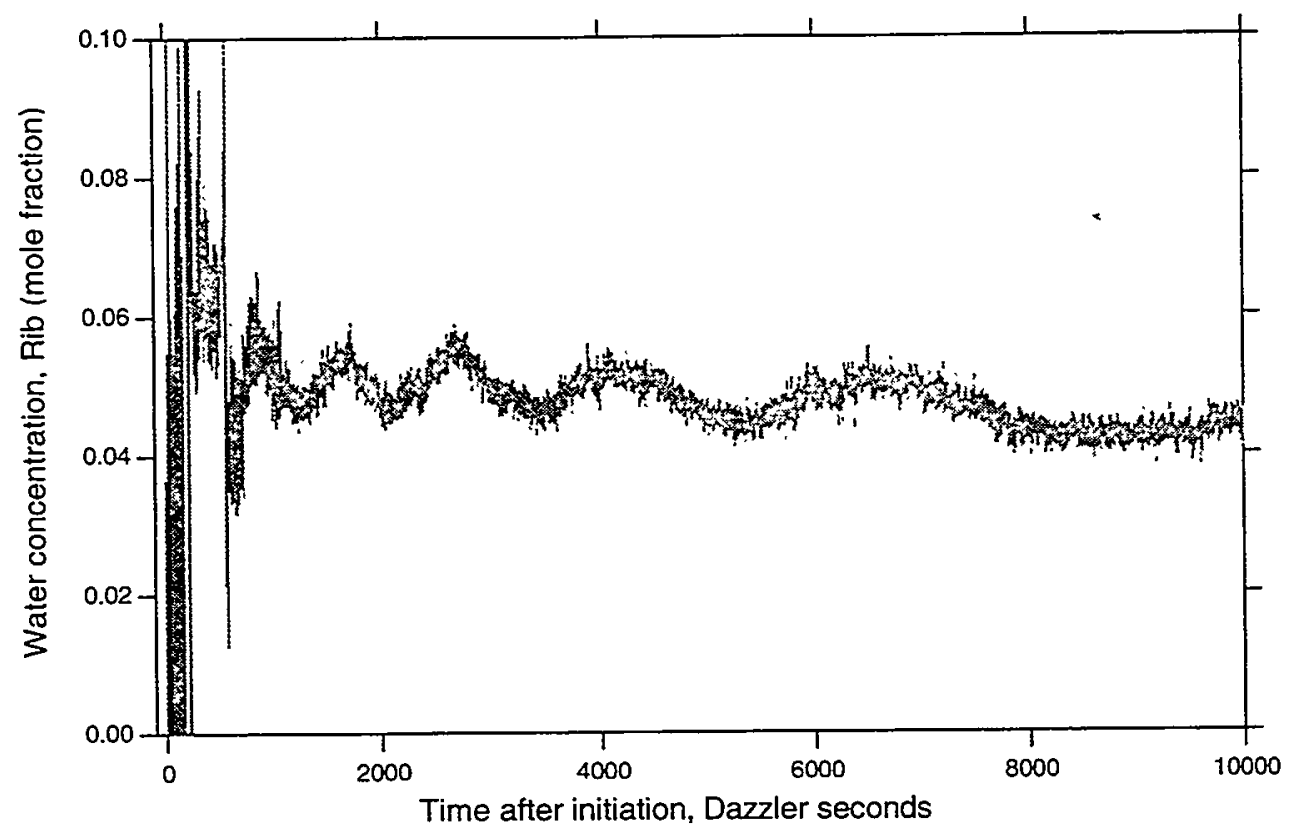

Figure F3. Water concentration measured in rib location during DAZZLER. 


\section{APPENDIX G}

\section{Time-Resolved Measurements of Test Chamber Pressure and Gas Temperatures-LLNL and Bechtel Nevada}

The pressure transients produced by the hot combustion gases mixing with and heating the ambient air in the test chamber are shown in Figure G1. The first $500 \mathrm{~s}$ of the data from each test are overlaid in this figure. The times to reach maximum pressure differ somewhat from test-to-test, but they correlate well with the burn times of the propellant that are observed in the video records of the tests. The characteristics of the pressure decay in each test also correlate with the cooling rates of the gases observed from the thermocouple records from each test. We note, however, that a containment seal failure in the THUNDERBIRD test resulted in a significant pressure leak at roughly the same time that the peak pressure was reached in this test. It is likely that this leak reduced the magnitude of the maximum pressure recorded in this test.

Representative temperature histories obtained from the thermocouple arrays are shown in Figures G2-G4 for the SUNSPOT, THUNDERBIRD, and DAZZLER tests, respectively. The thermocouple array used in SUNSPOT was positioned over the two motors and attached at the invert near the left rib and to the back, near the center, of the chamber. We see in Figure G2 that the thermocouples near the back of the chamber recorded extremely high temperature transients when the propellant was burning, whereas the thermocouples near the invert recorded much more gradual temperature increases. These data are consistent with the presence of significant thermal stratification in the test chamber as the gases are heated by the burning propellant. It is also evident in Figure G2 that the remnants of this stratification persist as the gases cool. Similar obsenvations apply to the recorded temperature histories for THUNDERBIRD and DAZZLER that are shown in Figures G3 and G4, respectively. However, the thermocouple array was in a different location in the test chamber for these tests compared to its location in SUNSPOT. In THUNDERBIRD and DAZZLER, the array was oriented away from direct contact with the propellant flame and was anchored between the chamber invert and the mid-height of the chamber rib near the containment plug. The temperature variations seen in Figures G3 and G4, while still significant, are therefore not as severe as observed in Figure G2 for SUNSPOT. 


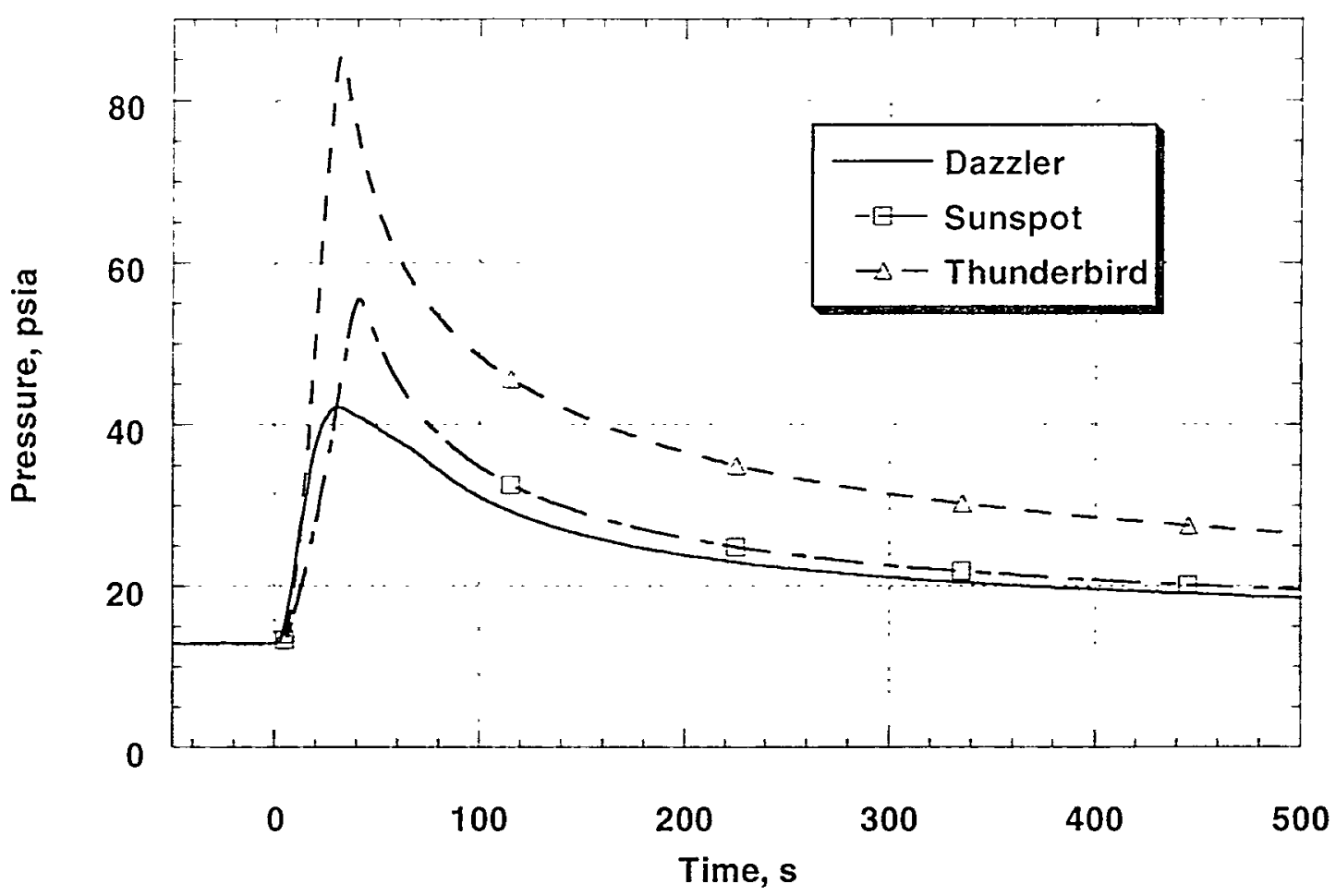

Figure G1. Comparison of chamber pressure histories in rocket motor burn tests.

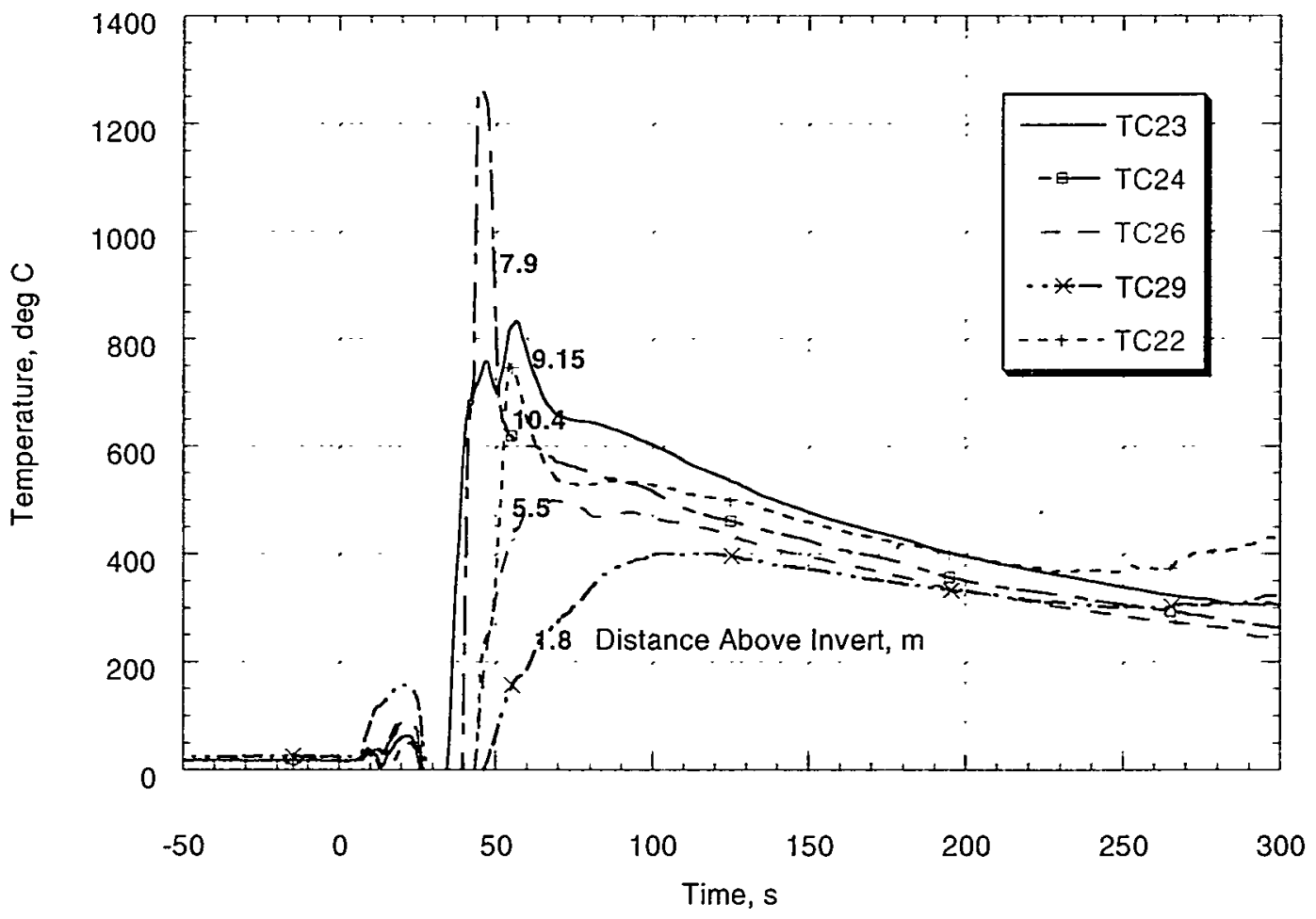

Figure G2. Temperature histories from thermocouple array in SUNSPOT. 


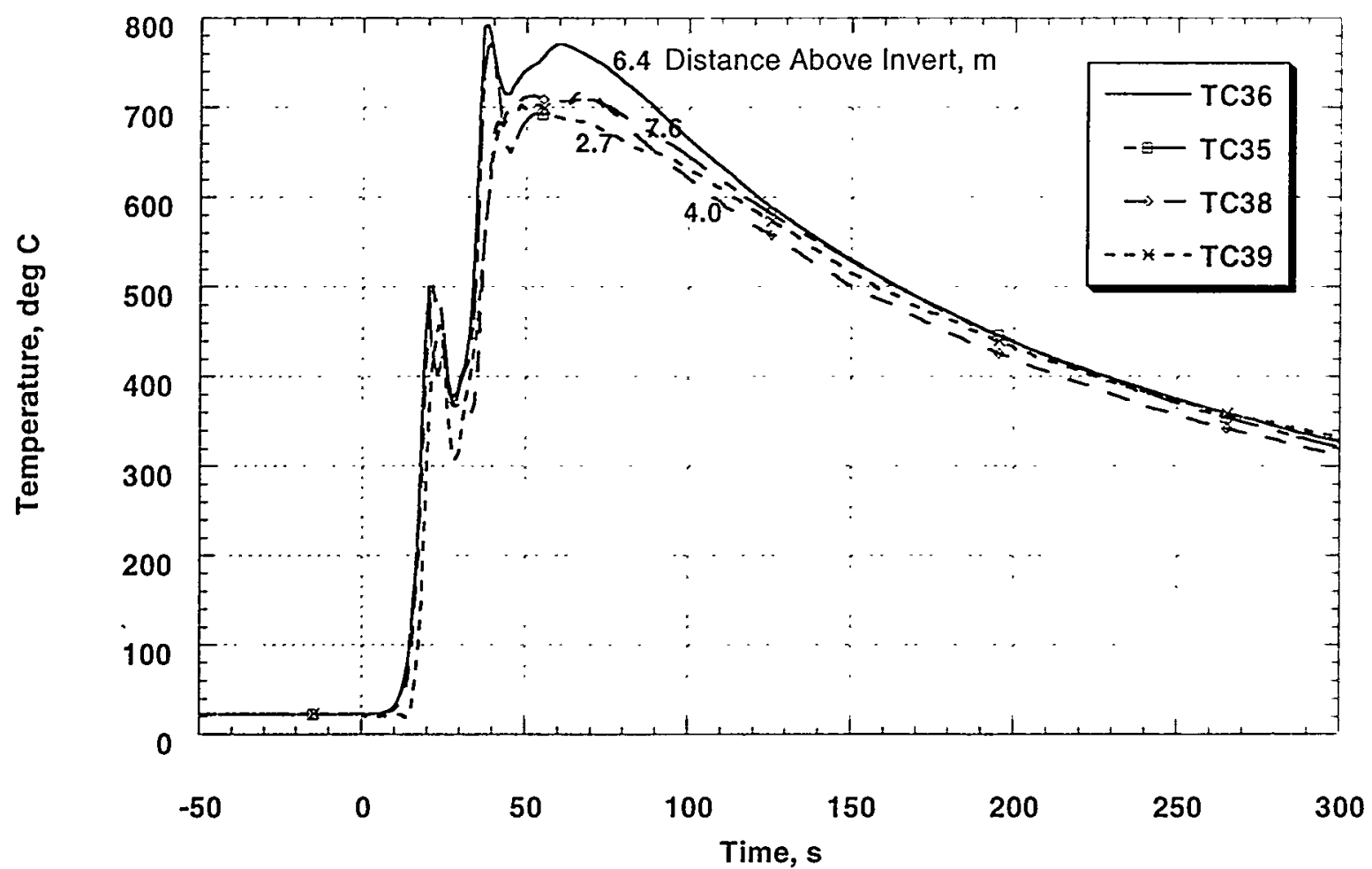

Figure G3. Temperature histories from thermocouple array in THUNDERBIRD.

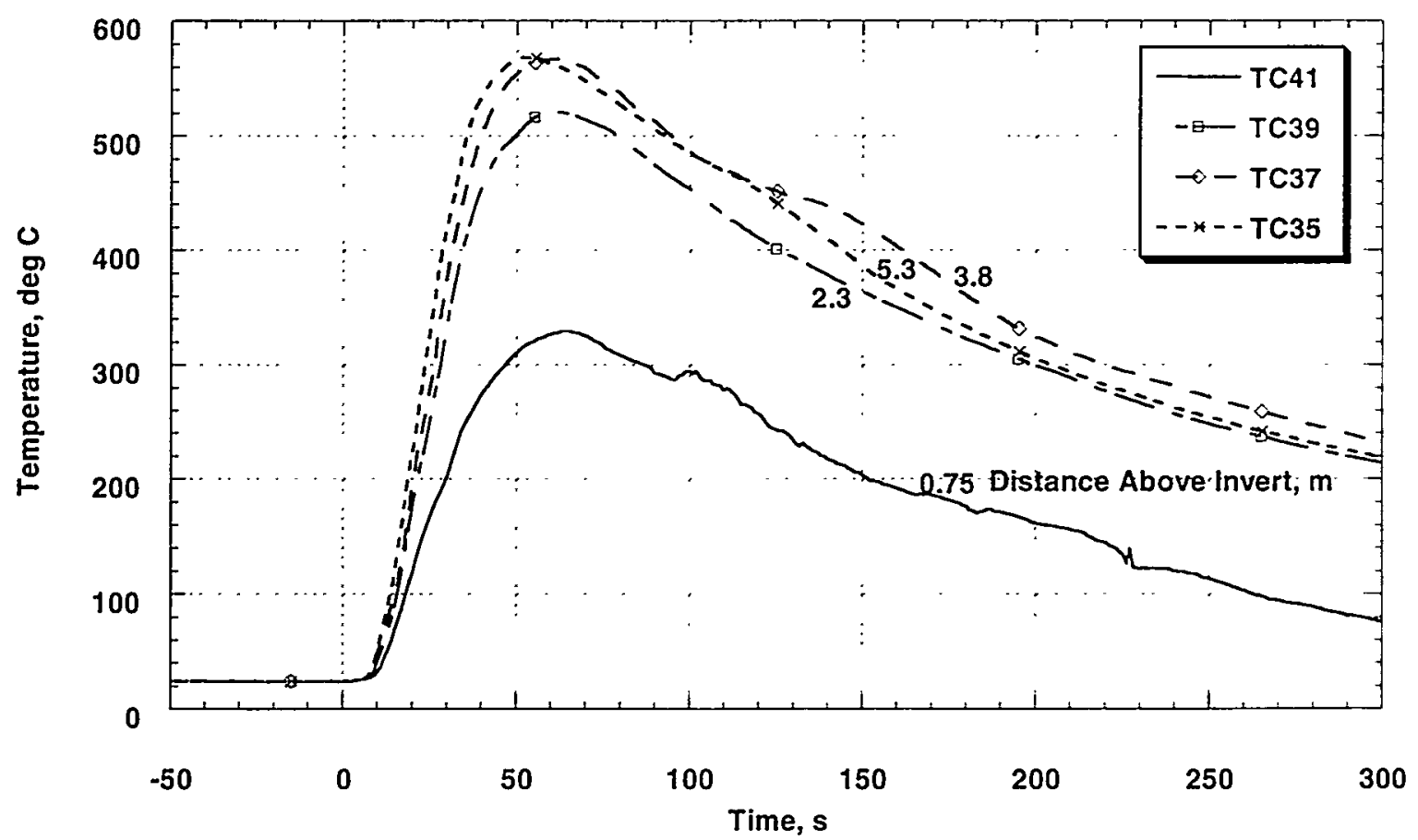

Figure G4. Temperature histories from thermocouple array in DAZZLER. 


\section{Distribution:}

2 The Johns Hopkins University

Chemical Propulsion Information Agency

Attn: Jim Cocchiaro

Tom Moore

10630 Little Patuxent Parkway, Suite 202

Columbia, MD 2104-3200

1 US Environmental Protection Agency

Attn: William Mitchell

Mail Drop 46 - ERC Annex

79 T. W. Alexander Dr

Research Triangle Park, NC 27711

$4 \quad$ University of California

Los Alamos National Laboratory

Attn: John Stephens, CST-1

John Sanchez, DX-2

Herb Fry, CST-6

Cliff Hewitt, CST-6

P.O. Box 1663

Los Alamos, New Mexico 87545

$4 \quad$ University of California

Lawrence Livermore National Laboratory

Attn: Bruce Watkins, L 282

Carol Velsko, L 231

César Prunada, L 282

Ray Heinle, L 221

P.O. Box 808

Livermore, CA 94550

2 Bechtel Nevada

Attn: Sam Williams

Al Moeller

2621 Losee Road

North Las Vegas, NV $89030-4134$

1 Thiokol Propulsion Group

Attn: William Munson

M/S: 130

P.O. Box 707

Brigham City, UT 84302-0689 


\section{Distribution: (continued)}

1 US Department of Energy/Nevada Operations Office

Attn: Deborah Howard

P.O. Box 98518

Las Vegas, NV 89193-8518

2 University of Nevada Las Vegas

Energy Research Center

Attn: Bob Boehm

Klaus Stezenbach

P.O. Box 454027

Las Vegas, NV 89154-4027

3 US Army Defense Ammunition Center

Attn: Jim Wheeler Solim Kwak Eddie Ansell

$1 \mathrm{C}$ Tree Road

McAlester, OK 74501-9002

3 Radian International LLC

Attn: John Carson

Tim Tope

Walt Gray

1093 Commerce Park Drive, Suite 100

Oak Ridge, TN 37830

1 Washington State University

Manufacturing-Technology Applications

Attn: Prof. Jack C. Swearengen

14204 NE Salmon Creek Ave

Vancouver, WA 98686-9600

$\begin{array}{ll}1 & 9042 \\ 1 & 9042 \\ 1 & 9052 \\ 1 & 9052 \\ 1 & 9052 \\ 1 & 9403 \\ 1 & 9403 \\ 1 & 9403 \\ 1 & 9409 \\ 1 & 9105 \\ 5 & 9105 \\ 1 & 1156 \\ 1 & 1157\end{array}$

Bob Nilson

Stewart Griffiths

Don Hardesty, 8361

Chris Shaddix, 8361

Sarah Allendorf, 8361

Jim Wang, 8723

Dave Ottesen, 8723

Howard Johnsen, 8723

Larry Carrillo, 8421

Jane Ann Lamph, 8119

Joel Lipkin, 8119

Rob Tachau, 15322

Ray Peabody, 153221 


\section{Distribution: (continued)}

$\begin{array}{lll}1 & 1391 & \text { Harold Roberts, 153221 } \\ 1 & 1167 & \text { Larry Posey, 15343 } \\ 3 & \text { MS 9018 } & \text { Central Technical Files, 8940-2 } \\ 1 & \text { MS 0899 } & \text { Technical Library, 4916 } \\ 1 & \text { MS 9021 } & \begin{array}{l}\text { Technical Communications Department, 8528/ } \\ \text { Technical Library, MS 0899, 4916 }\end{array} \\ 1 & \text { MS 9021 } & \text { Technical Communications Department, 8528 For DOE/OSTI }\end{array}$

